\title{
Angiospermas em remanescentes de floresta montana no sul da Bahia, Brasil
}

\author{
André Márcio Amorim ${ }^{1,6}$, Jomar Gomes Jardim², Márdel Miranda Mendes Lopes ${ }^{2}$, Pedro Fiaschi ${ }^{3}$, \\ Rafael Augusto Xavier Borges ${ }^{4}$, Ricardo de Oliveira Perdiz ${ }^{1} \&$ William Wayt Thomas $^{5}$ \\ ${ }^{1}$ Departamento de Ciências Biológicas, Universidade Estadual de Santa Cruz, \\ CEP 45662-900, Ilhéus, BA, Brasil \\ ${ }^{2}$ Herbário André Maurício Vieira de Carvalho, CEPEC, CEPLAC, \\ CP 07, CEP 45600-970, Itabuna, BA, Brasil \\ ${ }^{3}$ Department of Biology, Virginia Commonwealth University, VA 23284-2012, U.S.A. \\ ${ }^{4}$ Instituto de Pesquisas Jardim Botânico do Rio de Janeiro, Rio de Janeiro, RJ, Brasil \\ ${ }^{5}$ The New York Botanical Garden, Bronx, New York 10458-5126, U.S.A. \\ ${ }^{6}$ Autor para correspondência: André Márcio Amorim, e-mail: aamorimm@terra.com.br
}

\begin{abstract}
AMORIM, A.M., JARDIM, J.G., LOPES, M.M.M., FIASCHI, P., BORGES, R.A.X., PERDIZ, R.O. \& THOMAS, W.W. Angiosperms of Montane Forest areas in southern Bahia, Brazil. Biota Neotrop. 9(3): http://www. biotaneotropica.org.br/v9n3/en/abstract?inventory+bn02909032009.
\end{abstract}

\begin{abstract}
A floristic study of three areas of montane Atlantic forest in southern Bahia, Brazil, was carried out. From 2004 to 2008 regular botanical collections were made, principally along trails in the interior of the forest fragments at: the Reserva Serra da Pedra Lascada (SPL), the Reserva Serra das Lontras (SLO) and the Reserva Particular do Patrimônio Natural Serra Bonita (SBO). The species richness of each area was compared to that of the other two, and together to other areas of Atlantic coastal forest in Bahia and southeastern Brazil. For all three areas, a total of 1129 species in 467 genera and 124 families were found. Trees represented $46.9 \%$ of the species, followed by herbs $(20.1 \%)$, epiphytes (19.5\%), and vines and lianas (13.5\%). The families Araceae, Asteraceae, Bromeliaceae, Fabaceae, Lauraceae, Melastomataceae, Myrtaceae, Orchidaceae, Piperaceae, Poaceae, Rubiaceae, and Solanaceae showed the highest species richness for the three areas together. The genus Psychotria (Rubiaceae) had the highest number of species for all three areas (21 spp.), followed by Miconia (20 spp.), Solanum (20 spp.), Piper (19 spp.), Ocotea (16 spp.), Leandra (16 spp.), Peperomia (15 spp.), and Myrcia (14 spp.). The results confirm the high species diversity of angiosperms in southern Bahia and demonstrate for the first time the presence of species characteristic of montane regions of southeastern Brazil in this region.
\end{abstract}

Keywords: Atlantic forest, checklist, floristics, Montane Forests, Bahia, Brazil.

AMORIM, A.M., JARDIM, J.G., LOPES, M.M.M., FIASCHI, P., BORGES, R.A.X., PERDIZ, R.O. \& THOMAS, W.W. Angiospermas em remanescentes de Floresta Montana no sul da Bahia, Brasil. Biota Neotrop. 9(3): http://www.biotaneotropica.org.br/v9n3/pt/abstract?inventory+bn02909032009.

Resumo: Foi realizado um levantamento florístico de três remanescentes de floresta montana localizados na Mata Atlântica do sul da Bahia. Durante os anos de 2004 a 2008 foram feitas coletas periódicas de material botânico, principalmente ao longo de trilhas no interior dos fragmentos das áreas: Reserva Serra da Pedra Lascada - SPL, Reserva Serra das Lontras - SLO e Reserva Particular do Patrimônio Natural Serra Bonita - SBO. A riqueza florística em cada área foi comparada entre si e com outras áreas de Mata Atlântica na Bahia e no Sudeste do Brasil. Foi registrado um total de 1.129 espécies em 467 gêneros e 124 famílias. O hábito arbóreo representou 46,9\% das espécies, seguido de herbáceas (20,1\%), epífitas (19,5\%) e trepadeiras (13,5\%). As famílias Araceae, Asteraceae, Bromeliaceae, Fabaceae, Lauraceae, Melastomataceae, Myrtaceae, Orchidaceae, Piperaceae, Poaceae, Rubiaceae e Solanaceae apresentaram a maior riqueza florística nas três áreas em conjunto. O gênero Psychotria (Rubiaceae) apresentou o maior número de espécies em todas as áreas (21 spp.), destacando-se também Miconia (20 spp.), Solanum (20 spp.), Piper (19 spp.), Ocotea (16 spp.), Leandra (16 spp.), Peperomia (15 spp.) e Myrcia (14 spp.). Os resultados confirmam a elevada riqueza de angiospermas no sul da Bahia e evidenciam, pela primeira vez, a ocorrência de espécies características de regiões montanhosas da Mata Atlântica do Sudeste do Brasil nessa região.

Palavras-chave: Mata Atlântica, checklist, florística, Florestas Montanas, Bahia, Brasil. 


\section{Introdução}

A cobertura florestal da Mata Atlântica tem sofrido uma redução considerável de área e estimativas recentes sugerem que hoje restem apenas 7 a $8 \%$ de uma área original de ca. $1.400 .000 \mathrm{~km}^{2}$ (Galindo-Leal \& Câmara 2003, Tabarelli et al. 2005). A Mata Atlântica possui uma biota única, caracterizada por elevados níveis de diversidade e endemismo (Mori et al. 1981, Silva \& Castelletti, 2003), sendo que no sul da Bahia são registrados os mais elevados níveis de diversidade e endemismo de plantas no bioma (Thomas et al. 1998, 2003, Amorim et al. 2008, Sousa \& Wendt 2008). Devido a essas características, juntamente com a redução da cobertura original - no sul da Bahia os remanescentes de floresta nativa cobrem menos de 4\% de sua área original (Thomas et al. 1998) — a Mata Atlântica é considerada uma das mais importantes áreas do mundo para a conservação da biodiversidade (Myers et al. 2000, Mittermeier et al. 2004).

Embora a vegetação da Mata Atlântica seja em sua maior parte caracterizada por florestas ombrófilas (Galindo-Leal et al. 2003), diversos autores reconhecem uma heterogeneidade tanto florística como fisionômica ao longo da área total (Oliveira-Filho \& Fontes 2000, Scarano 2002, Oliveira-Filho et al. 2006). Os principais motivos dessa heterogeneidade são as variações climáticas associadas à amplitude latitudinal (ca. 27 graus), longitudinal (da costa ao interior) e altitudinal (do nível do mar até ca. $2.700 \mathrm{~m}$ alt.) ao longo de sua área de ocorrência (Oliveira-Filho \& Fontes 2000).

Variações florísticas e fisionômicas ao longo de gradientes altitudinais são recorrentes em áreas de florestas tropicais onde muitas vezes é difícil delimitar objetivamente essas fitofisionomias (Grubb et al. 1963, Grubb \& Whitmore 1966, Richards 1996, Ashton 2003). Visando padronizar a classificação de fisionomias florestais ao longo da Cadeia dos Andes, Webster (1995) propôs um limite altitudinal mínimo de ca. $1.000 \mathrm{~m}$ de altitude para as florestas nebulares (cloud forests), estabelecendo uma discussão sobre o reconhecimento de uma separação entre florestas ombrófilas de terras baixas (lowland tropical rain forests) e florestas ombrófilas montanas (tropical montane rain forests).

Devido a variações climáticas e topográficas encontradas ao longo da extensão latitudinal ocupada pela Mata Atlântica, a delimitação entre fisionomias submontanas, baixo-montanas e alto-montanas torna-se bastante variável (Veloso 1992, Oliveira-Filho \& Fontes 2000). Mesmo assim, Veloso (1992) sugeriu um limite mínimo de $600 \mathrm{~m}$ para florestas montanas tropicais no Brasil, enquanto Oliveira-Filho \& Fontes (2000) estipularam um mínimo de $700 \mathrm{~m}$, e distinguiram entre florestas baixo-montanas (700-1.100 m) e altomontanas (>1.100 m). Thomas \& Barbosa (2008) sugerem que, para florestas montanas no nordeste do Brasil, o limite mínimo deve variar entre 600 a $800 \mathrm{~m}$. Dado que até agora quase todos os estudos florísticos no sul da Bahia têm enfatizado a diversidade vegetal em áreas de terras baixas (e.g., Mori et al. 1981, 1983, Martini et al. 2007, Amorim et al. 2008, Thomas et al. 2008), a flora das montanhas da região permanece insuficientemente conhecida.

Visando preencher uma lacuna no conhecimento florístico da Mata Atlântica, contribuindo com registros botânicos que irão incrementar informações sobre diversidade, formas de vida e distribuição de espécies, este estudo apresenta uma lista das angiospermas de três fragmentos situados em regiões montanhosas no sul da Bahia.

\section{Material e Métodos}

As áreas de floresta estudadas estão situadas nos municípios de Barro Preto (Reserva Serra da Pedra Lascada - SPL), Arataca/São José da Vitória (Reserva Serra das Lontras - SLO) e Camacan (Reserva

Particular do Patrimônio Natural Serra Bonita - SBO), todos no sul da Bahia. A situação geográfica das três áreas é indicada na Figura 1.

Reserva Serra da Pedra Lascada: A SPL é um remanescente florestal de aproximadamente 300 ha situado próximo à coordenada $14^{\circ} 46^{\prime} \mathrm{S}$ e $39^{\circ} 32^{\prime} \mathrm{O}$, em altitudes que variam entre 600 e $950 \mathrm{~m}$. A floresta reveste uma encosta íngreme e apresenta bordas abruptas com pastagens circunvizinhas alternadas a plantações de cacau em sistema cabruca. Na vertente leste da encosta há dois grandes afloramentos rochosos do tipo inselberg, atribuindo um aspecto de relevância geomorfológica e paisagística a esta área (Figura 2a). A floresta exibe áreas bem preservadas (Figura 2f), mas em pontos mais íngremes é visível o recente aumento no grau de perturbação da floresta, devido à extração seletiva de madeira e queimadas.

Reserva Serra das Lontras: A SLO situa-se numa região bastante acidentada, em altitudes variando entre 400 e 1.000 m.s.m., e área estimada de ca. 6.000 ha. O levantamento florístico concentrou-se em duas encostas conhecidas localmente como Peito de Moça e Lontras, ambas localizadas próximo à coordenada $15^{\circ} 10^{\prime} \mathrm{S}$ e $39^{\circ} 20^{\prime} \mathrm{O}$. A floresta exibe áreas bem preservadas nos pontos mais altos (Figuras $2 b$, c, e), alternadas a um mosaico de estádios sucessionais determinados por um histórico de intervenções humanas, com indicação de corte raso, plantações de cacau, pastagens e cultivos de subsistência. Os contrafortes da SLO estão conectados a fragmentos da planície litorânea, que, em sua maioria, fazem parte da Reserva Biológica de Una (REBIO Una).

Reserva Particular do Patrimônio Natural Serra Bonita: A SBO situa-se na coordenada geográfica aproximada de $15^{\circ} 23^{\prime} \mathrm{S}$ e $39^{\circ} 33^{\prime} \mathrm{O}$ e possui uma área total de ca. 7.500 ha, com altitudes que variam de 300 a 1.080 m. O inventário florístico concentrou-se nas áreas mais altas, onde está localizada a Reserva Particular do Patrimônio Natural (RPPN) Serra Bonita, cuja área atual é de ca. 2.000 ha. O grau de

41

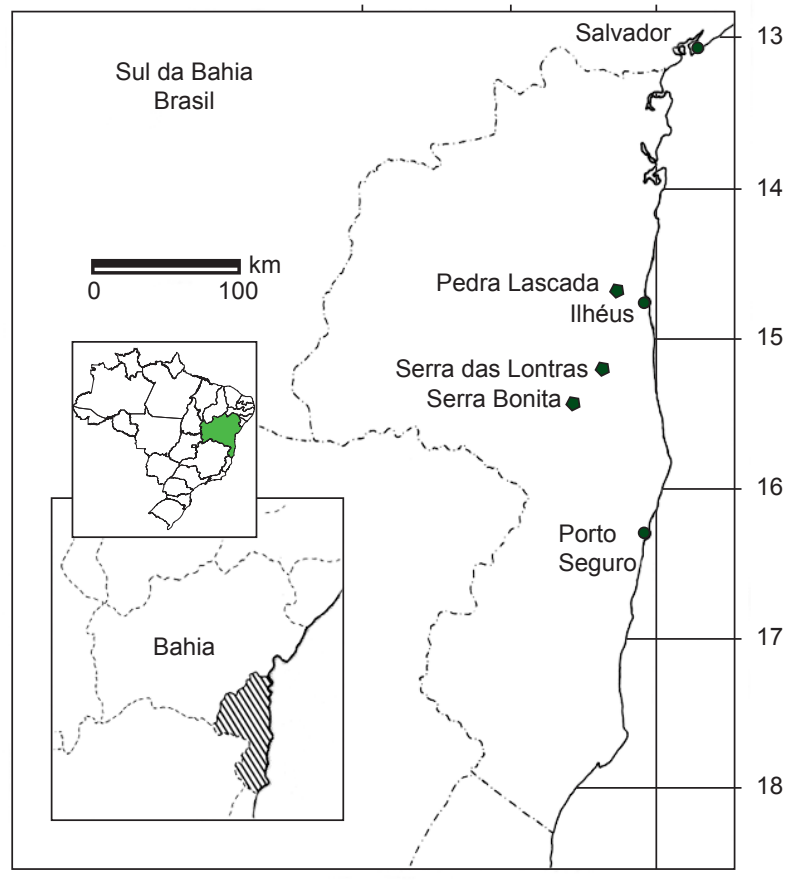

Figura 1. Mapa indicando a localização das três áreas de floresta montana inventariadas no sul da Bahia, Brasil.

Figure 1. Map showing locations of the three areas of montane forest studied in southern Bahia, Brazil. 

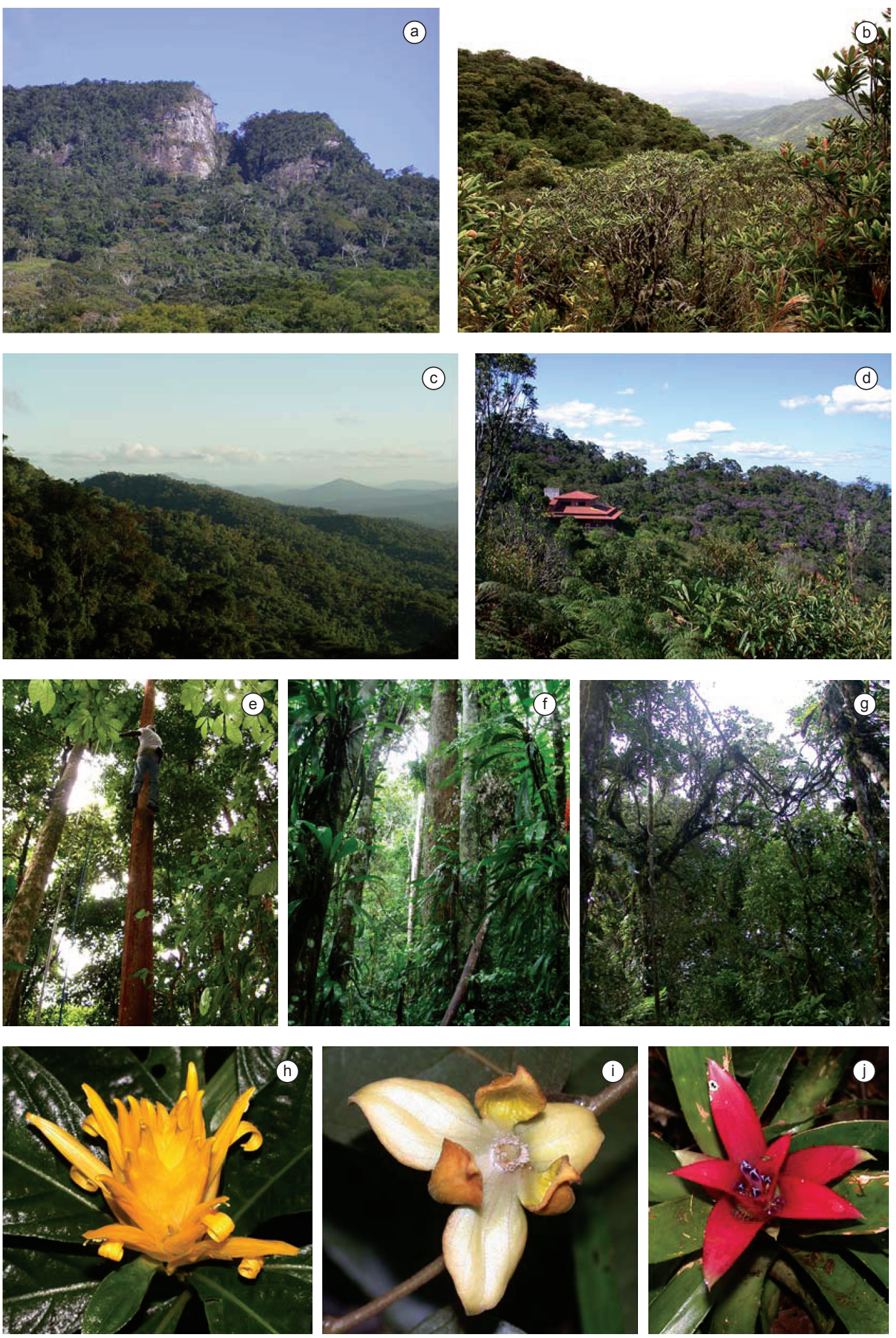

Figura 2. Aspectos fisionômicos das três áreas de floresta montana inventariadas no sul da Bahia e algumas espécies documentadas. a) Vista geral da Serra da Pedra Lascada (SPL). b) Vegetação no topo da Serra das Lontras (SLO). c) Vista do alto da SLO. d) Vegetação secundária nos arredores da sede da RPPN Serra Bonita (SBO). e-g) Vistas do interior das florestas. h) Justicia sp.5 (Acanthaceae). i) Annona sp.1 (Annonaceae). j) Nidularium bicolor (Bromeliaceae). Fotos: a,b,d,e,g-j) A.Amorim; c) A.Fontana; f) W.Thomas.

Figure 2. Physiognomy of the three areas of montane forest studied and some of the documented species. a) General view from Serra da Pedra Lascada (SPL). b) Vegetation at the top of Serra das Lontras (SLO). c) View from the peak of SLO. d) Secondary vegetation near the headquarters of the RPPN Serra Bonita (SBO). e-g) View of forest interiors. h) Justicia sp. 5 (Acanthaceae). i) Annona sp. 1 (Annonaceae). j) Nidularium bicolor (Bromeliaceae). Photos: a,b,d,e,g-j) A.Amorim; c) A.Fontana; f) W.Thomas. 
conservação da vegetação é muito variado (Figuras 2d, g). Algumas porções apresentam florestas que aparentemente não sofreram corte raso, trechos em diferentes estádios de sucessão ecológica e grandes áreas de plantações de cacau. Parte da RPPN é cortada por uma estrada que dá acesso à parte mais alta da SBO, onde foi instalada uma torre de transmissão, o que determinou nesse local, a erradicação da vegetação original há mais de 30 anos.

Na região que abrange as três áreas estudadas, o clima pode ser caracterizado como quente e úmido, sem estação seca, do tipo Af (Köppen 1936), apresentando uma precipitação anual média entre 1.500 e $1.750 \mathrm{~mm}$, sendo a precipitação média diária de 50 a $100 \mathrm{~mm}$ (podendo chegar a $150 \mathrm{~mm}$ ). A temperatura média anual varia de $23^{\circ}$ a $24^{\circ} \mathrm{C}$, e a amplitude térmica varia de $10^{\circ}$ a $14^{\circ} \mathrm{C}$. A evapotranspiração potencial total anual é de 1.200 a $1.300 \mathrm{~mm}$ e a umidade relativa do ar é < 80\% (Roeder 1975). Não há informações de precipitação e temperatura específicas para as áreas estudadas. No entanto, são evidentes as variações climáticas entre os topos das serras e as áreas mais baixas, onde estão situados os municípios.

Os trabalhos de campo do levantamento florístico ocorreram entre os anos de 2004 a 2008, com curtas expedições de coleta em intervalos que variaram entre 30 e 60 dias. Ao término de quatro anos, foi realizada pelo menos uma expedição a cada mês do ano em cada uma das áreas de estudo. Foram amostradas apenas as angiospermas em fase reprodutiva ao longo de trilhas e estradas de acesso. Nos casos que se conhecia a identidade da espécie, mesmo que em estágio vegetativo, e não houve a possibilidade de documentação fértil, optou-se por registrar a ocorrência do táxon (e.g., Euterpe edulis Mart.).

O material coletado foi depositado prioritariamente no herbário CEPEC e duplicatas enviadas a NY, RB e SPF. A identificação das amostras foi realizada por consulta a especialistas, auxílio de bibliografia especializada ou comparação com exsicatas previamente identificadas da coleção CEPEC. As amostras indeterminadas em diferentes níveis hierárquicos foram acrescidas de "sp." e discriminadas por uma numeração ordinal (e.g., Convolvulac. sp.1, Myrcia sp.1, Myrcia sp.2) seguindo o mesmo critério nas três áreas de estudo. As espécies foram posicionadas nas famílias reconhecidas segundo o APG (2003). De cada espécie ou morfo-espécie foi selecionada uma amostra como material testemunho de cada área (Tabela 1).

As formas de vida de todos os táxons foram quantificadas e a porcentagem de contribuição destas foi calculada. Posteriormente, os valores encontrados para as áreas estudadas foram comparados com os reportados para outros levantamentos florísticos em Mata Atlântica no sul da Bahia (Amorim et al. 2005, 2008), e no Sudeste do Brasil (Lima \& Guedes-Bruni 1997, Marques 1997, Mamede et al. 2001).

\section{Resultados e Discussão}

A flora de angiospermas nas três áreas foi representada por 1.129 espécies em 467 gêneros e 124 famílias (Tabela 1). Desse total, 884 foram identificadas ao nível de espécie, 236 ao nível de gênero e de nove conhece-se apenas a família. Analisando separadamente as diferentes áreas estudadas, a SLO apresentou 709 espécies em 351 gêneros e 110 famílias e foi a área com maior riqueza, seguida da SBO com 628 espécies em 325 gêneros e 103 famílias, e da SPL, que apresentou 412 espécies em 248 gêneros e 87 famílias (Tabela 2). A lista aqui apresentada confirma a elevada diversidade de plantas tipicamente verificada em áreas de floresta no sul da Bahia (Thomas et al. 1998, 2008, Martini et al. 2007, Amorim et al. 2005, 2008). Das 884 espécies identificadas neste estudo, ca. 7,4\% (66 no total) são endêmicas de áreas do sul da Bahia e norte do Espírito Santo (Thomas et al. 2003). A porcentagem de espécies endêmicas registrada nas áreas estudadas assemelhou-se muito ao valor obtido por Amorim et al. (2005) numa área de floresta estacional do sul da Bahia, embora tenha sido consideravelmente menor que valores obtidos em áreas de florestas ombrófilas de terras baixas, que variaram entre 18,9 e 28,1\% do total da flora (Thomas et al. 1998, 2008, Amorim et al. 2008).

Até o momento, ca. 40 espécies foram apontadas como novas por diversos especialistas, sendo que algumas já se encontram publicadas (Amorim \& Leme 2009, Jardim \& Zappi 2008; Borges et al., no prelo). Dentre as novidades taxonômicas chama a atenção Clistax sp.1 (Acanthaceae), cujo hábito epifítico é pela primeira vez reportado em Acanthaceae neotropicais. Já a ocorrência de Bahiella infundibuliflora (Apocynaceae), Dendropanax amorimii (Araliaceae), Heteropterys bullata e Stigmaphyllon hispidum (Malpighiaceae), Mendoncia bahiensis (Acanthaceae) e Portea nana (Bromeliaceae) representaram o primeiro registro de espécies conhecidas apenas de suas coleções-tipo, provenientes de localidades distintas das do presente estudo. Conostegia icosandra (Melastomataceae) e Siparuna brasiliensis (Siparunaceae) estavam representadas na Bahia apenas por coletas feitas há mais de 40 anos.

O elevado número de espécies não descritas e de outras até então pouco conhecidas no sul da Bahia atesta para o ainda insuficiente conhecimento florístico de áreas tropicais, neste caso especificamente da Mata Atlântica (Prance 2001, Prance et al. 2000). Desta forma, informações geradas em levantamentos florísticos, tais como a descrição de novas espécies e a determinação da extensão de ocorrência de táxons em geral, constituem fontes de informação fundamentais para o estudo e conservação da biodiversidade (Mori 1989, Raven 2004, Funk 2006).

As famílias Araceae, Asteraceae, Bromeliaceae, Fabaceae, Lauraceae, Melastomataceae, Myrtaceae, Orchidaceae, Piperaceae, Poaceae, Rubiaceae e Solanaceae apresentaram o maior número de espécies nas três áreas estudadas (Figura 3). Essas 12 famílias abrangeram mais de $55 \%$ da flora de angiospermas amostrada, algumas das quais parecem ser mais diversificadas em áreas montanas do que em terras baixas. Como exemplo disso, Pereira et al. (2006) mostraram que $57 \%$ da flora arbórea do maciço do Itatiaia, amostrada entre 1.000 e $1.500 \mathrm{~m}$ de altitude, foi composta por espécies de Annonaceae, Asteraceae, Euphorbiaceae, Fabaceae, Lauraceae, Melastomataceae, Myrtaceae, Rubiaceae, Salicaceae e Sapotaceae, famílias que contribuíram com $52 \%$ (276 de 530 spp.) do compartimento arbóreo nas florestas montanas do sul da Bahia. Em outro estudo sobre a composição florística da Mata Atlântica, Oliveira-Filho \& Fontes (2000) indicaram que a importância relativa de Asteraceae, Melastomataceae e Solanaceae, que constam entre as famílias mais ricas em áreas montanhosas do sul da Bahia, tende a aumentar positivamente com a altitude em áreas de Mata Atlântica, assim como Myrsinaceae, cuja riqueza nessas mesmas áreas (13 spp.) é muito mais expressiva que na REBIO Una e na RPPN Serra do Teimoso (2-3 spp. - Amorim et al. 2005, 2008). Segundo esses mesmos autores, a riqueza de Chrysobalanaceae, Moraceae, Rutaceae e Sapotaceae tende a diminuir com o aumento da altitude, o que pode ser corroborado pela ocorrência de apenas 32 espécies dessas quatro famílias nas áreas montanas contra as 62 amostradas na RPPN Serra do Teimoso (Amorim et al. 2005) e as 64 na REBIO Una (Amorim et al. 2008). A ausência de Burseraceae, Combretaceae e Connaraceae também merecem destaque, uma vez que são grupos predominantemente amazônicos, e geralmente encontrados em áreas baixas do sul da Bahia (Mori et al. 1983, Martini et al. 2007, Amorim et al. 2008). Esses dados corroboram sugestões de que haja uma substituição de famílias ao longo de gradientes altitudinais em florestas ombrófilas neotropicais (Gentry 1995, Webster 1995, Oliveira-Filho \& Fontes 2000).

Dentre os gêneros com maior riqueza específica, Psychotria (21 spp.) apareceu em primeiro lugar em todas as áreas. Destacaramse também Miconia (20 spp.), Solanum (20 spp.), Piper (19 spp.), Ocotea (16 spp.), Leandra (16 spp.), Peperomia (15 spp.) e Myrcia 
Tabela 1. Lista das 1.129 espécies de angiospermas registradas em três áreas de floresta ombrófila montana no sul da Bahia, Brasil. As espécies estão organizadas em ordem alfabética das famílias e seguidas do registro de ocorrência depositado no Herbário CEPEC. O símbolo (-) indica a ausência da espécie na área correspondente. Os coletores estão representados pelas siglas: AA - André M. Amorim, AJ - Alessandra Jardim, AF - André Fontana, AL - Adriana Lobão, FF - Fabrício Ferreira, JJ - Jomar G. Jardim, JP - José Lima da Paixão, ML - Márdel Lopes, MR - Marcelo Reginato, PF - Pedro Fiaschi, RB - Rafael X. Borges, RC - Ricardo Castro, RG - Renato Goldenberg, RP - Ricardo Perdiz, SV - Silvana Vieira, TS - Talmon Santos e WT - Wm. Wayt Thomas.

Table 1. List of the 1129 species of angiosperms collected in three areas of montane forest in southern Bahia, Brazil. The families and species are organized alphabetically and followed by the habit and a CEPEC voucher collection for each site where the species has been collected. The dash symbol (-) indicates that the species has not been collected in that area. The collectors are represented by the following abbreviations: AA - André M. Amorim, AJ - Alessandra Jardim, AF - André Fontana, AL - Adriana Lobão, FF - Fabrício Ferreira, JJ - Jomar G. Jardim, JP - José Lima da Paixão, ML - Márdel Lopes, MR - Marcelo Reginato, PF - Pedro Fiaschi, RB - Rafael X. Borges, RC - Ricardo Castro, RG - Renato Goldenberg, RP - Ricardo Perdiz, SV - Silvana Vieira, TS - Talmon Santos e WT - Wm. Wayt Thomas.

\begin{tabular}{|c|c|c|c|c|}
\hline Espécie & Hábito & SBO & SPL & SLO \\
\hline \multicolumn{5}{|l|}{ ACANTHACEAE } \\
\hline Aphelandra cf. bahiensis (Nees) Wassh. & Sub-arbustivo & AA 7479 & - & - \\
\hline Aphelandra blanchetiana (Nees) Hook. & Sub-arbustivo & AA 4732 & AA 4080 & AA 4977 \\
\hline Clistax sp.1 & Epifítico & AA 4170 & - & AA 5301 \\
\hline Hygrophila brasiliensis (Spreng.) Lindau & Sub-arbustivo & RB 630 & - & - \\
\hline Justicia sp.1 & Sub-arbustivo & ML 1299 & - & - \\
\hline Justicia sp.2 & Sub-arbustivo & ML 1034 & - & - \\
\hline Justicia sp.3 & Sub-arbustivo & ML 1038 & - & - \\
\hline Justicia sp.4 & Sub-arbustivo & FF 1328 & - & - \\
\hline Justicia sp.5 & Sub-arbustivo & AA 6512 & - & - \\
\hline Justicia anagallis Lindau & Sub-arbustivo & ML 1060 & - & - \\
\hline Justicia beyrichii (Nees) Lindau & Sub-arbustivo & - & AA 4242 & - \\
\hline Justicia cf. luschnathii Lindau & Sub-arbustivo & AA 7477 & - & - \\
\hline Justicia cf. symphyantha (Nees) Lindau & Sub-arbustivo & - & RB 476 & AA 5300 \\
\hline Mendoncia bahiensis Profice & Trepador & ML 582 & - & JJ 4846 \\
\hline Mendoncia velloziana Mart. & Trepador & AA 4370 & - & WT 14089 \\
\hline Pseuderanthemum sp.1 & Sub-arbustivo & - & - & WT 14083 \\
\hline Pseuderanthemum verbenaceum (Nees \& Mart.) Radlk. & Sub-arbustivo & - & - & AA 4449 \\
\hline Ruellia sp.1 & Sub-arbustivo & - & - & FF 1400 \\
\hline Ruellia affinis (Nees) Lindau & Sub-arbustivo & AA 6996 & - & AA 5725 \\
\hline Ruellia cearensis Lindau & Sub-arbustivo & AA 4356 & - & - \\
\hline Thunbergia alata Bojer ex Sims & Trepador & AA 7286 & - & - \\
\hline \multicolumn{5}{|l|}{ AMARANTHACEAE } \\
\hline Alternanthera ramosissima (Mart.) Chodat & Arbustivo & - & - & WT 14071 \\
\hline Iresine diffusa Humb. \& Bonpl. ex Willd. & Trepador & AA 5186 & - & - \\
\hline \multicolumn{5}{|l|}{ ANACARDIACEAE } \\
\hline Tapirira guianensis Aubl. & Arbóreo & PF 2850 & RB 472 & AA 6081 \\
\hline \multicolumn{5}{|l|}{ ANNONACEAE } \\
\hline Annona sp.1 & Arbóreo & RB 640 & - & - \\
\hline Annona acutiflora Mart. & Arbustivo & - & PF 1907 & AA 6355 \\
\hline Annona cacans Warm. & Arbóreo & - & - & ML 530 \\
\hline Annona dolabripetala Raddi & Arbóreo & AA 6955 & PF 1915 & ML 551 \\
\hline Annona mucosa Jacq. & Arbóreo & AL 719 & - & - \\
\hline Guatteria ferruginea A.St.-Hil. & Arbóreo & - & AL 722 & WT 14107 \\
\hline Guatteria glabrescens R.E.Fr. & Arbóreo & AA 5413 & AL 720 & ML 1007 \\
\hline Guatteria macropus Mart. & Arbóreo & - & - & JJ 4890 \\
\hline Guatteria oligocarpa Mart. & Arbóreo & - & - & AA 6366 \\
\hline Guatteria pogonopus Mart. & Arbóreo & AA 5699 & - & AA 5345 \\
\hline Unonopsis sp.1 & Arbóreo & - & - & AL 741 \\
\hline Unonopsis bahiensis Maas \& Orava & Arbóreo & - & WT 14294 & - \\
\hline Xylopia sericea A.St.-Hil. & Arbóreo & - & - & ML 1435 \\
\hline \multicolumn{5}{|l|}{ APOCYNACEAE } \\
\hline Allamanda cathartica $\mathrm{L}$. & Trepador & - & - & ML 503 \\
\hline
\end{tabular}


Tabela 1. Continuação...

\begin{tabular}{|c|c|c|c|c|}
\hline Espécie & Hábito & SBO & SPL & SLO \\
\hline Bahiella infundibuliflora J.F.Morales & Trepador & - & RB 515 & - \\
\hline Forsteronia leptocarpa (Hook. \& Arn.) A.DC. & Arbóreo & - & PF 1756 & - \\
\hline Himatanthus bracteatus (A. DC.) Woodson & Arbóreo & AA s.n. & - & AA 7219 \\
\hline Macroditassa grandiflora (E.Fourn.) Malme & Trepador & AA 6975 & - & - \\
\hline Malouetia arborea (Vell.) Miers & Arbóreo & - & RB 518 & - \\
\hline Mandevilla funiformis (Vell.) K.Schum. & Trepador & - & AA 4785 & - \\
\hline Mandevilla cf. sellowii (Müll. Arg.) Woodson & Trepador & AA 5420 & - & AA 6410 \\
\hline Marsdenia sp.1 & Trepador & ML 1059 & - & - \\
\hline Matelea sp.1 & Trepador & - & - & PF 2803 \\
\hline $\begin{array}{l}\text { Peplonia bradeana (Fontella \& E.A.Schwarz) } \\
\text { Fontella \& Rapini }\end{array}$ & Trepador & - & - & AA 5799 \\
\hline Rauvolfia grandiflora Mart. ex A.DC. & Arbóreo & AA 4371 & JP 766 & AA 6325 \\
\hline Tabernaemontana linkii A.DC. & Arbóreo & - & - & JJ 4876 \\
\hline \multicolumn{5}{|l|}{ AQUIFOLIACEAE } \\
\hline Ilex sp.1 & Arbóreo & AA 6953 & - & AA 6405 \\
\hline Ilex sp.2 & Arbóreo & - & - & AA 5339 \\
\hline Ilex aff. conocarpa Reissek & Arbóreo & - & PF 2642 & AA 5314 \\
\hline \multicolumn{5}{|l|}{ ARACEAE } \\
\hline Anthurium sp.1 & Epifítico & - & - & AA 6399 \\
\hline Anthurium sp.2 & Epifítico & - & PF 1830 & JJ 4919 \\
\hline Anthurium sp.3 & Hemi-epifítico & - & FF 1494 & - \\
\hline Anthurium bellum Schott & Herbáceo & - & AA 4079 & - \\
\hline Anthurium gladiifolium Schott & Epifítico & RB 625 & PF 1904 & AA 5770 \\
\hline Anthurium harrisii G.Don & Epifítico & AA 4376 & ML 1106 & AA 4387 \\
\hline Anthurium pentaphyllum (Aubl.) G.Don & Epifítico & AA 5405 & PF 1856 & AA $5770 \mathrm{a}$ \\
\hline Anthurium scandens (Aubl.) Engl. & Hemi-epifítico & AA 4392 & RB 503 & ML 1473 \\
\hline Anthurium solitarium Schott & Epifítico & - & - & AA 6610 \\
\hline Asterostigma riedelianum Kuntze & Herbáceo & AA 5447 & PF 1782 & - \\
\hline Heteropsis sp.1 & Hemi-epifítico & AA 4751 & - & - \\
\hline Heteropsis oblongifolia H.B.K. & Hemi-epifítico & MS 757 & - & JJ 4886 \\
\hline Monstera sp.1 & Hemi-epifítico & JP 639 & AA 4209 & JP 956 \\
\hline Philodendron sp.1 & Hemi-epifítico & AA 6516 & AA 4820 & JJ 4898 \\
\hline Philodendron sp.2 & Hemi-epifítico & - & - & FF 1413 \\
\hline Philodendron blanchetianum Schott & Hemi-epifítico & AA 5389 & - & - \\
\hline Philodendron cordatum Kunth & Hemi-epifítico & AA 5441 & WT 14315 & AA 6580 \\
\hline Philodendron fragrantissimum (Hook.) G.Don & Hemi-epifítico & ML 1044 & AA 4818a & ML 1449 \\
\hline Philodendron insigne Schott & Epifítico & - & - & JJ 4896 \\
\hline Philodendron longilaminatum Schott & Epifítico & ML 426 & - & - \\
\hline Philodendron ornatum Schott & Epifítico & AA 6297 & - & AA 6727 \\
\hline Philodendron pedatum (Hook.) H.B.K. & Hemi-epifítico & AA 7468 & - & AA 6599 \\
\hline Philodendron propinquum Schott & Hemi-epifítico & AA 6945 & JP 774 & AA 5296 \\
\hline Philodendron scandens C.Koch. \& Sello & Hemi-epifítico & - & - & AA 5960 \\
\hline Rhodospatha sp.1 & Hemi-epifítico & RB 300 & JP 780 & JJ 4842 \\
\hline Rhodospatha oblongata Poepp. & Hemi-epifítico & - & - & AA 5753 \\
\hline Stenospermation spruceanum Schott & Hemi-epifítico & AA $6945 \mathrm{a}$ & WT 14322 & AA 5298 \\
\hline $\begin{array}{l}\text { Syngonium podophyllum } \\
\text { Schott var. vellozianum (Schott) Croat }\end{array}$ & Hemi-epifítico & RB 639 & - & AA 5960a \\
\hline Xanthosoma maximilianum Schott & Herbáceo & AA 5468 & - & AA 4439 \\
\hline \multicolumn{5}{|l|}{ ARALIACEAE } \\
\hline Dendropanax amorimii Fiaschi & Arbóreo & - & ML 321 & WT 14591 \\
\hline
\end{tabular}


Tabela 1. Continuação...

\begin{tabular}{|c|c|c|c|c|}
\hline Espécie & Hábito & SBO & SPL & SLO \\
\hline Dendropanax bahiensis Fiaschi & Arbustivo & - & - & JJ 4365 \\
\hline Oreopanax capitatus (Jacq.) Decne. \& Planch. & Hemi-epifítico & AA 4357 & - & AA 6568 \\
\hline Schefflera angustissima (Marchal) Frodin & Arbóreo & AA 4178 & - & - \\
\hline Schefflera morototoni (Aubl.) Maguire, Steyerm. \& Frodin & Arbóreo & - & - & ML 1223 \\
\hline Schefflera aff. varisiana Frodin & Arbóreo & - & AA 4542 & AA 5344 \\
\hline \multicolumn{5}{|l|}{ ARECACEAE } \\
\hline Attalea oleifera Barb. Rodr. & Arbóreo & - & - & AA s.n. \\
\hline Bactris pickelii Burret & Arbustivo & AA 5438 & - & JJ 4838 \\
\hline Euterpe edulis Mart. & Arbóreo & AA s.n. & AA s.n. & AA s.n. \\
\hline Geonoma sp.1 & Arbustivo & - & - & AA 6345 \\
\hline Geonoma pauciflora Mart. & Arbustivo & - & ML 305 & AA 5756 \\
\hline Geonoma pohliana Mart. & Arbustivo & WT 14236 & AA 4208 & WT 14115 \\
\hline \multicolumn{5}{|l|}{ ARISTOLOCHIACEAE } \\
\hline Aristolochia sp.1 & Trepador & WT 13793 & - & - \\
\hline Aristolochia brasiliensis Mart. ex Zucc. & Trepador & - & - & AA 5776 \\
\hline \multicolumn{5}{|l|}{ ASTERACEAE } \\
\hline Achyrocline satureioides DC. & Herbáceo & AA 7018 & - & - \\
\hline $\begin{array}{l}\text { Austroeupatorium inulaefolium (H.B.K.) R.M.King \& } \\
\text { H.Rob. }\end{array}$ & Arbustivo & AA 7289 & - & AA 5778 \\
\hline Baccharis calvescens DC. & Arbustivo & AA 6935 & RB 514 & - \\
\hline Baccharis cf. myriocephala DC. & Arbustivo & - & - & AA 6754 \\
\hline Baccharis oblongifolia (Ruiz \& Pav.) Pers. & Arbóreo & - & PF 1770 & AA 5327 \\
\hline Baccharis singularis (Vell.) Barroso & Arbustivo & AA 6934 & - & AA 6067 \\
\hline Baccharis trinervis (Lam.) Pers. var. rhexioides (H.B.K.) Baker & Trepador & RB 637 & - & - \\
\hline Baccharis trinervis (Lam.) Pers. var. trinervis & Trepador & ML 815 & - & - \\
\hline Barrosoa atlantica R.M.King \& H.Rob. & Herbáceo & - & - & AA 5326 \\
\hline Centhraterum punctatum Cass. & Sub-arbustivo & - & - & AA 7218 \\
\hline Chaptalia nutans (L.) Polak & Herbáceo & AA 7016 & - & - \\
\hline Cyrtocymura scorpioides (Lam.) H.Rob. & Sub-arbustivo & MR 226 & AA 4106 & AA 6738 \\
\hline Diacranthera hebeclinia H.Rob. & Herbáceo & FF 1332 & - & AA 6354 \\
\hline Diacranthera ulei R.M.King \& H.Rob. & Herbáceo & - & - & AA 5319 \\
\hline Elephantopus mollis H.B.K. & Sub-arbustivo & - & AA 4243 & ML 1458 \\
\hline Fleischmannia remotifolia (DC.) R.M.King \& H.Rob. & Sub-arbustivo & AA 4173 & - & WT 14062 \\
\hline Heterocondylus sp.1 & Arbustivo & - & - & AA 5784 \\
\hline Heterocondylus alatus (Vell.) R.M.King \& H.Rob. & Arbustivo & - & - & WT 14065 \\
\hline Heterocondylus vitalbae (DC.) R.M.King \& H.Rob. & Trepador & AA 5432 & - & AA 6324 \\
\hline Lepidaploa cotoneaster (Willd. ex Spreng.) H.Rob. & Arbustivo & - & - & AA 6734 \\
\hline Lepidaploa aff. mucronifolia (DC.) H.Rob. & Sub-arbustivo & - & PF 1546 & - \\
\hline Lepidaploa persericea (H.Rob.) H.Rob. & Arbustivo & - & - & AA 5790 \\
\hline Lepidaploa salzmanii (DC.) H.Rob. & Sub-arbustivo & - & - & AA 6334 \\
\hline Lessingianthus macrophyllus (Less.) H.Rob. & Arbustivo & AA 6305 & - & - \\
\hline Mikania sp.1 & Trepador & - & - & AA 5000 \\
\hline Mikania sp.2 & Trepador & - & - & FF 1435 \\
\hline Mikania biformis DC. & Trepador & ML 566 & - & ML 1184 \\
\hline Mikania callineura Sch.Bip. ex Baker & Trepador & - & JP 571 & AA 6376 \\
\hline Mikania candolleana Gardner & Trepador & AA 7692 & PF 1526 & AA 5304 \\
\hline Mikania aff. hookeriana DC. & Trepador & AA 4373 & AA 4909 & AA 6713 \\
\hline Mikania kubitzkii R.M.King \& H.Rob. & Trepador & - & PF 2636 & - \\
\hline Mikania lundiana DC. & Trepador & ML 1058 & - & - \\
\hline Mikania mattos-silvae R.M.King \& H.Rob. & Trepador & AA 6540 & - & - \\
\hline
\end{tabular}


Tabela 1. Continuação...

\begin{tabular}{|c|c|c|c|c|}
\hline Espécie & Hábito & SBO & SPL & SLO \\
\hline Mikania micrantha H.B.K. & Trepador & RB 628 & - & - \\
\hline Mikania perhirta R.M.King \& H.Rob. & Trepador & AA 6991 & - & - \\
\hline Mikania salzmaniifolia DC. & Trepador & - & - & AA 5785 \\
\hline Mikania sericea Hook. \& Arn. & Trepador & ML 1028 & - & AA 5237 \\
\hline Mikania ternata (Vell.) B.L.Rob. & Trepador & ML 1056 & - & AA 5730 \\
\hline Mikania trinervis Hook. \& Arn. & Trepador & AA 6529 & AA 4241 & ML 988 \\
\hline Mikania ulei Hieron. & Trepador & FF 1301 & AA 4077 & - \\
\hline Paralychnophora santosii (H.Rob.) D.J.N.Hind & Arbóreo & - & - & AA 5343 \\
\hline Pentacalia desiderabilis (Vell.) Cuatr. & Trepador & RB 351 & - & - \\
\hline Piptocarpha lundiana (Less.) Baker & Trepador & - & - & AA 5245 \\
\hline Piptocarpha oblonga (Gardner) Baker & Trepador & - & - & AA 6342 \\
\hline Piptocarpha ramiflora (Spreng.) Baker & Trepador & RB 279 & - & - \\
\hline Pluchea sagittalis (Lam.) Cabrera & Arbustivo & AA 5197 & - & - \\
\hline Solidago chilensis Meyen & Arbustivo & - & RB 502 & - \\
\hline Sphagneticola trilobata (L.) Pruski & Herbáceo & RB 337 & - & ML 1190 \\
\hline Steyermarkina pyrifolia (DC.) R.M.King \& H.Rob. & Trepador & AA 5417 & - & - \\
\hline Synedrella nodiflora (L.) Gaertn. & Herbáceo & FF 1321 & - & - \\
\hline Tagetes minuta $\mathrm{L}$. & Sub-arbustivo & AA 7278 & - & - \\
\hline Tithonia diversifolia (Hemsl.) A.Gray & Arbustivo & AA 5192 & - & - \\
\hline Vernonanthura diffusa (Less.) H.Rob. & Arbóreo & FF 1333 & - & - \\
\hline Vernonanthura discolor (Less.) H.Rob. & Arbóreo & - & PF 1845 & AA 5306 \\
\hline Vernonanthura phosphorica (Vell.) H.Rob. & Arbustivo & FF 1347 & - & - \\
\hline Vernonanthura vinhae (H.Rob.) H.Rob. & Arbustivo & - & - & AA 6635 \\
\hline \multicolumn{5}{|l|}{ BALANOPHORACEAE } \\
\hline Helosis cayennensis (Sw.) Spreng. & Herbáceo & ML 1306 & - & - \\
\hline Langsdorffia hypogaea Mart. & Herbáceo & - & - & WT 14557 \\
\hline Lophophytum mirabile Schott \& Endl. subsp. Mirabile & Herbáceo & AA 4436 & - & - \\
\hline \multicolumn{5}{|l|}{ BALSAMINACEAE } \\
\hline Impatiens walleriana Hook.f. & Herbáceo & AA 5456 & - & - \\
\hline \multicolumn{5}{|l|}{ BEGONIACEAE } \\
\hline Begonia sp.1 & Herbáceo & - & - & RB 597 \\
\hline Begonia sp.2 & Herbáceo & - & - & RB 602 \\
\hline Begonia sp.3 & Herbáceo & - & AA 4847 & - \\
\hline Begonia convolvulacea A.DC. & Hemi-epifítico & ML 753 & AA 4912 & AA 5280 \\
\hline Begonia digitata Raddi & Sub-arbustivo & - & ML 347 & - \\
\hline Begonia fischeri Schrank & Herbáceo & AA 5453 & - & - \\
\hline Begonia fruticosa (Klotzsch) A.DC. & Epifítico & ML 756 & AA 4229 & AA 5265 \\
\hline Begonia grisea A.DC. & Epifítico & AA 6290 & - & - \\
\hline Begonia itaguassuensis Brade & Herbáceo & WT 14221 & PF 1533 & AA 5005 \\
\hline Begonia radicans Vell. & Hemi-epifítico & WT 14206 & - & AA 5275 \\
\hline Begonia aff. reniformis Dryand. & Herbáceo & ML 604 & - & AA 5953 \\
\hline Begonia rufa Thumb. & Herbáceo & - & AA 4906 & - \\
\hline Begonia smilacina A.DC. & Hemi-epifítico & - & AA 4527 & - \\
\hline \multicolumn{5}{|l|}{ Bignoniaceae } \\
\hline Adenocalymma sp. 1 & Trepador & - & PF 1777 & - \\
\hline Anemopaegma sp.1 & Trepador & AA 6988 & - & ML 535 \\
\hline Callichlamys latifolia (Rich.) K.Schum. & Trepador & AA 6987 & ML 1177 & RB 605 \\
\hline Jacaranda puberula Cham. & Arbóreo & AA 7005 & - & - \\
\hline Lundia cordata (Vell.) DC. & Trepador & FF 1334 & - & - \\
\hline Handroanthus heptaphyllus (Vell.) Mattos & Arbóreo & AA 7448 & - & ML 1225 \\
\hline
\end{tabular}


Tabela 1. Continuação...

\begin{tabular}{|c|c|c|c|c|}
\hline Espécie & Hábito & SBO & SPL & SLO \\
\hline Pithecoctenium crucigerum (L.) A.H. Gentry & Arbóreo & AA 6944 & - & - \\
\hline Pleonotoma albiflora (Salzm. ex DC.) A.H.Gentry & Trepador & - & JP 771 & - \\
\hline Pleonotoma melioides (S.Moore) A.H.Gentry & Trepador & - & - & ML 1222 \\
\hline Pleonotoma cf. stichadenia K.Schum. & Trepador & ML 626 & - & - \\
\hline Tabebuia elliptica (DC.) Sandw. & Arbóreo & - & - & ML 1221 \\
\hline Tanaecium jaroba $\mathrm{Sw}$. & Trepador & - & ML 686 & - \\
\hline \multicolumn{5}{|l|}{ BONNETIACEAE } \\
\hline Bonnetia stricta (Nees) Nees \& Mart. & Arbóreo & - & - & WT 14608 \\
\hline \multicolumn{5}{|l|}{ BORAGINACEAE } \\
\hline Cordia bifurcata Roem. \& Schult. & Sub-arbustivo & RB 647 & - & - \\
\hline Cordia ecalyculata Vell. & Arbóreo & - & AA 4218 & JJ 4888 \\
\hline Cordia longifolia A.DC. & Arbustivo & - & JP 798 & ML 524 \\
\hline Cordia polycephala (Lam.) I.M.Johnst. & Sub-arbustivo & AA 7015 & - & - \\
\hline Cordia silvestris Fresen. & Arbóreo & - & - & JP 961 \\
\hline Cordia trichoclada DC. & Arbóreo & AA 5466 & - & AA 4453 \\
\hline Tournefortia floribunda H.B.K. & Trepador & AA 5386 & - & - \\
\hline Tournefortia gardneri A.DC. & Trepador & - & ML 340 & - \\
\hline \multicolumn{5}{|l|}{ BROMELIACEAE } \\
\hline Aechmea sp.1 & Epifítico & - & ML 678 & - \\
\hline Aechmea sp. 2 & Epifítico & - & PF 2626 & - \\
\hline Aechmea aff. capitata Baker & Epifítico & AA 4199 & - & AA 6602 \\
\hline Aechmea froesii Leme \& J.R.Siqueira & Epifítico & ML 1293 & ML 685 & AA 6594 \\
\hline Aechmea linharesiorum Leme & Epifítico & - & ML 1169 & - \\
\hline Aechmea miniata Baker & Epifítico & - & WT 14308 & - \\
\hline Aechmea nudicaulis Griseb. & Epifítico & RB 696 & - & AA 7217 \\
\hline Aechmea ramosa Mart. & Epifítico & - & AA 4110 & - \\
\hline Aechmea tentaculifera Leme, Amorim \& J.R.Siqueira & Epifítico & WT 14218 & - & ML 1491 \\
\hline Aechmea turbinocalyx $\mathrm{Mez}$ & Epifítico & - & PF 1763 & - \\
\hline Aechmea viridostigma Leme \& H.Luther & Epifítico & ML 433 & PF 1560 & JJ 4680 \\
\hline Billbergia chlorosticta Saunders & Epifítico & AA 5437 & AA 4849 & JP 976 \\
\hline Billbergia euphemiae E.Morr. & Epifítico & - & - & AA 5752 \\
\hline Billbergia horrida Regel & Epifítico & AA 6965 & - & - \\
\hline Canistrum camacaensis Martinelli \& Leme & Epifítico & WT 13803 & - & AA 5751 \\
\hline Canistrum montanum Leme & Epifítico & - & AA 4797 & AA 5269 \\
\hline Canistrum aff. seidelianum W.Weber & Epifítico & - & PF 1917 & ML 1462 \\
\hline Guzmania lingulata (L.) Mez & Epifítico & - & - & RB 591 \\
\hline Hohenbergia sp.1 & Epifítico & JJ 4419 & - & - \\
\hline Hohenbergia belemii (L.B.Sm.) Read & Epifítico & WT 13020 & - & - \\
\hline Hohenbergia edmundoi L.B.Sm. \& Read & Epifítico & - & - & JJ 4920 \\
\hline Hohenbergia minor L.B.Sm. & Epifítico & ML 1052 & - & - \\
\hline Lymania marantoides (L.B.Sm.) Read & Epifítico & - & AA 4840 & - \\
\hline Neoregelia azevedoi Leme & Epifítico & - & - & AA 6624 \\
\hline Neoregelia crispata Leme & Epifítico & - & - & AA 5991 \\
\hline Neoregelia kerryi Leme & Epifítico & AA 6978 & AA 4806 & AA 5807 \\
\hline Neoregelia pauciflora L.B.Sm. & Epifítico & - & - & AA 6590 \\
\hline Nidularium bicolor (E.Pereira) Leme & Epifítico & AA 5439 & RB 493 & WT 14093b \\
\hline Nidularium innocentii Lem. & Epifítico & ML 1053 & AA 4530 & AA 6696 \\
\hline Pitcairnia flammea Lindl. & Epifítico & - & AA 4216 & AA 5814 \\
\hline Portea filifera L.B.Sm. & Epifítico & - & AA 4825 & - \\
\hline Portea nana Leme & Epifítico & - & - & AA 6597 \\
\hline
\end{tabular}


Tabela 1. Continuação...

\begin{tabular}{|c|c|c|c|c|}
\hline Espécie & Hábito & SBO & SPL & SLO \\
\hline Portea petropolitana Mez var. noettigii (Wawra) L.B.Sm. & Epifítico & WT 13033 & - & - \\
\hline Quesnelia koltesii Amorim \& Leme & Epifítico & AA 5443 & - & - \\
\hline Quesnelia clavata Amorim \& Leme & Epifítico & - & - & AA 5351 \\
\hline Racinaea spiculosa (Griseb.) M.A.Spencer \& L.B.Sm. & Epifítico & - & AA $4817 \mathrm{a}$ & AA 5820 \\
\hline Ronnbergia aff. brasiliensis E.Pereira \& I.A.Penna & Epifítico & - & - & ML 1484 \\
\hline Ronnbergia silvana Leme & Epifítico & - & PF 1764 & - \\
\hline Tillandsia $\mathrm{cf}$ meridionalis Baker & Epifítico & FF 1315 & JP 505 & JJ 4895 \\
\hline Tillandsia pohliana $\mathrm{Mez}$ & Epifítico & - & - & AA 6391 \\
\hline Tillandsia stricta Sol. & Epifítico & RB 319 & - & AA 6086 \\
\hline Vriesea sp.1 & Epifítico & - & - & AA 6758 \\
\hline Vriesea sp.2 & Epifítico & - & - & AA 6592 \\
\hline Vriesea sp.3 & Epifítico & AA 6560 & - & - \\
\hline Vriesea blackburniana Leme & Epifítico & - & RB 494 & - \\
\hline Vriesea duvaliana E.Morren & Epifítico & AA 5708 & - & JP 965 \\
\hline Vriesea ensiformis (Vell.) Beer & Epifítico & WT 13760 & PF 1887 & JP 975 \\
\hline Vriesea flammea L.B.Sm. & Epifítico & - & RB 497 & RB 590 \\
\hline Vriesea gamba F.J. Müll. & Epifítico & - & - & AA 6097 \\
\hline Vriesea longicaulis $\mathrm{Mez}$ & Epifítico & - & - & AA 5303 \\
\hline Vriesea longiscapa Ule & Epifítico & - & - & AA 5797 \\
\hline Vriesea minuta Leme & Epifítico & ML 1045 & RB 511 & - \\
\hline Vriesea paratiensis E.Pereira & Epifítico & AA 6950 & - & AA 6646 \\
\hline Vriesea psittacina (Hook.) Lindl. & Epifítico & - & ML 1178 & - \\
\hline Vriesea regnelli $\mathrm{Mez}$ & Epifítico & - & - & AA 6759 \\
\hline Vriesea rhodostachys L.B.Sm. & Epifítico & - & JJ 4783 & - \\
\hline Vriesea rodigasiana E.Morren & Epifítico & - & - & AA 6688 \\
\hline Vriesea ruschii L.B.Sm. & Epifítico & AA 6545 & RB 501 & - \\
\hline Vriesea simplex (Vell.) Beer & Epifítico & AA 4764 & JP 777 & AA s.n. \\
\hline \multicolumn{5}{|l|}{ BURMANNIACEAE } \\
\hline Gymnosiphon divaricatus (Benth.) Benth. \& Hook.f. & Herbáceo & AA 6949 & ML 691 & AA 5944 \\
\hline \multicolumn{5}{|l|}{ CACTACEAE } \\
\hline Epiphyllum phyllanthus (L.) Haw. & Epifítico & - & - & JJ 4401 \\
\hline Hatiora salicornioides (Haw.) Britton \& Rose & Epifítico & - & AA 4823 & - \\
\hline Rhipsalis oblonga Lofgr. & Epifítico & RB 682 & PF 1778 & ML 1019 \\
\hline Rhipsalis teres (Vell.) Steud. & Epifítico & AA 4762 & - & - \\
\hline \multicolumn{5}{|l|}{ CAMPANULACEAE } \\
\hline Centropogon cornutus (L.) Druce & Sub-arbustivo & RB 699 & AA 4211 & WT 14074 \\
\hline Lobelia organensis Gardner & Sub-arbustivo & - & - & AA 5357 \\
\hline \multicolumn{5}{|l|}{ CANNABACEAE } \\
\hline Celtis iguanae (Jacq.) Sarg. & Arbustivo & AA 7295 & - & - \\
\hline Trema micrantha (L.) Blume & Arbóreo & AA 4423 & - & AA 6694 \\
\hline \multicolumn{5}{|l|}{ CANNACEAE } \\
\hline Canna paniculata Ruiz \& Pav. & Sub-arbustivo & - & AA 4236 & - \\
\hline \multicolumn{5}{|l|}{ CARICACEAE } \\
\hline Jacaratia heptaphylla (Vell.) A.DC. & Arbóreo & ML 781 & ML 350 & AA 5989 \\
\hline \multicolumn{5}{|l|}{ CARYOCARACEAE } \\
\hline Caryocar edule Casar. & Arbóreo & AA 7706 & AA 4544 & AA 5336a \\
\hline \multicolumn{5}{|l|}{ CELASTRACEAE } \\
\hline Cheiloclinium cognatum (Miers) A.C.Sm. & Arbóreo & AA 5149 & JJ 4784 & AA 5308 \\
\hline Maytenus aff. brasiliensis Mart. & Arbóreo & ML 592 & PF 1805 & WT 14555 \\
\hline Salacia sp.1 & Trepador & - & - & ML 487 \\
\hline
\end{tabular}


Angiospermas em florestas montanas da Bahia

Tabela 1. Continuação...

\begin{tabular}{|c|c|c|c|c|}
\hline Espécie & Hábito & SBO & SPL & SLO \\
\hline Salacia elliptica (Mart. ex Schult.) G.Don & Trepador & - & JP 498 & ML 1008 \\
\hline Tontelea miersii (Peyr.) A.C.Sm. & Trepador & - & - & WT 14563 \\
\hline \multicolumn{5}{|l|}{ CHLORANTHACEAE } \\
\hline Hedyosmum brasiliense Miq. & Arbustivo & - & AA 4791 & AA 5336 \\
\hline \multicolumn{5}{|l|}{ CHRYSOBALANACEAE } \\
\hline Couepia monteclarensis Prance & Arbóreo & MR 204 & - & AA 6639 \\
\hline Hirtella santosii Prance & Arbóreo & - & JJ 4791 & AA 6562 \\
\hline Licania sp.1 & Arbóreo & FF 1330 & - & - \\
\hline Licania belemii Prance & Arbóreo & - & - & ML 560 \\
\hline \multicolumn{5}{|l|}{ CLETHRACEAE } \\
\hline Clethra scabra Pers. & Arbóreo & RB 661 & - & JP 955 \\
\hline \multicolumn{5}{|l|}{ CLUSIACEAE } \\
\hline Clusia sp.1 & Arbóreo & - & ML 323 & - \\
\hline Clusia sp.2 & Arbóreo & - & - & AA 7205 \\
\hline Clusia melchiori Gleason & Arbóreo & MR 200 & WT 14318 & AA 4968 \\
\hline Garcinia gardneriana (Planch. \& Triana) Zappi & Arbóreo & AA 7302 & - & ML 521 \\
\hline Garcinia macrophylla Mart. & Arbóreo & - & - & AA 6689 \\
\hline Kielmeyera sp. 1 & Arbóreo & AA 7202 & - & - \\
\hline Symphonia globulifera L.f. & Arbóreo & - & - & ML 1447 \\
\hline Tovomita sp.1 & Arbóreo & AA 6539 & - & - \\
\hline Tovomita sp.2 & Arbóreo & AA 7707 & - & - \\
\hline Tovomita mangle G.Mariz & Arbóreo & - & - & JJ 4403 \\
\hline \multicolumn{5}{|l|}{ COMMELINACEAE } \\
\hline Commelina sp.1 & Herbáceo & - & ML 1152 & - \\
\hline Dichorisandra sp. 1 & Herbáceo & AA 4771 & RB 496 & AA 5254 \\
\hline Dichorisandra sp.2 & Herbáceo & FF 1305 & - & - \\
\hline Dichorisandra aff. acaulis Cogn. & Herbáceo & AA 4736 & - & - \\
\hline Dichorisandra procera Mart. & Sub-arbustivo & RB 320 & - & - \\
\hline \multicolumn{5}{|l|}{ CONVOLVULACEAE } \\
\hline Convolvulac sp.1 & Trepador & AA 6954 & - & - \\
\hline Ipomoea ramosissima (Poir.) Choisy & Trepador & AA 5193 & - & - \\
\hline Merremia aegyptia (L.) Urban & Trepador & RB 656 & - & - \\
\hline \multicolumn{5}{|l|}{ COSTACEAE } \\
\hline Costus scaber Ruiz \& Pav. & Sub-arbustivo & AA 4735 & - & AA 6726 \\
\hline \multicolumn{5}{|l|}{ CUCURBITACEAE } \\
\hline Cucurbitac sp.1 & Trepador & RB 665 & - & - \\
\hline Cucurbitac sp.2 & Trepador & FF 1335 & - & - \\
\hline Cayaponia cf. tayuya (Vell.) Cogn. & Trepador & RB 281 & - & - \\
\hline Cayaponia rigida (Cogn.) Cogn. & Trepador & - & - & JJ 4875 \\
\hline Cayaponia cf. trilobata Cogn. & Trepador & - & - & AA 6573 \\
\hline Gurania sp.1 & Trepador & - & AA 4219 & - \\
\hline Gurania sp.2 & Trepador & - & - & AA 5948 \\
\hline Gurania sp.3 & Trepador & RB 334 & - & - \\
\hline Gurania acuminata Cogn. & Trepador & AA 4742 & JP 788 & ML 508 \\
\hline Gurania cissoides (Benth.) Cogn. & Trepador & - & - & PF 2819 \\
\hline Gurania speciosa (Poepp. \& Endl.) Cogn. & Trepador & - & ML 1145 & ML 504 \\
\hline Gurania subumbellata (Miq.) Cogn. & Trepador & MR 197 & - & - \\
\hline Melothria pendula L. & Trepador & AA 5189 & - & - \\
\hline \multicolumn{5}{|l|}{ CUNONIACEAE } \\
\hline Lamanonia ternata Vell. & Arbóreo & AA 6963 & AA 4830 & JJ 4406 \\
\hline
\end{tabular}


Tabela 1. Continuação...

\begin{tabular}{|c|c|c|c|c|}
\hline Espécie & Hábito & SBO & SPL & SLO \\
\hline Weinmannia paullinifolia Pohl. ex Ser. & Arbóreo & - & - & AA 5789 \\
\hline \multicolumn{5}{|l|}{ CYCLANTHACEAE } \\
\hline Evodianthus funifer (Poit.) Lindm. & Hemi-epifítico & AA 4759 & ML 303 & ML 1464 \\
\hline \multicolumn{5}{|l|}{ CYPERACEAE } \\
\hline Becquerelia cymosa Brongn. & Herbáceo & AA 5718 & AA $4532 a$ & PF 2808 \\
\hline Cryptangium sp.1 & Herbáceo & - & ML 660 & - \\
\hline Cyperus diffusus Vahl & Herbáceo & RB 301 & - & - \\
\hline Cyperus luzulae (L.) Rottb. ex Retz. & Herbáceo & - & - & JJ 4837 \\
\hline Eleocharis sp.1 & Herbáceo & - & - & WT 14067 \\
\hline Hypolytrum sp.1 & Herbáceo & AA 6534 & - & - \\
\hline Hypolytrum glomerulatum M.Alves \& W.W.Thomas & Herbáceo & - & - & AA 5286 \\
\hline Hypolytrum aff. lucennoi M.Alves \& W.W.Thomas & Herbáceo & - & PF 1836 & - \\
\hline Hypolytrum schraderianum Nees & Herbáceo & AA 4758 & AA 4532 & JJ 4694 \\
\hline Kyllinga sp.1 & Herbáceo & - & ML 1163 & - \\
\hline Pleurostachys sp.1 & Herbáceo & - & - & AA 6577 \\
\hline Pleurostachys sp.2 & Herbáceo & - & - & AA 6065 \\
\hline Pleurostachys sp. 3 & Herbáceo & AA 4435 & - & - \\
\hline Pleurostachys gaudichaudii Brongn. & Herbáceo & WT 13753 & ML 1151 & JJ 4391 \\
\hline Pleurostachys aff. millegrana (Nees) Steud. & Herbáceo & AA 6999 & - & - \\
\hline $\begin{array}{l}\text { Pleurostachys puberula Boeck. var. montana } \\
\text { (Palla) Kük. \& R.Gross }\end{array}$ & Herbáceo & - & - & AA 6346 \\
\hline Pleurostachys puberula Boeck. var. puberula & Herbáceo & - & - & WT 14104 \\
\hline Rhynchospora sp.1 & Herbáceo & - & - & ML 1021 \\
\hline Rhynchospora cryptantha C.B.Clarke & Herbáceo & - & WT 14326 & WT 14605 \\
\hline Rhynchospora nervosa Boeck. subsp. ciliata T.Koyama & Herbáceo & - & - & AA 6670 \\
\hline $\begin{array}{l}\text { Rhynchospora radicans (Schltdl. \& Cham.) H.Pfeiff. subsp. } \\
\text { microcephala (Bertero ex Spreng.) W.W.Thomas }\end{array}$ & Herbáceo & - & - & AA 6576 \\
\hline Rhynchospora splendens Lindm. & Herbáceo & - & WT 14332 & AA 6381 \\
\hline Scleria sp.1 & Herbáceo & - & AA 4235 & AA 5332 \\
\hline Scleria aff. bracteata Cav. & Herbáceo & FF 1303 & - & - \\
\hline Scleria latifolia $\mathrm{Sw}$. & Herbáceo & - & - & AA 6326 \\
\hline Scleria secans (L.) Urban & Herbáceo & AA 6503 & - & WT 14595 \\
\hline \multicolumn{5}{|l|}{ DICHAPETALACEAE } \\
\hline Stephanopodium blanchetianum Baill. & Arbóreo & AA 6518 & - & ML 546 \\
\hline \multicolumn{5}{|l|}{ DILLENIACEAE } \\
\hline Davilla sp.1 & Trepador & AA 7465 & - & - \\
\hline Davilla kunthii A.St.-Hil. & Trepador & RB 653 & - & - \\
\hline \multicolumn{5}{|l|}{ DIOSCOREACEAE } \\
\hline Dioscorea sp.1 & Trepador & - & JP 566 & ML 979 \\
\hline \multicolumn{5}{|l|}{ EBENACEAE } \\
\hline Diospyros sp.1 & Arbóreo & RB 702 & PF 1826 & FF 1382 \\
\hline \multicolumn{5}{|l|}{ ELAEOCARPACEAE } \\
\hline Sloanea sp.1 & Arbóreo & - & - & JJ 4354 \\
\hline Sloanea guianensis (Aubl.) Benth. & Arbóreo & ML 778 & PF 2637 & AA 5302 \\
\hline \multicolumn{5}{|l|}{ ERICACEAE } \\
\hline Gaylussacia sp.1 & Arbustivo & - & - & WT 14615 \\
\hline \multicolumn{5}{|l|}{ ERYTHROXYLACEAE } \\
\hline Erythroxylum citrifolium A.St.-Hil. & Arbóreo & RB 694 & WT 14320 & JJ 4832 \\
\hline Erythroxylum cuspidifolium Mart. & Arbóreo & AA 5414 & AA 4834 & JJ 4878 \\
\hline Erythroxylum grandifolium Peyr. & Arbóreo & AA 4412 & - & - \\
\hline
\end{tabular}


Tabela 1. Continuação...

\begin{tabular}{|c|c|c|c|c|}
\hline Espécie & Hábito & SBO & SPL & SLO \\
\hline \multicolumn{5}{|l|}{ EUPHORBIACEAE } \\
\hline Actinostemon appendiculatus Jabl. & Arbóreo & RB 635 & - & - \\
\hline Alchornea triplinervia (Spreng.) Müll.Arg. & Arbóreo & AA 5181 & - & - \\
\hline Aparisthmium cordatum (A.Juss.) Baill. & Arbóreo & RB 269 & ML 295 & WT 14547 \\
\hline Bernardia scabra Müll.Arg. & Arbustivo & AA 7694 & WT 14291 & AA 6353 \\
\hline Croton floribundus Spreng. & Arbóreo & ML 1055 & - & JJ 4405 \\
\hline Croton macrobothrys Baill. & Arbóreo & RB 322 & - & WT 14540 \\
\hline Dalechampia ficifolia Lam. & Trepador & RB 277 & RB 484 & - \\
\hline Dalechampia ilheotica Wawra & Trepador & - & WT 14288 & AA 5272 \\
\hline Dalechampia pentaphylla Lam. & Trepador & AA 5184 & - & - \\
\hline Mabea brasiliensis Müll.Arg. & Arbóreo & - & FF 1501 & - \\
\hline Microstachys aff. hispida (Mart.) Govaerts & Arbustivo & - & RB 485 & - \\
\hline Ophthalmoblapton pedunculare Müll.Arg. & Arbustivo & - & - & AA $6346 a$ \\
\hline Pausandra morisiana (Casar.) Radlk. & Arbóreo & ML 619 & PF 2627 & - \\
\hline Plukenetia serrata (Vell.) L.Gillespie & Trepador & - & - & PF 2828 \\
\hline Tetrorchidium rubrivenium Poepp. \& Endl. & Arbóreo & - & JP 782 & - \\
\hline Tragia cuneata Müll.Arg. & Trepador & - & - & AA 5735 \\
\hline \multicolumn{5}{|l|}{ FABACEAE (Leguminosae) } \\
\hline Andira fraxinifolia Benth. & Arbóreo & - & PF 1543 & ML 1016 \\
\hline Bauhinia sp.1 & Trepador & FF 1280 & - & - \\
\hline Bauhinia angulosa Vogel & Trepador & - & - & ML 1434 \\
\hline Bauhinia cf. forficata Link & Arbóreo & AA 7271 & - & JP 929 \\
\hline Bauhinia integerrima Mart. ex Benth. & Arbóreo & - & JP 765 & - \\
\hline Chamaecrista nictitans Moench. & Sub-arbustivo & AA 5196 & - & WT 14064 \\
\hline Copaifera trapaezifolia Hayne & Arbóreo & ML 1289 & - & JJ 4704 \\
\hline Dalbergia frutescens (Vell.) Britton & Arbóreo & RB 663 & - & ML 981 \\
\hline Desmodium adscendens (Sw.) DC. & Sub-arbustivo & - & - & ML 1192 \\
\hline Dioclea cf. edulis Kuhlm. & Trepador & AA 5457 & - & - \\
\hline $\begin{array}{l}\text { Hymenaea oblongifolia Huber var. latifolia } \\
\text { Lee \& Langenheim }\end{array}$ & Arbóreo & - & - & FF 1410 \\
\hline Inga sp.1 & Arbóreo & - & - & AA 7228 \\
\hline Inga sp.2 & Arbóreo & - & - & ML 978 \\
\hline Inga blanchetiana Benth. & Arbóreo & - & - & AA 5257 \\
\hline Inga capitata Desv. & Arbóreo & WT 13778 & ML 1089 & ML 544 \\
\hline Inga conchifolia L.P. de Queiroz & Arbóreo & - & PF 2648 & - \\
\hline Inga grazielae (Vinha) T.D.Penn. & Arbóreo & ML 400 & ML 1097 & JJ 4879 \\
\hline Inga leptantha Benth. & Arbóreo & - & - & AA 6658 \\
\hline Inga marginata Willd. & Arbóreo & ML 798 & - & JJ 4825 \\
\hline Inga subnuda T.D.Penn. subsp. subnuda & Arbóreo & AA 5450 & - & JP 936 \\
\hline Inga tenuis (Vell.) Mart. & Arbóreo & RB 679 & ML 669 & AA 6380 \\
\hline Inga vera Willd. & Arbóreo & AA 6504 & - & - \\
\hline Machaerium triste Vogel & Trepador & MR 212 & - & JJ 4412 \\
\hline Macrolobium latifolium Vogel & Arbóreo & - & PF 1820 & AA 6365 \\
\hline Mucuna urens (L.) Medik & Trepador & RB 652 & - & - \\
\hline Ormosia fastigiata Tul. & Arbóreo & AA 6536 & ML 313 & AA 5342 \\
\hline Piptadenia cf. adiantoides (Spreng.) J.F.Macbr. & Arbóreo & ML 792 & - & ML 1443 \\
\hline Senegalia martiusiana (Steud.) Seigler \& Ebinger & Arbóreo & AA 6940 & - & - \\
\hline Senna affinis (Benth.) H.S.Irwin \& Barneby & Arbustivo & AA 6938 & AA 4091 & ML 983 \\
\hline $\begin{array}{l}\text { Senna angulata (Vogel) H.S.Irwin \& Barneby var. miscadena } \\
\text { (Vogel) H.S.Irwin \& Barneby }\end{array}$ & Trepador & ML 802 & - & - \\
\hline
\end{tabular}


Tabela 1. Continuação...

\begin{tabular}{|c|c|c|c|c|}
\hline Espécie & Hábito & SBO & SPL & SLO \\
\hline Senna multijuga (Rich.) H.S.Irwin \& Barneby & Arbóreo & ML 625 & - & - \\
\hline Swartzia sp.1 & Arbóreo & ML 615 & - & - \\
\hline Swartzia flaemingii Raddi var. flaemingii & Arbóreo & - & - & JJ 4847 \\
\hline Swartzia simplex (Sw.) Spreng. var. continentalis Urb. & Arbóreo & - & JP 494 & AA 5312 \\
\hline Tephrosia candida DC. & Arbustivo & ML 621 & - & - \\
\hline Zollernia latifolia Benth. & Arbóreo & AA 7693 & - & - \\
\hline \multicolumn{5}{|l|}{ GENTIANACEAE } \\
\hline Macrocarpaea sp.1 & Arbustivo & ML 807 & - & AA 5798 \\
\hline Macrocarpaea sp.2 & Arbustivo & - & AA 4792 & - \\
\hline Macrocarpaea obtusifolia (Griseb.) Gilg & Arbustivo & - & WT 14304 & - \\
\hline Voyria flavescens Griseb. & Herbáceo & AA 7025 & AA 4237 & AA 5817 \\
\hline Voyria obconica Progel & Herbáceo & - & JJ 4769 & ML 985 \\
\hline Voyria tenella Hook. & Herbáceo & - & RB 712 & - \\
\hline \multicolumn{5}{|l|}{ GESNERIACEAE } \\
\hline Besleria flavovirens Nees \& Mart. & Sub-arbustivo & MR199 & PF 1853 & JJ 4361 \\
\hline Besleria laxiflora Benth. & Sub-arbustivo & ML 833 & - & AA 4463 \\
\hline Codonanthe cordifolia Chautems & Epifítico & - & AA 4526 & JJ 4892 \\
\hline Codonanthe uleana Fritsch & Epifítico & - & PF 1919 & AA 7221 \\
\hline Dalbergaria sanguinea (Pers.) Steud. & Epifítico & AA 5165 & AA 4203 & RB 622 \\
\hline Napeanthus primulifolius (Raddi) Sandwith & Herbáceo & AA 4770 & - & AA 5781 \\
\hline Nematanthus albus Chautems & Epifítico & ML 1068 & AA 4907 & JJ 4907 \\
\hline Nematanthus corticola Schrad. & Epifítico & AA 5166 & AA 4777 & JP 973 \\
\hline Nematanthus lanceolatus (Poir.) Chautems & Epifítico & AA 5449 & - & AA 5276 \\
\hline Sinningia barbata (Nees \& Mart.) G.Nicholson & Herbáceo & AA 5374 & AA 4848 & AA 6566 \\
\hline $\begin{array}{l}\text { Sinningia brasiliensis } \\
\text { (Regel \& E.Schmidt) Wiehler \& Chautems }\end{array}$ & Epifítico & RB 631 & - & - \\
\hline Sinningia elatior (Kunth) Chautems & Herbáceo & - & - & AA 5353 \\
\hline \multicolumn{5}{|l|}{ HELICONIACEAE } \\
\hline Heliconia sp.1 & Herbáceo & - & AA 4245 & AA 6603 \\
\hline Heliconia pendula Wawra & Herbáceo & AA 4422 & - & RB 610 \\
\hline Heliconia richardiana Miq. & Herbáceo & WT 13779 & PF 1538 & AA 6579 \\
\hline \multicolumn{5}{|l|}{ HUMIRIACEAE } \\
\hline Humiriac sp. 1 & Arbóreo & - & - & ML 1482 \\
\hline \multicolumn{5}{|l|}{ HYPERICACEAE } \\
\hline Vismia guianensis (Aubl.) Choisy & Arbóreo & RB 659 & ML 687 & JP 934 \\
\hline Vismia latifolia Choisy & Arbóreo & AA 6489a & - & AA 6669 \\
\hline \multicolumn{5}{|l|}{ ICACINACEAE } \\
\hline Leretia cordata Vell. & Trepador & - & - & RB 598 \\
\hline \multicolumn{5}{|l|}{ IRIDACEAE } \\
\hline Crocosmia X crocosmiiflora (Anonymous) N.E.Br. & Herbáceo & AA 4394 & - & - \\
\hline Neomarica sp.1 & Herbáceo & AA 6506 & RB 499 & JJ 4827 \\
\hline \multicolumn{5}{|l|}{ LACISTEMATACEAE } \\
\hline Lacistema robustum Schnizl. & Arbóreo & FF 1320 & ML 1090 & ML 998 \\
\hline \multicolumn{5}{|l|}{ LAMIACEAE } \\
\hline Aegiphila fluminensis Vell. & Arbustivo & AA 6968 & - & ML 1014 \\
\hline Aegiphila sellowiana Cham. & Arbóreo & RB 267 & - & AA 6656 \\
\hline Hyptis cf. atrorubens Poit. & Sub-arbustivo & FF 1322 & AA 4239 & - \\
\hline Hyptis brevipes Poit. & Sub-arbustivo & AA 5397 & - & - \\
\hline Marsypianthes chamaedrys (Vahl) Kuntze & Herbáceo & AA 5198 & - & - \\
\hline \multicolumn{5}{|l|}{ LAURACEAE } \\
\hline Aniba sp.1 & Arbóreo & AA 5455a & - & - \\
\hline
\end{tabular}


Angiospermas em florestas montanas da Bahia

Tabela 1. Continuação...

\begin{tabular}{|c|c|c|c|c|}
\hline Espécie & Hábito & SBO & SPL & SLO \\
\hline Aniba sp.2 & Arbóreo & - & - & AA 6618 \\
\hline Beilschmiedia linharensis Sa.Nishida \& van der Werff & Arbóreo & - & - & AA 6723 \\
\hline Cryptocarya velloziana P.L.R.Moraes & Arbóreo & JP 413 & - & - \\
\hline Endlicheria paniculata (Spreng.) J.F.Macbr. & Arbóreo & - & - & JJ 4809 \\
\hline Licaria bahiana $\mathrm{H}$. Kurz & Arbóreo & - & PF 1781 & JJ 4870 \\
\hline Nectandra membranacea (Sw.) Griseb. & Arbóreo & - & - & AA 6641 \\
\hline Nectandra oppositifolia Nees \& Mart. & Arbóreo & - & - & PF 2835 \\
\hline Nectandra reticulata (Ruiz \& Pav.) Mez & Arbóreo & RB 662 & - & - \\
\hline Ocotea sp.1 & Arbóreo & ML 827 & - & - \\
\hline Ocotea sp. 2 & Arbóreo & - & - & ML 1013 \\
\hline Ocotea sp.3 & Arbóreo & - & - & AA 6569 \\
\hline Ocotea aciphylla (Nees) Mez & Arbóreo & - & PF 2645 & JJ 4684 \\
\hline Ocotea cernua (Nees) Mez & Arbóreo & RB 348 & JJ 4781 & JJ 4870 \\
\hline Ocotea corymbosa (Meisn.) Mez & Arbóreo & JJ 4452 & - & - \\
\hline Ocotea daphnifolia (Meisn.) Mez & Arbóreo & PF 2854 & ML 668 & - \\
\hline Ocotea dispersa (Nees) Mez & Arbóreo & - & PF 1774 & - \\
\hline Ocotea divaricata (Nees) Mez & Arbóreo & FF 1352 & ML 1102 & AA 5289 \\
\hline Ocotea cf. insignis $\mathrm{Mez}$ & Arbóreo & JP 444 & - & - \\
\hline Ocotea lancifolia (Schott) Mez & Arbóreo & PF 2885 & - & - \\
\hline Ocotea nitida (Meisn.) Rohwer & Arbóreo & - & ML 346 & - \\
\hline Ocotea notata (Nees \& Mart.) Mez & Arbóreo & - & - & WT 14058 \\
\hline Ocotea puberula (Rich.) Nees & Arbóreo & AA 5124 & - & - \\
\hline Ocotea tabacifolia (Meisn.) Rohwer & Arbóreo & - & AA 4233 & - \\
\hline Ocotea cf. velloziana (Meisn.) Mez & Arbóreo & AA 6367 & - & AA 5772 \\
\hline Persea americana Mill. & Arbóreo & ML 1057 & AA 4232 & AA $5289 a$ \\
\hline Persea pseudofasciculata L.E.Kopp & Arbóreo & AA 6489 & - & PF 2839 \\
\hline Persea splendens Meisn. & Arbóreo & - & - & AA 6707 \\
\hline Rhodostemonodaphne sp.1 & Arbóreo & - & PF 1792 & - \\
\hline \multicolumn{5}{|l|}{ LECYTHIDACEAE } \\
\hline Cariniana estrellensis (Raddi) Kuntze & Arbóreo & - & JP 506 & - \\
\hline Lecythis lanceolata Poir. & Arbóreo & - & PF 1843 & - \\
\hline \multicolumn{5}{|l|}{ LENTIBULARIACEAE } \\
\hline Utricularia sp.1 & Epifítico & AA 6980a & - & JJ 4908 \\
\hline \multicolumn{5}{|l|}{ LINACEAE } \\
\hline Roucheria columbiana Hallier f. & Arbóreo & - & ML 1159 & - \\
\hline \multicolumn{5}{|l|}{ LOASACEAE } \\
\hline Aosa parviflora (Schrad. ex DC.) Weigend & Herbáceo & - & AA 4225 & - \\
\hline \multicolumn{5}{|l|}{ LOGANIACEAE } \\
\hline Spigelia laurina Cham. \& Schltdl. & Sub-arbustivo & AA 5169 & - & AA 4994 \\
\hline \multicolumn{5}{|l|}{ LORANTHACEAE } \\
\hline Ixocactus clandestinus (Mart.) Kuijt & Epifítico & - & PF 1525 & - \\
\hline Phthirusa sp.1 & Epifítico & - & - & WT 14616 \\
\hline Psittacanthus sp.1 & Epifítico & - & - & JJ 4867 \\
\hline Psittacanthus dichrous Mart. & Epifítico & AA 7482 & - & - \\
\hline Struthanthus sp.1 & Epifítico & - & ML 316 & ML 1009 \\
\hline Struthanthus polyrhyzus Mart. & Epifítico & AA 6976 & - & - \\
\hline Struthanthus salicifolius Mart. & Epifítico & ML 1061 & - & ML 1489 \\
\hline Struthanthus syringifolius Mart. & Epifítico & RB 288 & - & - \\
\hline \multicolumn{5}{|l|}{ LYTHRACEAE } \\
\hline Cuphea racemosa (L.f.) Spreng. & Sub-arbustivo & RP 44 & - & FF 1424 \\
\hline
\end{tabular}


Tabela 1. Continuação...

\begin{tabular}{|c|c|c|c|c|}
\hline Espécie & Hábito & SBO & SPL & SLO \\
\hline \multicolumn{5}{|l|}{ MALPIGHIACEAE } \\
\hline Amorimia rigida (A.Juss.) W.R.Anderson & Arbustivo & - & AA 4102 & - \\
\hline Banisteriopsis sp.1 & Trepador & - & AA 4104 & - \\
\hline Banisteriopsis membranifolia (A.Juss.) B.Gates & Trepador & - & PF 1539 & - \\
\hline Bunchosia glandulifera (Jacq.) Kunth. & Arbóreo & - & - & AA 6757 \\
\hline Byrsonima cacaophila W.R.Anderson & Arbóreo & - & - & RB 589 \\
\hline Byrsonima laevigata (Poir.) DC. & Arbóreo & FF 1295 & - & ML 1219 \\
\hline Byrsonima stipulacea A.Juss. & Arbóreo & AA 7464 & - & JJ 4418 \\
\hline Diplopterys patula (B.Gates) W.R.Anderson \& C.C.Davis & Trepador & - & AA 4838 & - \\
\hline Heteropterys bullata Amorim & Trepador & AA 7013 & - & AA 6735 \\
\hline Heteropterys coleoptera A.Juss. & Trepador & - & - & RB 614 \\
\hline Heteropterys cordifolia Moric. ex A.Juss. & Trepador & ML 1042 & - & - \\
\hline Heteropterys imperata Amorim & Trepador & - & PF 2632 & AA 5348 \\
\hline Heteropterys intermedia (Griseb.) A.Juss. & Trepador & JJ 4420 & - & JJ 4829 \\
\hline Heteropterys nitida (Lam.) DC. & Trepador & AA 5182 & AA 4105 & AA 5732 \\
\hline Heteropterys nordestina Amorim & Trepador & PF 2865 & - & - \\
\hline Hiraea sp.1 & Trepador & - & - & AA 6361 \\
\hline Hiraea sp.2 & Trepador & AA 7700 & - & - \\
\hline Hiraea bullata W.R.Anderson & Trepador & - & AA 4559 & FF 1422 \\
\hline Niedenzuella acutifolia (Cav.) W.R.Anderson & Arbustivo & ML 773 & AA 4524 & - \\
\hline Niedenzuella sericea (A.Juss.) W.R.Anderson & Trepador & - & - & AA 6733 \\
\hline Stigmaphyllon blanchetii C.E.Anderson & Trepador & - & PF 1920 & AA 7220 \\
\hline Stigmaphyllon cavernulosum C.E.Anderson & Trepador & FF 1355 & - & - \\
\hline Stigmaphyllon hispidum C.E.Anderson & Trepador & AA 6284 & - & - \\
\hline Stigmaphyllon macropodum A.Juss. & Trepador & - & - & AA 6737 \\
\hline \multicolumn{5}{|l|}{ MALVACEAE } \\
\hline Malvac sp.1 & Herbáceo & AA 7473 & - & - \\
\hline Abutilon rufinerve A.St.-Hil. & Arbustivo & AA 5409 & - & - \\
\hline Bombacopsis glabra (Pasq.) A.Robyns & Arbóreo & AA s.n. & WT 14287 & - \\
\hline Eriotheca globosa (Aubl.) A.Robyns & Arbóreo & - & ML 657 & AA 6377 \\
\hline Eriotheca macrophylla (K.Schum.) A.Robyns & Herbáceo & - & - & - \\
\hline Malachra cf. helodes Mart. & Arbustivo & RB 657 & - & - \\
\hline Pavonia sp.1 & Arbustivo & AA 6291 & - & - \\
\hline Pavonia cf. morii Krapov. & Arbustivo & - & - & RB 600 \\
\hline Quararibea cf. turbinata Poir. & Arbóreo & AA 5696 & - & AA 5745 \\
\hline Triumfetta semitriloba Jacq. & Sub-arbustivo & AA 5191 & - & AA 6084 \\
\hline \multicolumn{5}{|l|}{ MARANTACEAE } \\
\hline Calathea sp.1 & Herbáceo & - & - & AA 4445 \\
\hline Calathea sp.2 & Herbáceo & ML 567 & - & - \\
\hline Calathea sp.3 & Herbáceo & - & - & AA 6615 \\
\hline Calathea sp.4 & Herbáceo & RB 313 & - & - \\
\hline Calathea crocata E.Morren \& Joriss. & Herbáceo & RB 690 & - & - \\
\hline Calathea cylindrica (Roscoe) K.Schum. & Herbáceo & SV 293 & - & JJ 4849 \\
\hline Calathea zebrina Lindl. & Herbáceo & RB 347 & - & AA 4442 \\
\hline Ctenanthe sp.1 & Herbáceo & RB 276 & - & SV 289 \\
\hline Ctenanthe sp.2 & Herbáceo & - & - & SV 288 \\
\hline Ctenanthe casupoides Petersen & Herbáceo & RB 676 & - & - \\
\hline Ctenanthe glabra (Körn.) Eichler & Herbáceo & AA 6527 & - & AA 6644 \\
\hline Iscnosiphon sp.1 & Sub-arbustivo & - & - & AA 6098 \\
\hline Monotagma sp.1 & Herbáceo & - & - & SV 290 \\
\hline
\end{tabular}


Angiospermas em florestas montanas da Bahia

Tabela 1. Continuação...

\begin{tabular}{|c|c|c|c|c|}
\hline Espécie & Hábito & SBO & SPL & SLO \\
\hline Monotagma grallatum Hagberg & Herbáceo & SV 292 & ML 1157 & - \\
\hline Stromanthe porteana Griseb. & Sub-arbustivo & - & - & AA 6695 \\
\hline Stromanthe tonckat (Aubl.) Eichler & Sub-arbustivo & SV 294 & ML 1156 & JP 947 \\
\hline \multicolumn{5}{|l|}{ MARCGRAVIACEAE } \\
\hline Marcgravia coriacea Vahl & Hemi-epifítico & - & - & AA 6679 \\
\hline Marcgravia myriostigma Triana \& Planch. & Hemi-epifítico & WT 14217 & AA 4250 & JJ 4697 \\
\hline Schwartzia jucuensis Giraldo-Caňas & Hemi-epifítico & - & PF 1850 & - \\
\hline \multicolumn{5}{|l|}{ MELASTOMATACEAE } \\
\hline Aciotis sp.1 & Herbáceo & AA 5384 & - & - \\
\hline Aciotis rubricaulis (Mart. ex DC.) Triana & Herbáceo & - & - & RG 850 \\
\hline Bertolonia sp.1 & Herbáceo & - & AA 4521 & - \\
\hline Bertolonia sp.2 & Herbáceo & - & - & JJ 4906 \\
\hline Bertolonia sp. 3 & Herbáceo & AA 4408 & - & - \\
\hline Bertolonia sp.4 & Herbáceo & - & - & JP 970 \\
\hline Bertolonia marmorata (Naudin) Naudin & Herbáceo & MR 203 & - & WT 14581 \\
\hline Bertolonia cf. wurdackiana Baumgratz & Herbáceo & - & AA 4523 & AA 5979 \\
\hline Clidemia blepharodes DC. & Epifítico & RB 317 & AA 4774 & JJ 4921 \\
\hline Clidemia capilliflora Cogn. & Arbustivo & RG 842 & - & AA 5017 \\
\hline Clidemia hirta (L.) D.Don & Sub-arbustivo & AA 7019 & - & ML 1201 \\
\hline Conostegia icosandra (Sw. ex Wikstr.) Urb. & Arbóreo & AA 7267 & JP 764 & - \\
\hline Graffenrieda intermedia Triana & Arbóreo & AA 4185 & ML 1103 & RG 867 \\
\hline Henriettea succosa (Aubl.) DC. & Arbóreo & - & - & RG 876 \\
\hline Huberia sp.1 & Arbóreo & - & - & AJ 35 \\
\hline Leandra sp.1 & Arbustivo & - & - & AA 6742 \\
\hline Leandra sp.2 & Arbóreo & - & WT 14301 & - \\
\hline Leandra aurea (Cham.) Cogn. & Arbustivo & - & - & RG 864 \\
\hline Leandra bergiana Cogn. & Arbóreo & RB 642 & - & AA 4465 \\
\hline Leandra aff. carassana (DC.) Cogn. & Arbóreo & - & AA 4819 & RG 868 \\
\hline Leandra clidemioides (Naudin) Wurdack & Arbustivo & RG 844 & ML 682 & RG 863 \\
\hline Leandra cuneata (Mart.) Cogn. & Arbóreo & AA 5421 & PF 1823 & AA 5240 \\
\hline Leandra dasytricha (A.Gray) Cogn. & Arbóreo & - & PF 1901 & RG 857 \\
\hline Leandra ionopogon (Mart.) Cogn. & Arbustivo & AA 4162 & AA 4789 & AA 5011 \\
\hline Leandra laevigata Cogn. & Arbustivo & AA 5383 & WT 14297 & - \\
\hline Leandra melastomoides Raddi & Arbustivo & WT 13767 & AA 4539 & AA 5010 \\
\hline Leandra nianga Cogn. & Arbustivo & WT 13764 & - & - \\
\hline Leandra reversa (DC.) Cogn. & Arbustivo & TS 1425 & - & - \\
\hline Leandra rhamnifolia (Naudin) Cogn. & Sub-arbustivo & RB 633 & RB 521 & RG 860 \\
\hline Leandra rufescens (DC.) Cogn. & Sub-arbustivo & FF 1346 & - & AA 5981 \\
\hline Leandra aff. umbellata (Mart. \& Schr.) DC. & Sub-arbustivo & - & - & PF 2816 \\
\hline Meriania tetramera Wurdack & Arbóreo & FF 1300 & - & - \\
\hline Miconia albicans (Sw.) Triana & Arbustivo & - & - & RG 877 \\
\hline Miconia budlejoides Triana & Arbóreo & AA 5460 & - & JJ 4834 \\
\hline Miconia calvescens DC. & Arbóreo & AA 5177 & AA 4234 & - \\
\hline Miconia centrodesma Naudin & Arbóreo & - & AA 4803 & - \\
\hline Miconia chartacea Triana & Arbóreo & RG 838 & WT 14305 & RG 866 \\
\hline Miconia dodecandra (Desr.) Cogn. & Arbóreo & - & AA 4214 & - \\
\hline Miconia doriana Cogn. & Arbóreo & AA 7472 & - & ML 1002 \\
\hline Miconia fasciculata Gardner & Arbóreo & RB 678 & - & WT 14584 \\
\hline Miconia hypoleuca (Benth.) Triana & Arbóreo & RG 849 & - & RG 858 \\
\hline Miconia latecrenata (DC.) Naudin & Arbóreo & - & - & WT 14119 \\
\hline
\end{tabular}


Tabela 1. Continuação...

\begin{tabular}{|c|c|c|c|c|}
\hline Espécie & Hábito & SBO & SPL & SLO \\
\hline Miconia minutiflora (Bonpl.) DC. & Arbóreo & RG 840 & - & - \\
\hline Miconia mirabilis (Aubl.) L.O.Williams & Arbóreo & RG 845 & - & RG 861 \\
\hline Miconia nervosa (Sm.) Triana & Arbustivo & RG 848 & - & RB 620 \\
\hline Miconia octopetala Cogn. & Arbóreo & - & ML 1105 & - \\
\hline Miconia prasina (Sw.) DC. & Arbóreo & RG 839 & - & RG 878 \\
\hline Miconia pussiliflora (DC.) Naudin & Arbóreo & RG 843 & - & RG 859 \\
\hline Miconia aff. rimalis Naudin & Arbóreo & AA 4179 & ML 697 & AA 5012 \\
\hline Miconia ruficalyx Gleason & Arbóreo & - & PF 2639 & - \\
\hline Miconia sclerophylla Triana & Arbóreo & - & - & RG 873 \\
\hline Miconia tristis Spring & Arbustivo & AA 5146 & ML 671 & AA 5013 \\
\hline Ossaea sp.1 & Arbustivo & - & - & JJ 4352 \\
\hline Ossaea sp.2 & Arbustivo & - & - & AJ 27 \\
\hline Ossaea angustifolia (DC.) Triana & Arbustivo & - & WT 14302 & AA 5014 \\
\hline Ossaea quadrisulca (Naudin) Wurdack & Arbustivo & AA 7007 & AA 4224 & RG 856 \\
\hline Pleiochiton sp.1 & Epifítico & AA 6979 & - & - \\
\hline Pterolepis glomerata (Rottb.) Miquel & Herbáceo & - & - & AJ 14 \\
\hline Tibouchina arborea (Gardner) Cogn. & Arbóreo & RB 293 & ML 304 & JJ 4826 \\
\hline Tibouchina fissinervia (DC.) Cogn. & Arbóreo & AA 5161 & AA 4787 & JJ 4413 \\
\hline Tibouchina grandifolia Cogn. & Arbustivo & RG 847 & - & AJ 28 \\
\hline \multicolumn{5}{|l|}{ MELIACEAE } \\
\hline Cabralea canjerana (Vell.) Mart. subsp. canjerana & Arbóreo & AA 5411 & ML 1087 & - \\
\hline Guarea blanchetii C.DC. & Arbóreo & - & PF 1529 & ML 1460 \\
\hline Guarea kunthiana A.Juss. & Arbóreo & ML 784 & - & - \\
\hline Guarea macrophylla Vahl subsp. pachycarpa T.D.Penn. & Arbóreo & RB 645 & - & AA 5961 \\
\hline Trichilia lepidota Mart. & Arbóreo & - & JP 773 & - \\
\hline Trichilia quadrijuga H.B.K. & Arbóreo & ML 421 & - & - \\
\hline Trichilia silvatica C.DC. & Arbóreo & - & - & WT 14548 \\
\hline Trichilia tetrapetala C.DC. & Arbóreo & - & ML 330 & JJ 4856 \\
\hline \multicolumn{5}{|l|}{ MENISPERMACEAE } \\
\hline Anomospermum reticulatum (Mart.) Eichler & Trepador & PF 2880 & - & ML 1470 \\
\hline Chondrodendron microphyllum (Eichl.) Mold. & Trepador & AA 5710 & - & AA 4999 \\
\hline Cissampelos andromorfa DC. & Trepador & AA 5377 & - & AA 6327 \\
\hline Disciphania hernandia (Vell.) Barneby & Trepador & AA 7467 & - & RB 582 \\
\hline Orthomene schomburgkii (Miers) Barneby \& Krukoff & Trepador & - & - & AA 6571 \\
\hline \multicolumn{5}{|l|}{ MONIMIACEAE } \\
\hline Monimiac sp.1 & Arbóreo & AA 7459 & - & - \\
\hline Mollinedia sp.1 & Arbustivo & - & PF 1818 & - \\
\hline Mollinedia gilgiana Perkins & Arbóreo & AA 4427 & - & - \\
\hline Mollinedia marquetiana Peixoto & Arbustivo & FF 1314 & - & - \\
\hline Mollinedia oligantha Perkins & Arbóreo & - & JP 499 & JJ 4806 \\
\hline \multicolumn{5}{|l|}{ MORACEAE } \\
\hline Dorstenia bahiensis Klotzsch ex Fisch. \& C.A.Mey. & Herbáceo & - & AA 4238 & - \\
\hline Dorstenia hirta Desv. & Herbáceo & AA 7001 & WT 14295 & - \\
\hline Dorstenia setosa Moric. & Herbáceo & AA 5693 & - & - \\
\hline Ficus castellviana Dugand & Arbóreo & - & - & PF 2811 \\
\hline Ficus citrifolia Mill. & Arbóreo & - & - & WT 14112 \\
\hline Ficus insipida Willd. & Arbóreo & AA 6984 & - & RC 1044 \\
\hline Ficus trigona L.f. & Arbóreo & - & RC 1046 & - \\
\hline Helicostylis tomentosa (Poepp. \& Endl.) Rusby & Arbóreo & - & JP 767 & - \\
\hline Morus nigra $\mathrm{L}$. & Arbóreo & AA 7017 & - & - \\
\hline
\end{tabular}


Tabela 1. Continuação...

\begin{tabular}{|c|c|c|c|c|}
\hline Espécie & Hábito & SBO & SPL & SLO \\
\hline Sorocea bonplandii (Baill.) W.Burger & Arbóreo & AA 6535 & - & - \\
\hline Sorocea racemosa Gaudich. & Arbóreo & AA 5373 & AA 4560 & JJ 4362 \\
\hline \multicolumn{5}{|l|}{ MYRISTICACEAE } \\
\hline Virola bicuhyba (Schott ex Spreng.) Warb. & Arbóreo & ML 574 & - & - \\
\hline \multicolumn{5}{|l|}{ MYRSINACEAE } \\
\hline Ardisia sp.1 & Arbustivo & - & - & AA 5966 \\
\hline Ardisia semiserrata Miq. & Arbóreo & AA 6533 & - & PF 2829 \\
\hline Cybianthus sp.1 & Sub-arbustivo & AA 4755 & - & - \\
\hline Cybianthus sp.2 & Arbóreo & ML 758 & - & JJ 4887 \\
\hline Cybianthus amplus (Mez) G.Agostini & Arbóreo & ML 766 & - & WT 14572 \\
\hline Cybianthus detergens Mart. & Arbóreo & ML 595 & - & PF 2814 \\
\hline Cybianthus oblongifolius (A.DC.) G.Agostini & Arbóreo & - & - & AA 5290 \\
\hline Cybianthus peruvianus (A.DC.) Miq. & Arbóreo & - & WT 14341 & AA 6747 \\
\hline Myrsine sp.1 & Arbóreo & - & JP 579 & JJ 4698 \\
\hline Myrsine coriacea (Sw.) R.Br. ex Roem. \& Schult. & Arbóreo & ML 573 & - & - \\
\hline $\begin{array}{l}\text { Myrsine hermogenesii (Jung-Mend. \& Bernacci) } \\
\text { M.F.Freitas \& L.S.Kinoshita }\end{array}$ & Arbóreo & - & - & PF 2807 \\
\hline Myrsine umbellata Mart. & Arbóreo & AA 5178 & - & AA 4958 \\
\hline Myrsine cf. venosa A.DC. & Arbóreo & - & ML 349 & - \\
\hline \multicolumn{5}{|l|}{ MYRTACEAE } \\
\hline Myrtac sp.1 & Arbóreo & - & - & FF 1441 \\
\hline Blepharocalyx salicifolius (Kunth) O.Berg & Arbóreo & - & ML 696 & WT 14576 \\
\hline Calyptranthes sp.1 & Arbóreo & - & - & AA 5346 \\
\hline Calyptranthes sp.2 & Arbóreo & - & - & AA 6066 \\
\hline Calyptranthes pulchella DC. & Arbóreo & - & WT 14336 & - \\
\hline Campomanesia dichotoma (O.Berg) Mattos & Arbóreo & - & - & JJ 4404 \\
\hline Campomanesia laurifolia Gardner & Arbóreo & RB 684 & - & ML 1010 \\
\hline Eugenia sp.1 & Arbóreo & - & ML 310 & - \\
\hline Eugenia sp. 2 & Arbóreo & - & - & AA 6400 \\
\hline Eugenia sp.3 & Arbóreo & MR 196 & - & AA 4988 \\
\hline Eugenia sp.4 & Arbóreo & - & - & AA 5733 \\
\hline Eugenia sp.5 & Arbóreo & ML 794 & - & - \\
\hline Eugenia sp.6 & Arbóreo & - & - & WT 14534 \\
\hline Eugenia sp.7 & Arbóreo & - & - & AA 6406 \\
\hline Eugenia sp.8 & Arbustivo & - & - & JJ 4395 \\
\hline Eugenia sp.9 & Arbóreo & - & - & ML 1459 \\
\hline Eugenia adenantha O.Berg & Arbóreo & - & - & JJ 4877 \\
\hline Eugenia itapemirimensis Cambess. & Arbóreo & - & PF 1814 & - \\
\hline Eugenia rostrata O.Berg & Arbóreo & ML 810 & - & - \\
\hline Eugenia tinguyensis Cambess. & Arbóreo & AA 6502 & ML 1091 & AA 5261 \\
\hline Gomidesia sp.1 & Arbóreo & - & WT 14321 & - \\
\hline Gomidesia sp.2 & Arbóreo & - & - & AA 5977 \\
\hline Gomidesia sp.3 & Arbóreo & - & ML 658 & - \\
\hline Gomidesia blanchetiana O.Berg & Arbóreo & - & - & JJ 4800 \\
\hline Marlierea cf. obversa D.Legrand & Arbóreo & - & - & AA 6572 \\
\hline Marlierea cf. racemosa (Vell.) Kiaersk. & Arbóreo & - & AA 4213 & - \\
\hline Marlierea regeliana O.Berg & Arbóreo & ML 576 & - & - \\
\hline Myrceugenia sp.1 & Arbóreo & ML 813 & - & - \\
\hline Myrceugenia pilotantha (Kiaersk.) Landrum & Arbóreo & PF 2872 & - & PF 2837 \\
\hline Myrcia sp.1 & Arbóreo & - & - & AA 6614 \\
\hline
\end{tabular}


Tabela 1. Continuação...

\begin{tabular}{|c|c|c|c|c|}
\hline Espécie & Hábito & SBO & SPL & SLO \\
\hline Myrcia sp.2 & Arbóreo & MR 198 & - & - \\
\hline Myrcia sp. 3 & Arbóreo & - & - & RB 604 \\
\hline Myrcia sp.4 & Arbóreo & - & - & JJ 4814 \\
\hline Myrcia sp.5 & Arbóreo & - & - & AA 5771 \\
\hline Myrcia sp.6 & Arbóreo & - & - & WT 14558 \\
\hline Myrcia cf. bicolor Kiaersk. & Arbóreo & - & - & AA 4975 \\
\hline Myrcia brasiliensis Kiaersk. & Arbóreo & - & - & AA 5793 \\
\hline Myrcia lacerdaeana O.Berg & Arbóreo & - & - & ML 1006 \\
\hline Myrcia lutescens Cambess. & Arbóreo & - & - & WT 14590 \\
\hline Myrcia racemosa (O.Berg) Kiaersk. & Arbóreo & MS 410 & - & AA 6337 \\
\hline Myrcia spectabilis DC. & Arbóreo & - & - & JJ 4889 \\
\hline Myrcia splendens (SW.) DC. & Arbóreo & RB 632 & - & AA 6719 \\
\hline Myrcia tenuivenosa Kiaersk. & Arbóreo & - & JJ 4794 & - \\
\hline Myrciaria sp.1 & Arbóreo & - & - & AA 4976 \\
\hline Neomitranthes sp.1 & Arbóreo & AA 6525 & - & - \\
\hline Plinia sp.1 & Arbóreo & - & - & ML 1015 \\
\hline Plinia rara Sobral & Arbóreo & AA 5709 & - & - \\
\hline Plinia rivularis (Cambess.) Rotman & Arbóreo & PF 2892 & - & - \\
\hline \multicolumn{5}{|l|}{ NYCTAGINACEAE } \\
\hline Guapira sp.1 & Arbóreo & - & - & AA 6396 \\
\hline Guapira aff. laxa (Netto) Furlan & Arbustivo & FF 1317 & ML 336 & - \\
\hline Guapira laxiflora (Choisy) Lundell & Arbóreo & WT 13750 & PF 1851 & WT 14532 \\
\hline Guapira cf. obtusata (Jacq.) Little & Arbóreo & AA 6492 & AA 4535 & AA 5995 \\
\hline Guapira opposita (Vell.) Reitz & Arbóreo & - & ML 327 & AA 5248 \\
\hline Neea laxa Poepp. \& Endl. & Arbóreo & - & ML 1085 & AA 5740 \\
\hline \multicolumn{5}{|l|}{ OCHNACEAE } \\
\hline Ouratea sp.1 & Arbustivo & - & AA 4202 & - \\
\hline Ouratea sp. 2 & Arbóreo & - & - & AA 7214 \\
\hline Ouratea sp.3 & Arbóreo & - & - & JJ 4804 \\
\hline Ouratea aff. olivaeformis (A.St.-Hil.) Engl. & Arbóreo & - & - & AA 6371 \\
\hline Sauvagesia erecta $\mathrm{L}$. & Sub-arbustivo & - & - & FF 1424 \\
\hline Sauvagesia vellozii (Vell. ex St.-Hil.) Sastre & Sub-arbustivo & - & PF 1812 & - \\
\hline \multicolumn{5}{|l|}{ OLACACEAE } \\
\hline Cathedra aff. acuminata Miers & Arbóreo & - & - & WT 14587 \\
\hline Heisteria silvianii Schwacke & Arbóreo & AA 7203 & - & WT 14582 \\
\hline Tetrastylidium grandifolium (Baill.) Sleumer & Arbóreo & - & - & AA 6101 \\
\hline \multicolumn{5}{|l|}{ OLEACEAE } \\
\hline Chionanthus micranthus (Eichler) Lozano \& Fuertes & Arbustivo & AA 6295 & JJ 4780 & AA 5260 \\
\hline \multicolumn{5}{|l|}{ ONAGRACEAE } \\
\hline Fuchsia regia (Vand. ex Vell.) Munz & Trepador & - & - & AA 5806 \\
\hline \multicolumn{5}{|l|}{ ORCHIDACEAE } \\
\hline Orchidac sp.1 & Herbáceo & - & - & JJ 4676 \\
\hline Aspidogyne foliosa (Poepp. \& Endl.) Garay & Herbáceo & - & ML 342 & - \\
\hline Brachionidium restrepioides Hoehne \& Pabst & Epifítico & - & - & JJ 4677 \\
\hline Bulbophyllum napelli Lindl. & Epifítico & RP 10 & - & - \\
\hline Catasetum sp.1 & Epifítico & RP 32 & - & JJ 4385 \\
\hline Cleistes rosea Lindl. & Herbáceo & - & - & AA 5788 \\
\hline Coryanthes sp.1 & Epifítico & - & AF 2601 & - \\
\hline Dichaea sp.1 & Epifítico & AA 4188 & - & - \\
\hline Dichaea cogniauxiana Schltr. & Epifítico & RP 05 & AA 4537 & AA 5816 \\
\hline
\end{tabular}


Tabela 1. Continuação...

\begin{tabular}{|c|c|c|c|c|}
\hline Espécie & Hábito & SBO & SPL & SLO \\
\hline Dichaea pendula (Aubl.) Cogn. & Epifítico & ML 611 & - & - \\
\hline Elleanthus sp.1 & Epifítico & - & - & AA 4960 \\
\hline Elleanthus brasiliensis Rchb.f. & Herbáceo & PF 2881 & - & - \\
\hline Elleanthus crinipes Rchb.f. & Herbáceo & - & ML 1164 & AF 2673 \\
\hline Elleanthus linifolius C.Presl & Epifítico & WT 14213 & ML 1161 & AA 4983 \\
\hline Eltroplectris janeirensis (Porto \& Brade) Pabst & Herbáceo & FF 1341 & - & - \\
\hline Encyclia sp.1 & Epifítico & - & - & AF 2659 \\
\hline Encyclia sp. 2 & Epifítico & - & - & WT 14604 \\
\hline Epidendrum sp.1 & Epifítico & - & - & AA 5810 \\
\hline Epidendrum sp.2 & Epifítico & - & - & JJ 4904 \\
\hline Epidendrum sp.3 & Epifítico & - & - & AA 6581 \\
\hline Epidendrum cf. avicula Lindl. & Epifítico & RP 289 & - & - \\
\hline Epidendrum campacii Hágsater \& L.Sánchez & Epifítico & AF 2707 & - & - \\
\hline Epidendrum carpophorum Barb.Rodr. & Herbáceo & - & - & AA 6627 \\
\hline Epidendrum cinnabarinum Salzm. ex Lindl. & Epifítico & - & - & AA 6413 \\
\hline Epidendrum imatophyllum Lindl. & Epifítico & - & AF 2600 & - \\
\hline Epidendrum nocturnum Jacq. & Epifítico & FF 1316 & - & ML 539 \\
\hline Epidendrum parahybunense Barb.Rodr. & Epifítico & AF 2703 & ML 674 & JP 971 \\
\hline Epidendrum paranaense Barb.Rodr. & Epifítico & AA 5153 & JP 583 & AA 6412 \\
\hline Epidendrum ramosum Jacq. & Epifítico & RP 20 & AA 4808 & ML 993 \\
\hline Epidendrum saxatile Lindl. & Herbáceo & - & PF 1572 & - \\
\hline Epidendrum saximontanum Pabst & Epifítico & - & - & AF 2685 \\
\hline Epidendrum secundum Jacq. & Epifítico & - & - & JJ 4901 \\
\hline Epistephium cf. lucidum Schltr. & Herbáceo & - & - & JJ 4897 \\
\hline Erythrodes sp.1 & Herbáceo & AA 6304 & - & - \\
\hline Erythrodes sp.2 & Herbáceo & - & ML 690 & JJ 4914 \\
\hline Erythrodes aff. aratanhensis (Barb.Rodr.) Ames & Herbáceo & ML 417 & - & - \\
\hline Erythrodes fissirostris Brade \& Pabst & Herbáceo & ML 1036 & PF 1834 & - \\
\hline Eulophia alta (L.) Fawc. \& Rendle & Herbáceo & RP 288 & - & - \\
\hline Gomesa recurva Barb.Rodr. & Epifítico & ML 1033 & AF 2613 & AA 4448 \\
\hline Houlletia brocklehurstiana Lindl. & Epifítico & - & - & WT 14594 \\
\hline Isochilus linearis (Ruiz \& Pav.) R.Br. & Epifítico & AA 6286 & - & - \\
\hline Jacquiniella globosa (Jacq.) Schltr. & Epifítico & RP 15 & ML 1167 & AF 2675 \\
\hline Lankesterella sp.1 & Epifítico & JJ 4444 & - & AF 2684 \\
\hline Lankesterella sp.2 & Epifítico & AF 2704 & - & - \\
\hline Lockhartia lunifera Rchb.f. & Epifítico & - & - & AF 2654 \\
\hline Malaxis parthonii C.Morren & Herbáceo & JP 436 & AA 4073 & AA 5811 \\
\hline Masdevallia cf. infracta Lindl. & Epifítico & - & - & WT 14097 \\
\hline Maxillaria sp.1 & Epifítico & AF 2701 & - & - \\
\hline Maxillaria sp.2 & Epifítico & - & - & AF 2688 \\
\hline Maxillaria sp.3 & Epifítico & RP 31 & - & - \\
\hline Maxillaria sp.4 & Epifítico & - & - & JJ 4683 \\
\hline Maxillaria sp.5 & Epifítico & RP 285 & - & ML 1023 \\
\hline Maxillaria $\mathrm{cf}$. brasiliensis Brieger & Epifítico & AF 2694 & ML 664 & - \\
\hline Maxillaria cerifera Barb.Rodr. & Epifítico & AA 6549 & - & AA 5355 \\
\hline Maxillaria cf. crassifolia Rchb.f. & Epifítico & AA 5700 & AA 4541 & AA 4970 \\
\hline Maxillaria spiritusanctensis Pabst & Epifítico & AA 7440 & - & JJ 4912 \\
\hline Maxillaria jenischiana (Rchb.f.) C.Schweinf. & Epifítico & RP 01 & PF 1576 & AF 2666 \\
\hline Maxillaria leucaimata Barb.Rodr. & Epifítico & AF 2702 & PF 1573 & AA 5329 \\
\hline Maxillaria ochroleuca Lodd. ex Lindl. & Epifítico & - & ML 688 & JJ 4379 \\
\hline
\end{tabular}


Tabela 1. Continuação...

\begin{tabular}{|c|c|c|c|c|}
\hline Espécie & Hábito & SBO & SPL & SLO \\
\hline Maxillaria cf. rigida Barb.Rodr. & Epifítico & AA 5173 & - & - \\
\hline Octomeria alpina Barb.Rodr. & Epifítico & - & PF 1559 & AF 2657 \\
\hline Octomeria cf. grandiflora Lindl. & Epifítico & ML 805 & - & - \\
\hline Octomeria tricolor Rchb.f. & Epifítico & AA 6990 & JJ 4768 & JJ 4665 \\
\hline Oncidium sp.1 & Epifítico & - & - & AA 6628 \\
\hline Oncidium divaricatum Lindl. & Epifítico & AA 5716 & - & - \\
\hline Oncidium flexuosum (Kunth) Lindl. & Epifítico & AA 5390 & PF 1810 & JJ 4922 \\
\hline Oncidium hookeri Rolfe & Epifítico & - & - & AA 6626 \\
\hline Pelexia sp.1 & Herbáceo & - & - & JJ 4817 \\
\hline Phragmipedium sargentianum (Rolfe) Rolfe & Herbáceo & - & - & AF 2663 \\
\hline Phymatidium falcifolium Lindl. & Epifítico & AA 4350 & - & - \\
\hline Platystele sp.1 & Epifítico & - & AA 4839 & - \\
\hline Pleurothallis sp. 1 & Epifítico & AA 5163 & AA 4810 & AF 2658 \\
\hline Pleurothallis sp. 2 & Epifítico & AA 5162 & - & - \\
\hline Pleurothallis sp.3 & Epifítico & ML 748 & - & - \\
\hline Pleurothallis sp.4 & Epifítico & - & - & AF 2682 \\
\hline Pleurothallis deregularis (Barb.Rodr.) Luer & Epifítico & - & - & WT 14102 \\
\hline Pleurothallis pristeoglossa Rchb.f. \& Warm. & Epifítico & AA 6988 & - & - \\
\hline Pleurothallis ruscifolia (Jacq.) R.Br. & Epifítico & RP 30 & - & PF 2821 \\
\hline Pleurothallis sclerophylla Lindl. & Epifítico & RP 33 & AA 4083 & AA 5809 \\
\hline Polycycnis silvana F.Barros & Epifítico & - & AA 4090 & AA 5805 \\
\hline Polystachya concreta (Jacq.) Garay \& H.R.Sweet & Epifítico & AA 5171 & AA 4230 & RP 294 \\
\hline Polystachya hoehneana Kraenzl. & Epifítico & PF 2849 & - & - \\
\hline Prescottia sp.1 & Herbáceo & ML 1049 & - & - \\
\hline Prescottia sp. 2 & Herbáceo & - & JP 586 & - \\
\hline Prescottia stachyodes (Sw.) Lindl. & Epifítico & - & - & ML 994 \\
\hline Promenaea silvana F.Barros \& Cath. & Epifítico & - & - & JJ 4815 \\
\hline Promenaea xanthina Lindl. & Epifítico & JJ 4466 & - & - \\
\hline Prosthechea sp.1 & Epifítico & AF 2690 & AA 4207 & - \\
\hline Prosthechea sp.2 & Epifítico & - & - & AF 2674 \\
\hline Prosthechea bueraremensis (Campacci) Campacci & Epifítico & WT 14202 & - & - \\
\hline Prosthechea fragans (Sw.) W.E.Higgins & Epifítico & AA 5174 & ML 1104 & AA 5361 \\
\hline Prosthechea pygmaea (Hook.) W.E.Higgins & Epifítico & AA 5175 & - & WT 14101 \\
\hline Prosthechea vespa (Vell.) W.E.Higgins & Epifítico & AA 6946 & PF 1567 & ML 549 \\
\hline Psilochilus modestus Barb.Rodr. & Herbáceo & AF 2706 & AA 4788 & AF 2660 \\
\hline Rodrigueziella handroi (Hoehne) Pabst & Epifítico & RP 283 & WT 14310 & - \\
\hline Sacoila lanceolata (Aubl.) Garay & Herbáceo & AA 5171 & - & - \\
\hline Sarcoglottis sp.1 & Herbáceo & - & - & JJ 4918 \\
\hline Sauroglossum cf. nitidum (Vell.) Schltr. & Herbáceo & - & - & AA 5356 \\
\hline Scaphyglottis modesta (Rchb.f.) Schltr. & Epifítico & AF 2692 & AF 2603 & AF 2672 \\
\hline Scaphyglottis reflexa Lindl. & Epifítico & - & - & WT 14096 \\
\hline Sobralia sessilis Lindl. & Epifítico & - & - & AF 2651 \\
\hline $\begin{array}{l}\text { Sophronites grandis (Lindl. \& Paxton) } \\
\text { Van den Berg \& M.W.Chase }\end{array}$ & Epifítico & - & PF 1769 & - \\
\hline Stelis sp.1 & Epifítico & - & PF 1553 & - \\
\hline Stelis sp.2 & Epifítico & AA 6553 & ML 348 & - \\
\hline Stelis sp.3 & Epifítico & AF 2695 & - & JJ 4713 \\
\hline Stelis sp.4 & Epifítico & AA 5168 & - & AA 5363 \\
\hline Stelis cf. aprica Lindl. & Epifítico & - & - & AA 5746 \\
\hline Stenia pallida Lindl. & Epifítico & MR 230 & - & - \\
\hline
\end{tabular}


Tabela 1. Continuação...

\begin{tabular}{|c|c|c|c|c|}
\hline Espécie & Hábito & SBO & SPL & SLO \\
\hline Xylobium colleyi (Bateman ex Lindl.) Rolfe & Epifítico & - & - & RP 69 \\
\hline Xylobium variegatum (Ruiz \& Pav.) Garay \& Dunst. & Epifítico & - & ML 1165 & - \\
\hline Zygopetalum sp.1 & Herbáceo & - & - & AF 2665 \\
\hline Zygopetalum crinitum Lodd. & Epifítico & - & - & AA 7264 \\
\hline Zygopetalum aff. mackaii Hook. & Herbáceo & - & - & WT 14592 \\
\hline \multicolumn{5}{|l|}{ OXALIDACEAE } \\
\hline Oxalis sp.1 & Herbáceo & AA 7475 & - & - \\
\hline Oxalis debilis Kunth & Herbáceo & - & - & WT 12380 \\
\hline \multicolumn{5}{|l|}{ PASSIFLORACEAE } \\
\hline Passiflora alata Dryand. & Trepador & RB 677 & - & AA 6329 \\
\hline Passiflora amethystina J.C.Mikan & Trepador & SS 1261 & - & ML 976 \\
\hline Passiflora capsularis L. & Trepador & AA 4741 & - & - \\
\hline Passiflora contracta Vitta & Trepador & AA 5442 & ML 677 & AA 6364 \\
\hline Passiflora edulis Sims & Trepador & ML 1066 & - & - \\
\hline Passiflora mansoi Mast. & Trepador & ML 609 & - & - \\
\hline Passiflora misera H.B.K. & Trepador & - & - & ML 1191 \\
\hline \multicolumn{5}{|l|}{ PENTAPHYLLACACEAE } \\
\hline Ternstroemia alnifolia Wawra & Arbóreo & - & WT 14339 & - \\
\hline \multicolumn{5}{|l|}{ PHYLLANTHACEAE } \\
\hline Hyeronima alchorneoides M.Allemão & Arbóreo & RB 664 & - & WT 14556 \\
\hline Hyeronima oblonga Müll. Arg. & Arbóreo & - & AA 4827 & ML 559 \\
\hline Margaritaria nobilis L.f. & Arbóreo & - & JP 776 & PF 2804 \\
\hline Phyllanthus gradyi M.J.Silva \& M.F.Sales & Arbóreo & - & AA 4842 & - \\
\hline Phyllanthus subemarginatus Müll. Arg. & Sub-arbustivo & - & - & AA 5802 \\
\hline \multicolumn{5}{|l|}{ PHYTOLACCACEAE } \\
\hline Phytolacca thyrsiflora Fenzl. ex J.A.Schmidt & Arbustivo & AA 4424 & WT 14338 & - \\
\hline \multicolumn{5}{|l|}{ PICRAMNIACEAE } \\
\hline Picramnia ciliata Mart. & Arbóreo & ML 614 & AA 4223 & AA 4989 \\
\hline Picramnia glazioviana Engl. & Arbóreo & AA 5446 & ML 672 & - \\
\hline \multicolumn{5}{|l|}{ PIPERACEAE } \\
\hline Peperomia sp.1 & Epifítico & - & - & MJ 840 \\
\hline Peperomia sp.2 & Epifítico & - & - & AA 5008 \\
\hline Peperomia sp. 3 & Epifítico & - & - & AA 6649 \\
\hline Peperomia alata Ruiz \& Pav. & Epifítico & AA 5695 & - & JJ 4346 \\
\hline Peperomia emarginella (Sw.) C.DC. & Epifítico & - & MJ 890 & WT 14541 \\
\hline $\begin{array}{l}\text { Peperomia glabella (Sw.) } \\
\text { A.Dietr. var. nigropunctata (Miq.) Dahlst. }\end{array}$ & Epifítico & AA 5717 & - & JJ 4356 \\
\hline Peperomia hernandiifolia (Vahl) A.Dietr. & Epifítico & AA 6538 & AA 4783 & ML 1020 \\
\hline Peperomia macrostachya (Vahl) A.Dietr. & Epifítico & RB 333 & PF 1892 & JJ 4798 \\
\hline Peperomia magnoliifolia (Jacq.) A.Dietr. & Epifítico & ML 565 & ML 317 & AA 5952 \\
\hline Peperomia obtusifolia (L.) A.Dietr. & Epifítico & AA 7010 & - & AA 5946 \\
\hline Peperomia pernambucensis Miq. & Epifítico & - & PF 1797 & - \\
\hline Peperomia pseudoestrelensis C.DC. & Epifítico & AA 4767 & PF 2630 & AA 6357 \\
\hline Peperomia tenella (Sw.) A.Dietr. & Epifítico & ML 1054 & - & - \\
\hline Peperomia tetraphylla (G.Forst.) Hook. \& Arn. & Epifítico & AA 5431 & PF 2625 & AA 6681 \\
\hline Peperomia urocarpa Fisch. \& C.A.Mey. & Epifítico & WT 13771 & - & AA 5287 \\
\hline Piper sp.1 & Arbustivo & PF 2891 & - & - \\
\hline Piper sp.2 & Arbustivo & WT 14197 & - & - \\
\hline Piper amplum (Kunth) Steud. & Arbustivo & - & MJ 880 & MJ 834 \\
\hline Piper arboreum Aubl. & Arbustivo & - & - & MJ 839 \\
\hline
\end{tabular}


Tabela 1. Continuação...

\begin{tabular}{|c|c|c|c|c|}
\hline Espécie & Hábito & SBO & SPL & SLO \\
\hline Piper bowiei Yuncker & Arbustivo & MJ 813 & MJ 879 & - \\
\hline Piper caldense C.DC. & Arbustivo & AA 4390 & - & MJ 832 \\
\hline Piper cernuит Vell. & Arbóreo & WT 13752 & - & - \\
\hline Piper cuyabanum C.DC. & Arbustivo & MJ 825 & - & - \\
\hline Piper dilatatum Rich. & Arbustivo & - & MJ 885 & MJ 829 \\
\hline Piper divaricatum G.Mey. & Arbustivo & - & - & MJ 836 \\
\hline Piper eucalyptiphyllum C.DC. & Arbustivo & AA 4727 & MJ 878 & - \\
\hline Piper gigantifolium C.DC. & Arbóreo & MJ 826 & - & JJ 4374 \\
\hline Piper hayneanum C.DC. & Arbustivo & - & - & MJ 838 \\
\hline Piper hispidum $\mathrm{Sw}$. & Arbustivo & WT 14228 & MJ 887 & AA 5239 \\
\hline Piper lindbergii C.DC. & Arbustivo & - & - & MJ 831 \\
\hline Piper mollicomum Kunth & Arbustivo & - & MJ 884 & - \\
\hline Piper mosenii C.DC. & Arbustivo & - & MJ 876 & - \\
\hline Piper sprengelianum C.DC. & Arbustivo & AA 5379 & MJ 881 & MJ 837 \\
\hline Piper umbellatum $\mathrm{L}$. & Arbustivo & FF 1345 & MJ 882 & AA $6757 \mathrm{a}$ \\
\hline \multicolumn{5}{|l|}{ PLANTAGINACEAE } \\
\hline Angelonia procumbens (Schrad.) Nees \& Mart. & Herbáceo & - & - & AA 6731 \\
\hline Lindernia rotundifolia (L.) Alston & Herbáceo & ML 809 & - & - \\
\hline Stenodia vandellioides (Benth.) V.C.Souza & Herbáceo & - & - & JJ 3962 \\
\hline \multicolumn{5}{|l|}{ POACEAE } \\
\hline Alvimia lancifolia Soderstr. \& Londoño & Arbóreo & - & PO 1224 & - \\
\hline Andropogon bicornis $\mathrm{L}$. & Herbáceo & ML 834 & - & WT 14091 \\
\hline Arberella bahiensis Soderstr. \& Zuloaga & Herbáceo & - & AA 4843 & - \\
\hline Chusquea sp.1 & Arbóreo & - & PO 1223 & - \\
\hline Chusquea sp.2 & Arbóreo & WT 10466 & - & - \\
\hline Chusquea aff. attenuata (Döll) L.G.Clark & Arbóreo & - & PO 1220 & - \\
\hline Chusquea bambusoides (Raddi) Hack. & Arbóreo & AA 6532 & - & - \\
\hline Chusquea aff. longispiculata L.G.Clark & Arbóreo & - & - & AA 5367 \\
\hline Chusquea oxylepis (Hack.) Ekman & Arbóreo & - & PO 1222 & - \\
\hline Chloris pycnothrix Trin. & Herbáceo & AM 67 & - & - \\
\hline Diandrolyra bicolor Stapf & Herbáceo & PO 1238 & - & - \\
\hline Dichanthelium sp.1 & Herbáceo & - & PO 1219 & - \\
\hline Digitaria horizontalis Willd. & Herbáceo & PO 1237 & - & - \\
\hline Eremocaulon sp.1 & Arbóreo & - & PO 1226 & - \\
\hline Eremocaulon aureofimbriatum Soderstr. \& Londoño & Arbóreo & FF 1307 & - & - \\
\hline Ichnanthus lancifolius $\mathrm{Mez}$ & Herbáceo & FF s.n. & - & - \\
\hline Ichnanthus leiocarpus (Spreng.) Kunth & Herbáceo & RB 325 & PO 1215 & JJ 4848 \\
\hline Ichnanthus pallens (Sw.) Munro ex Benth. & Herbáceo & AA 6994 & PO 1212 & ML 1209 \\
\hline Ichnanthus robustus (Renvoize) R.P.Oliveira & Herbáceo & - & RB 505 & - \\
\hline Ichnanthus tenuis (J.Presl \& C.Presl) Hitchc. \& Chase & Herbáceo & AM 61 & PO 1210 & - \\
\hline Lasiacis ligulata Hitchc. \& Chase & Arbustivo & AM 57 & AA 4220 & AA 5278 \\
\hline Merostachys sp.1 & Arbóreo & - & PO 1221 & - \\
\hline Merostachys cf. calderoniana Send. & Arbóreo & - & - & AA 6757 \\
\hline Merostachys aff. fistulosa Döll & Arbóreo & PO 1235 & - & - \\
\hline Merostachys cf. sparsiflora Rupr. & Arbóreo & - & PF 2651 & - \\
\hline Olyra latifolia $\mathrm{L}$. & Herbáceo & AA 6993 & - & - \\
\hline Panicum sp.1 & Herbáceo & - & RB 478 & - \\
\hline Panicum brevifolium $\mathrm{L}$. & Herbáceo & AM 64 & - & - \\
\hline Panicum pilosum $\mathrm{Sw}$. & Herbáceo & FF 1313 & PO 1207 & ML 1195 \\
\hline Panicum rudgei Roem. \& Schult. & Herbáceo & PO 1234 & RB 510 & - \\
\hline
\end{tabular}


Tabela 1. Continuação...

\begin{tabular}{|c|c|c|c|c|}
\hline Espécie & Hábito & SBO & SPL & SLO \\
\hline Panicum stoloniferum Poir. & Herbáceo & RB 308 & - & - \\
\hline Panicum maximilianum Schrad. ex Schult. & Herbáceo & FF 1309 & - & - \\
\hline Parodiolyra micrantha (Kunth) Davidse \& Zuloaga & Herbáceo & FF 1308 & - & - \\
\hline Paspalum conjugatum P.J.Bergius & Herbáceo & AM 60 & PO 1211 & ML 1198 \\
\hline Paspalum corcovadense Raddi & Herbáceo & FF 1311 & PO 1209 & - \\
\hline Paspalum decumbens $\mathrm{Sw}$. & Herbáceo & PO 1232 & PO 1213 & - \\
\hline Paspalum millegranum Schrad. ex Schult. & Herbáceo & AM 69 & - & - \\
\hline Paspalum pilosum Lam. & Herbáceo & - & PO 1217 & - \\
\hline Pennisetum purpureum Schumach. & Herbáceo & AA 5188 & - & - \\
\hline Pharus lappulaceus Aubl. & Herbáceo & - & PO 1214 & - \\
\hline Pseudechinolaena polystachya (Kunth) Stapf & Herbáceo & PO 1236 & - & - \\
\hline Setaria poiretiana (Schult.) Kunth & Herbáceo & - & PO 1208 & ML 1197 \\
\hline Setaria scabrifolia (Nees) Kunth & Herbáceo & AM 68 & - & - \\
\hline Urochloa brizantha (A.Rich.) R.D. Webster & Herbáceo & AM 66 & - & - \\
\hline \multicolumn{5}{|l|}{ POLYGALACEAE } \\
\hline Polygala laureola A.St.-Hil. & Sub-arbustivo & AA 5458 & JP 797 & - \\
\hline Polygala paniculata $\mathrm{L}$. & Sub-arbustivo & AA 5199 & - & WT 12378 \\
\hline Securidaca macrocarpa A.W.Benn. & Trepador & RB 689 & - & - \\
\hline Securidaca revoluta (A.W.Benn.) M.C.M.Marques & Trepador & - & - & RB 607 \\
\hline \multicolumn{5}{|l|}{ POLYGONACEAE } \\
\hline Coccoloba sp. 1 & Trepador & ML 817 & - & AA 5963 \\
\hline Coccoloba ilheensis Wedd. & Trepador & AA 7002 & - & JP 922 \\
\hline Coccoloba mosenii Lind. & Trepador & AA 4740 & - & WT 14538 \\
\hline \multicolumn{5}{|l|}{ PROTEACEAE } \\
\hline Euplassa sp.1 & Arbóreo & - & - & JP 972 \\
\hline Euplassa sp.2 & Arbóreo & - & - & FF 1449 \\
\hline \multicolumn{5}{|l|}{ PUTRANJIVACEAE } \\
\hline Drypetes sessiliflora Allemão & Arbóreo & - & - & AA 6582 \\
\hline \multicolumn{5}{|l|}{ QUIINACEAE } \\
\hline Lacunaria decastyla Ducke & Arbóreo & AA s.n. & PF 1535 & AA 5774 \\
\hline \multicolumn{5}{|l|}{ RANUNCULACEAE } \\
\hline Clematis dioica $\mathrm{L}$. & Trepador & ML 765 & - & AA 6082 \\
\hline \multicolumn{5}{|l|}{ RHAMNACEAE } \\
\hline Gouania blanchetiana Miq. & Trepador & RB 658 & - & FF 1402 \\
\hline \multicolumn{5}{|l|}{ ROSACEAE } \\
\hline Prunus myrtifolia (L.) Urban & Arbóreo & ML 818 & - & - \\
\hline \multicolumn{5}{|l|}{ RUBIACEAE } \\
\hline Amaioua sp.1 & Arbóreo & PF 2859 & WT 14342 & JJ 4685 \\
\hline Amaioua guianensis Aubl. & Arbóreo & - & - & AA 5759 \\
\hline Amaioua intermedia Mart. & Arbóreo & - & - & ML 552 \\
\hline Bathysa sp.1 & Arbóreo & - & PF 1914 & - \\
\hline Bathysa cuspidata (A.St.-Hil.) Hook.f. ex K.Schum. & Arbóreo & AA 4431 & - & - \\
\hline Bathysa mendoncaei K.Schum. & Arbóreo & RB 278 & PF 2634 & AA 6002 \\
\hline Bathysa nicholsonii K.Schum. & Arbóreo & ML 591 & - & - \\
\hline Carrapichea lucida J.G.Jardim \& Zappi & Arbustivo & - & ML 683 & - \\
\hline Chomelia pubescens Cham. \& Schltdl. & Arbustivo & RB 695 & - & AA 6650 \\
\hline Coccocypselum cordifolium Nees \& Mart. & Herbáceo & AA 4418 & JP 790 & AA 5029 \\
\hline Coccocypselum hasslerianum Chodat & Herbáceo & - & AA 4227 & - \\
\hline Coccocypselum krauseanum Standl. & Herbáceo & MR 216 & JP 789 & AA 5028 \\
\hline Coccocypselum lanceolatum (Ruiz \& Pav.) Pers. & Herbáceo & - & - & AA 5027 \\
\hline
\end{tabular}


Tabela 1. Continuação...

\begin{tabular}{|c|c|c|c|c|}
\hline Espécie & Hábito & SBO & SPL & SLO \\
\hline Cordiera sp.1 & Arbóreo & - & - & AA 6333 \\
\hline Cordiera sp. 2 & Arbustivo & AA 6524 & ML 1096 & - \\
\hline Coussarea contracta Müll.Arg. & Arbóreo & AA 6288 & AA 4836 & AA 5729 \\
\hline Coussarea graciliflora Benth. \& Hook.f. & Arbustivo & - & ML 661 & AA 5030 \\
\hline Coussarea ilheotica Müll.Arg. & Arbóreo & WT 13775 & - & AA 5997 \\
\hline Coussarea cf. nodosa (Benth.) Müll.Arg. & Arbustivo & - & - & AA 5018 \\
\hline Coussarea violacea Aubl. & Arbóreo & - & - & AA 5026 \\
\hline Denscantia cymosa (Spreng.) E.L.Cabral \& Bacigalupo & Trepador & - & - & AA 5330 \\
\hline Emmeorhiza umbellata (Spreng.) K.Schum. & Trepador & ML 977 & - & AA 5350 \\
\hline Faramea sp.1 & Arbustivo & - & PF 1825 & AA 5033 \\
\hline Faramea sp.2 & Arbóreo & ML 622 & - & AA 6623 \\
\hline Faramea sp.3 & Arbóreo & - & - & AA 6564 \\
\hline Faramea coerulea (Nees \& Mart.) DC. & Arbustivo & - & - & AA 5031 \\
\hline Faramea martiana Müll. Arg. & Arbóreo & AA 4748 & - & - \\
\hline Faramea multiflora A.Rich. ex DC. & Arbustivo & AA 4729 & AA 4828 & PF 2818 \\
\hline Ferdinandusa ovalis (Pohl) Pohl & Arbóreo & - & - & AA 6702 \\
\hline Hillia aff. parasitica Jacq. & Hemi-epifítico & ML 597 & ML 1101 & AA 5800 \\
\hline Ixora sp.1 & Arbóreo & - & - & RB 577 \\
\hline Ixora $\mathrm{cf}$. bracteolaris Müll.Arg. & Arbustivo & PF 2889 & - & - \\
\hline Ixora grandifolia Müll.Arg. & Arbustivo & - & AA 4833 & AA 5762 \\
\hline Malanea sp.1 & Arbóreo & - & PF 1844 & - \\
\hline Malanea sp.2 & Arbustivo & RB 711 & - & - \\
\hline Malanea macrophylla Bartl. ex Griseb. & Trepador & - & - & JP 927 \\
\hline Margaritopsis astrellantha (Wernhan) L.Anderson & Arbustivo & - & PF 1544 & - \\
\hline Margaritopsis haematocarpa (Standl.) C.M.Taylor & Arbustivo & - & - & AA 5349 \\
\hline Notopleura bahiensis C.M.Taylor & Epifítico & AA 4195 & AA 4212 & AA 5741 \\
\hline Notopleura tapajozensis (Standl.) Bremek. & Arbóreo & - & AA 4815 & AA 5768 \\
\hline Palicourea sp.1 & Arbustivo & AA 5132 & - & AA 5323 \\
\hline Palicourea blanchetiana Schltdl. & Arbustivo & ML 635 & AA 4210 & JJ 4813 \\
\hline Palicourea guianensis Aubl. & Arbóreo & AA 4744 & WT 14319 & - \\
\hline Palicourea aff. rigida Kunth & Arbustivo & - & RB 520 & JJ 4923 \\
\hline Posoqueria acutifolia Mart. & Arbóreo & AA 6554 & - & JJ 4913 \\
\hline Psychotria sp.1 & Arbóreo & JJ 4438 & - & AA 5019 \\
\hline Psychotria sp.2 & Arbustivo & AA 5702 & - & RB 612 \\
\hline Psychotria appendiculata Müll.Arg. & Arbustivo & WT 13785 & - & - \\
\hline Psychotria barbiflora DC. & Arbustivo & - & - & AA 5994 \\
\hline Psychotria cf. capitata Ruiz \& Pav. & Arbustivo & - & JJ 4790 & - \\
\hline Psychotria carthagenensis Jacq. & Arbustivo & AA 5128 & AA 4215 & AA 6074 \\
\hline Psychotria chaenotricha DC. & Arbustivo & WT 13787 & - & - \\
\hline Psychotria colorata (Willd. ex Roem. \& Schult.) Müll.Arg. & Arbóreo & ML 564 & JJ 4788 & - \\
\hline Psychotria deflexa DC. & Arbustivo & RB 644 & PF 1889 & WT 14571 \\
\hline $\begin{array}{l}\text { Psychotria hoffmannseggiana (Willd. ex. Roem. \& Schult.) } \\
\text { Müll.Arg. }\end{array}$ & Arbustivo & AA 4419 & PF 2640 & AA 5720 \\
\hline Psychotria leiocarpa Cham. \& Schltdl. & Arbóreo & AA 4362 & PF 1787 & AA 5034 \\
\hline Psychotria malaneoides Müll.Arg. & Arbustivo & - & - & JJ 4409 \\
\hline Psychotria myriantha Müll.Arg. & Arbustivo & WT 13802 & PF 1897 & AA 5750 \\
\hline Psychotria nemorosa Gardner & Arbustivo & ML 594 & - & RB 613 \\
\hline Psychotria phyllocalymmoides Müll.Arg. & Arbustivo & AA 6301 & - & AA 5279 \\
\hline Psychotria platypoda DC. & Arbustivo & AA 4747 & WT 14300 & WT 14544 \\
\hline Psychotria pleiocephala Müll.Arg. & Arbustivo & RB 283 & PF 2641 & RB 578 \\
\hline Psychotria schlechtendaliana (Müll.Arg.) Müll.Arg. & Arbustivo & - & AA 4846 & - \\
\hline
\end{tabular}


Tabela 1. Continuação...

\begin{tabular}{|c|c|c|c|c|}
\hline Espécie & Hábito & SBO & SPL & SLO \\
\hline Psychotria aff. stachyoides Benth. & Arbustivo & - & AA 4534 & - \\
\hline Psychotria aff. suterella Müll.Arg. & Arbustivo & JJ 4446 & - & - \\
\hline Psychotria vellosiana Benth. & Arbóreo & - & - & JP 962 \\
\hline Randia sp.1 & Arbóreo & AA 5451 & - & RB 609 \\
\hline Randia armata (Sw.) DC. & Arbóreo & AA 5375 & AA 4829 & AA 6359 \\
\hline Ronabea latifolia Aubl. & Arbustivo & - & PF 1530 & WT 14549 \\
\hline Rudgea sp.1 & Arbustivo & AA 5249 & - & ML 518 \\
\hline Rudgea sp.2 & Arbóreo & ML 411 & - & AA 5282 \\
\hline Rudgea sp.3 & Arbustivo & - & - & AA 5999 \\
\hline Rudgea sp.4 & Arbóreo & AA 4739 & ML 308 & - \\
\hline Rudgea aff. celastrinea Müll.Arg. & Arbóreo & - & - & PF 2833 \\
\hline Rudgea conocarpa Müll.Arg. & Arbustivo & - & - & AA 6347 \\
\hline Rudgea aff. interrupta Benth. & Arbóreo & - & PF 1768 & - \\
\hline Rudgea cf. involucrata Müll.Arg. & Arbustivo & AA 5140 & - & AA 5334 \\
\hline Rudgea reticulata Benth. & Arbóreo & - & PF 1759 & ML 532 \\
\hline Sabicea sp.1 & Sub-arbustivo & - & AA 4228 & - \\
\hline Sabicea cinerea Aubl. & Trepador & - & - & JJ 4408 \\
\hline Schradera polycephala DC. & Hemi-epifítico & RB 371 & WT 14330 & JJ 4851 \\
\hline Tocoyena sellowiana (Cham. \& Schltdl.) K.Schum. & Arbóreo & - & - & JJ 4845 \\
\hline \multicolumn{5}{|l|}{ RUTACEAE } \\
\hline Dictyoloma vandellianum A.Juss. & Arbóreo & AA 6957 & - & FF 1409 \\
\hline Hortia brasiliana Vand. ex DC. & Arbóreo & - & - & WT 14536 \\
\hline Zanthoxylum nemorale Mart. & Arbóreo & - & - & WT 14554 \\
\hline Zanthoxylum rhoifolium Lam. & Arbóreo & ML 812 & - & ML 1181 \\
\hline \multicolumn{5}{|l|}{ SABIACEAE } \\
\hline Meliosma sp.1 & Arbóreo & - & JJ 4789 & AA 5333 \\
\hline Meliosma sellowii Urb. & Arbóreo & - & ML 667 & AA 6390 \\
\hline \multicolumn{5}{|l|}{ SALICACEAE } \\
\hline Banara sp.1 & Arbóreo & RB 330 & WT 14290 & JJ 4795 \\
\hline Banara kuhlmannii (Sleumer) Sleumer & Arbóreo & - & - & ML 561 \\
\hline Casearia sp.1 & Arbóreo & AA 6523 & - & AA 5964 \\
\hline Casearia arborea (Rich.) Urb. & Arbóreo & - & JP 783 & - \\
\hline Casearia commersoniana Cambess. & Arbóreo & ML 618 & PF 1780 & JP 953 \\
\hline Casearia decandra Jacq. & Arbóreo & PF 2871 & - & - \\
\hline Casearia obliqua Spreng. & Arbóreo & MR 215 & - & - \\
\hline \multicolumn{5}{|l|}{ SANTALACEAE } \\
\hline Phoradendron crassifolium (Pohl ex DC.) Eichler & Epifítico & AA 7004 & ML 302 & AA 6609 \\
\hline \multicolumn{5}{|l|}{ SAPINDACEAE } \\
\hline Allophylus leucoclados Radlk. & Arbóreo & ML 585 & - & AA 5241 \\
\hline Allophylus membranifolius Radlk. & Arbóreo & AA 4383 & - & - \\
\hline Allophylus sericeus (Cambess.) Radlk. & Arbóreo & - & PF 1913 & - \\
\hline Cupania sp.1 & Arbóreo & ML 746 & - & AA 6077 \\
\hline Cupania sp.2 & Arbóreo & ML 754 & - & - \\
\hline Cupania sp.3 & Arbóreo & - & PF 2647 & - \\
\hline Cupania sp.4 & Arbóreo & - & - & JJ 5409 \\
\hline Cupania cf. oblongifolia Mart. & Arbóreo & PF 2869 & - & JJ 4705 \\
\hline Matayba sp.1 & Arbóreo & RB 671 & - & - \\
\hline Matayba guianensis Aubl. & Arbóreo & - & ML 1086 & - \\
\hline Paullinia sp.1 & Trepador & - & - & AA 6563 \\
\hline Paullinia sp.2 & Trepador & ML 777 & - & - \\
\hline
\end{tabular}


Tabela 1. Continuação...

\begin{tabular}{|c|c|c|c|c|}
\hline Espécie & Hábito & SBO & SPL & SLO \\
\hline Paullinia carpopodea Cambess. & Trepador & AA 6960 & - & AA 6368 \\
\hline Paullinia racemosa Wawra & Trepador & - & - & ML 1185 \\
\hline Paullinia rubiginosa Cambess. & Trepador & RB 638 & ML 1173 & - \\
\hline Paullinia trigona Vell. & Trepador & ML 800 & - & AA 7222 \\
\hline Serjania communis Cambess. & Trepador & - & - & ML 982 \\
\hline Serjania paradoxa Radlk. & Trepador & - & RB 506 & - \\
\hline \multicolumn{5}{|l|}{ SAPOTACEAE } \\
\hline Chrysophyllum gonocarpum (Mart. ex Eichl.) Engl. & Arbóreo & $\mathrm{JJ} 4475$ & - & - \\
\hline Chrysophyllum splendens Spreng. & Arbóreo & FF 1337 & ML 670 & RB 593 \\
\hline Ecclinusa ramiflora Mart. & Arbóreo & - & - & AA 5294 \\
\hline Manilkara salzmannii (A.DC.) H.J.Lam. & Arbóreo & - & - & AA 6394 \\
\hline Micropholis gardneriana (A.DC.) Pierre & Arbóreo & - & FF 1471 & - \\
\hline Micropholis guyanensis (A.DC.) Pierre & Arbóreo & - & AA 4837 & PF 2842 \\
\hline Pouteria sp.1 & Arbóreo & AA 7686 & - & - \\
\hline Pouteria bangii (Rusby) T.D.Penn. & Arbóreo & - & - & WT 14539 \\
\hline Pouteria cf. butyrocarpa (Kuhlm.) T.D.Penn. & Arbóreo & PF 2878 & - & WT 14516 \\
\hline Pouteria caimito (Ruiz \& Pavon) Radlk. & Arbóreo & AA 6969 & - & AA 6596 \\
\hline Pouteria cf. gardneri (Mart. \& Miq.) Baehmi & Arbóreo & - & - & PF 2812 \\
\hline Pradosia lactescens (Vell.) Radlk. & Arbóreo & - & JP 503 & WT 14550 \\
\hline Sarcaulus brasiliensis (DC.) Eyma & Arbóreo & - & - & JJ 4909 \\
\hline \multicolumn{5}{|l|}{ SCHLEGELIACEAE } \\
\hline Schlegelia parviflora (Derst.) Monachino & Trepador & AA 6939 & AA 4543 & ML 1025 \\
\hline \multicolumn{5}{|l|}{ SIMAROUBACEAE } \\
\hline Simarouba amara Aubl. & Arbóreo & - & - & AA 6378 \\
\hline \multicolumn{5}{|l|}{ SIPARUNACEAE } \\
\hline Siparuna brasiliensis (Spreng.) A.DC. & Arbóreo & - & - & JJ 4836 \\
\hline Siparuna glycycarpa (Ducke) Renner \& Hausner & Arbóreo & RB 666 & - & - \\
\hline \multicolumn{5}{|l|}{ SMILACACEAE } \\
\hline Smilax sp.1 & Trepador & - & PF 1791 & - \\
\hline Smilax sp.2 & Trepador & AA 4724 & ML 1100 & AA 5767 \\
\hline Smilax sp.3 & Trepador & AA 4757 & - & ML 1017 \\
\hline Smilax syphylitica Humb. \& Bonpl. ex Willd. & Trepador & ML 578 & - & - \\
\hline \multicolumn{5}{|l|}{ SOLANACEAE } \\
\hline Acnistus arborescens (L.) Schlecht. & Arbóreo & RB 345 & JP 570 & - \\
\hline Athenaea micrantha Sendtn. & Arbustivo & MR 218 & - & AA 6090 \\
\hline Aureliana fasciculata (Vell.) Sendtn. & Arbóreo & RB 707 & WT 14286 & AA 6570 \\
\hline Brunfelsia cf. clandestina Plowman & Arbustivo & AA 4763 & - & JJ 4357 \\
\hline Brunfelsia hydrangeiformis (Pohl) Benth. & Arbustivo & AA 4353 & - & AA 4458 \\
\hline Capsicum sp.1 & Arbustivo & AA 5371 & - & AA 5967 \\
\hline Cestrum bracteatum Link \& Otto & Arbustivo & AA 6932 & - & - \\
\hline Cestrum cf. retrofractum Dunal & Arbustivo & - & - & JJ 4852 \\
\hline Cestrum salzmanni Dunal & Arbóreo & RB 343 & JP 796 & AA 6651 \\
\hline Cestrum schlechtendalii G.Don & Arbustivo & - & - & JP 948 \\
\hline Dyssochroma aff. viridiflorum (Sims) Miers & Epifítico & ML 1039 & - & AA 4962 \\
\hline Lycianthes pauciflora (Vahl) Bitter & Trepador & AA 6958 & - & AA 4456 \\
\hline Markea sp.1 & Epifítico & FF 1331 & - & - \\
\hline Solanum sp.1 & Trepador & - & - & AA $6727 \mathrm{a}$ \\
\hline Solanum sp.2 & Arbustivo & - & - & AA 6685 \\
\hline Solanum sp.3 & Arbustivo & - & - & PF 2838 \\
\hline Solanum sp.4 & Arbóreo & AA 7021 & - & JJ 4383 \\
\hline
\end{tabular}


Tabela 1. Continuação...

\begin{tabular}{|c|c|c|c|c|}
\hline Espécie & Hábito & SBO & SPL & SLO \\
\hline Solanum sp.5 & Arbustivo & ML 1304 & - & - \\
\hline Solanum acerifolium Dunal & Arbustivo & RB 291 & - & - \\
\hline Solanum asperum Rich. & Arbustivo & AA 4725 & - & AA 5765 \\
\hline Solanum asterophorum Mart. & Arbustivo & AA 4417 & - & - \\
\hline Solanum bahianum S.Knapp & Arbustivo & AA 6285 & - & ML 999 \\
\hline Solanum caavurana Vell. & Arbustivo & AA 4426 & - & AA 6663 \\
\hline Solanum crinitum Lam. & Arbóreo & RP 54 & - & AA 6091 \\
\hline Solanum hoehnei Morton & Trepador & ML 1549 & - & - \\
\hline Solanum melissarum Bohs & Arbustivo & JJ 4472 & - & RB 574 \\
\hline Solanum aff. odoriferum Vell. & Trepador & - & - & JJ 4860 \\
\hline Solanum aff. reflexiflorum Dunal & Arbustivo & - & ML 338 & - \\
\hline Solanum restingae S.Knapp & Arbustivo & FF 1326 & - & AA 6608 \\
\hline Solanum rupincola Sendtn. & Trepador & ML 757 & - & AA 6319 \\
\hline Solanum stipulatum Vell. & Arbustivo & AA 6521 & - & - \\
\hline Solanum swartzianum Roem. \& Schult. & Arbustivo & AA 5403 & AA 4082 & - \\
\hline Solanum sycocarpum Mart. \& Sendtn. & Arbóreo & JJ 4431 & PF 1817 & AA 5773 \\
\hline \multicolumn{5}{|l|}{ STEMONURACEAE } \\
\hline Discophora guianensis Miers & Arbóreo & - & - & AA 6402 \\
\hline \multicolumn{5}{|l|}{ STYRACACEAE } \\
\hline Styrax sp.1 & Arbóreo & - & - & AA 7227 \\
\hline \multicolumn{5}{|l|}{ SYMPLOCACEAE } \\
\hline Symplocos guianensis (Aublet) Gürke & Arbóreo & - & AA 4824 & AA 5340 \\
\hline Symplocos neglecta Brand & Arbustivo & AA 5183 & AA 4799 & - \\
\hline \multicolumn{5}{|l|}{ THEACEAE } \\
\hline Laplacea fruticosa (Schrad.) Kobuski & Arbóreo & AA 6526 & - & - \\
\hline \multicolumn{5}{|l|}{ THYMELAEACEAE } \\
\hline Daphnopsis sp.1 & Arbustivo & AA 4351 & - & - \\
\hline Daphnopsis racemosa Griseb. & Arbustivo & - & - & AA 4990 \\
\hline \multicolumn{5}{|l|}{ TRIGONIACEAE } \\
\hline Trigonia nivea Cambess. & Trepador & AA 7293 & - & - \\
\hline Trigonia paniculata Warm. & Trepador & AA 7298 & - & - \\
\hline \multicolumn{5}{|l|}{ URTICACEAE } \\
\hline Boehmeria cylindrica (L.) Sw. & Herbáceo & - & - & AA 4444 \\
\hline Cecropia glaziovii Snethl. & Arbóreo & AA 5467 & - & - \\
\hline Cecropia hololeuca Miq. & Arbóreo & ML 570 & - & FF 1423 \\
\hline Cecropia pachystachya Trécul & Arbóreo & - & RC 1047 & - \\
\hline Coussapoa microcarpa (Schott) Rizzini & Arbóreo & RB 349 & - & - \\
\hline Pilea sp.1 & Herbáceo & AA 4434 & - & JJ 4367 \\
\hline Pilea sp.2 & Herbáceo & AA 5697 & - & - \\
\hline Pilea cf. microphylla (L.) Liebm. & Herbáceo & WT 13008 & - & - \\
\hline Pilea rhizobola Miq. & Herbáceo & - & AA 4826 & AA 6653 \\
\hline Pourouma guianensis Aubl. & Arbóreo & FF 1285 & JP 781 & AA 7208 \\
\hline Pourouma cf. mollis Aubl. & Arbóreo & - & - & ML 1453 \\
\hline Urera caracasana Griseb. & Arbóreo & AA 4433 & - & JJ 4397 \\
\hline \multicolumn{5}{|l|}{ VALERIANACEAE } \\
\hline Valeriana scandens $\mathrm{L}$. & Trepador & AA 4347 & - & - \\
\hline \multicolumn{5}{|l|}{ VERBENACEAE } \\
\hline Verbenac sp.1 & Herbáceo & AA 7484 & - & - \\
\hline Lantana sp.1 & Arbustivo & - & AA 4239 & - \\
\hline Lantana camara $\mathrm{L}$. & Arbustivo & - & AA 4908 & AA 6728 \\
\hline
\end{tabular}


Tabela 1. Continuação...

\begin{tabular}{|c|c|c|c|c|}
\hline Espécie & Hábito & SBO & SPL & SLO \\
\hline Lantana morii Moldenke & Arbustivo & ML 763 & - & - \\
\hline Lantana undulata Schrank & Arbustivo & - & - & ML 502 \\
\hline \multicolumn{5}{|l|}{ VIOLACEAE } \\
\hline Noisettia orchidiflora Ging. & Herbáceo & - & RB 507 & AA 5722 \\
\hline Rinorea guianensis Aubl. & Arbóreo & - & PF 2633 & - \\
\hline \multicolumn{5}{|l|}{ VITACEAE } \\
\hline Cissus blanchetiana Planch. & Trepador & AA 4730 & - & JJ 4407 \\
\hline Cissus erosa Rich. & Trepador & - & RB 473 & - \\
\hline Cissus nobilis Kuhlm. & Trepador & RB 649 & - & AA 6336 \\
\hline Cissus paucinervia Lombardi & Trepador & AA 6941 & - & JJ 4672 \\
\hline Cissus stipulata Vell. & Trepador & AA 4750 & - & - \\
\hline Cissus verticillata (L.) Nicolson \& C.E.Jarvis & Trepador & RB 651 & - & - \\
\hline \multicolumn{5}{|l|}{ VOCHYSIACEAE } \\
\hline Qualea sp.1 & Arbóreo & - & PF 1528 & - \\
\hline Vochysia sp.1 & Arbóreo & AA s.n. & - & - \\
\hline \multicolumn{5}{|l|}{ WINTERACEAE } \\
\hline Drimys brasiliensis Miers & Arbóreo & - & - & WT 14603 \\
\hline \multicolumn{5}{|l|}{ ZINGIBERACEAE } \\
\hline Renealmia chrysotricha Peterson & Herbáceo & AA 5407 & - & JP 925 \\
\hline Renealmia petasites Gagnep. & Herbáceo & FF 1327 & ML 312 & - \\
\hline
\end{tabular}

Tabela 2. Comparação da diversidade taxonômica e de formas de vida entre três áreas montanas do sul da Bahia e outras áreas da Mata Atlântica. SBO = Serra Bonita, SPL = Pedra Lascada, SLO = Serra das Lontras. Epí./Hemi-epíf. = Epífitas e hemiepífitas, Trep. = Trepadeiras, Erv. = Herbáceas, Árv./Arb. = Árvores e arbustos.

Table 2. Comparison of taxonomic diversity and life forms in three montane areas in southern Bahia and other areas of the Atlantic forest. SBO = Serra Bonita, $\mathrm{SPL}=$ Pedra Lascada, $\mathrm{SLO}=$ Serra das Lontras. Epí./Hemi-epíf. $=$ Epiphytes and hemi-epiphytes, Trep. $=$ Vine, Erv. $=$ Herbs, Árv. $/$ Arb. $=$ Trees and shrubs.

\begin{tabular}{lccccccccc}
\hline \multicolumn{1}{c}{ Listas } & Estado & Sistema & N. spp. & N. gên. & N. fam. & \% Árv./Arb. & \% Erv. & \% Trep. & \% Epí./Hemi-epíf. \\
\hline SBO & BA & APG II & 628 & 326 & 103 & 43,7 & 20,4 & 14,8 & 21,1 \\
SPL & BA & APG II & 412 & 248 & 87 & 49,6 & 18,2 & 8,2 & 24 \\
SLO & BA & APG II & 709 & 351 & 110 & 49,5 & 16,2 & 12 & 22,3 \\
SBO/SPL/SLO & BA & APG II & 1129 & 467 & 124 & 46,9 & 20,1 & 13,5 & 17,5 \\
REBIO Una & BA & Cronquist & 947 & 435 & 108 & 51,3 & 20,5 & 17,8 \\
RPPN Serra do Teimoso & BA & APG II & 667 & 363 & 100 & 53,2 & 19,8 & 14,5 & 10,4 \\
Macaé de Cima & RJ & Cronquist & 1037 & 373 & 104 & 50,4 & 9,5 & 12,7 & 12,5 \\
APA Cairuçu & RJ & Cronquist & 923 & 437 & 108 & 57,5 & 12,6 & 17,5 & 27,4 \\
Serra da Juréia & SP & Cronquist & 757 & 399 & 113 & 49,3 & 19,7 & 14,1 \\
\hline
\end{tabular}

(14 spp.). Além destes, alguns gêneros tiveram riqueza bastante expressiva em relação à encontrada por Amorim et al. (2008) em estudo realizado numa área de terras baixas, tais como Mikania (16 vs. 8 spp.), Begonia (13 vs. 1 spp.), Epidendrum (15 vs. 1 spp.) e Maxillaria (13 vs. 4 spp.). O gênero Chusquea (Poaceae), elemento característico de áreas montanhosas neotropicais (Clark 1995) não foi reportado na REBIO Una (Amorim et a. 2008), mas apresentou seis espécies nas áreas montanas do sul da Bahia amostradas.

Dentre as espécies típicas de áreas montanas encontradas, algumas eram conhecidas, no estado da Bahia, apenas de coletas realizadas na Chapada Diamantina, tais como Schefflera angustissima e S. aff. varisiana (Araliaceae), Pentacalia desiderabilis recentemente registrada para Mucugê (Teles \& Stehmann 2008) - e Paralychnophora santosii (Asteraceae), Hedyosmum brasiliense (Chloranthaceae), Weinmannia paullinifolia (Cunoniaceae), Laplacea fruticosa (Theaceae, Figura 4k) e Drimys brasiliensis (Winteraceae). Outras eram conhecidas apenas de áreas do Sul e Sudeste do Brasil, a exemplo de Steyermarkina pyrifolia, Mikania callineura, M. candolleana e M. ulei (Asteraceae), Billbergia horrida, Nidularium bicolor (Figura 2j), Vriesea longicaulis, V. longiscapa, V. paratiensis e V. regnellii (Bromeliaceae), Copaifera trapaezifolia (Fabaceae), Macrocarpaea obtusifolia (Gentianaceae), Nematanthus lanceolatus (Gesneriaceae, Figura 4a), Virola bicuhyba 
Angiospermas em florestas montanas da Bahia
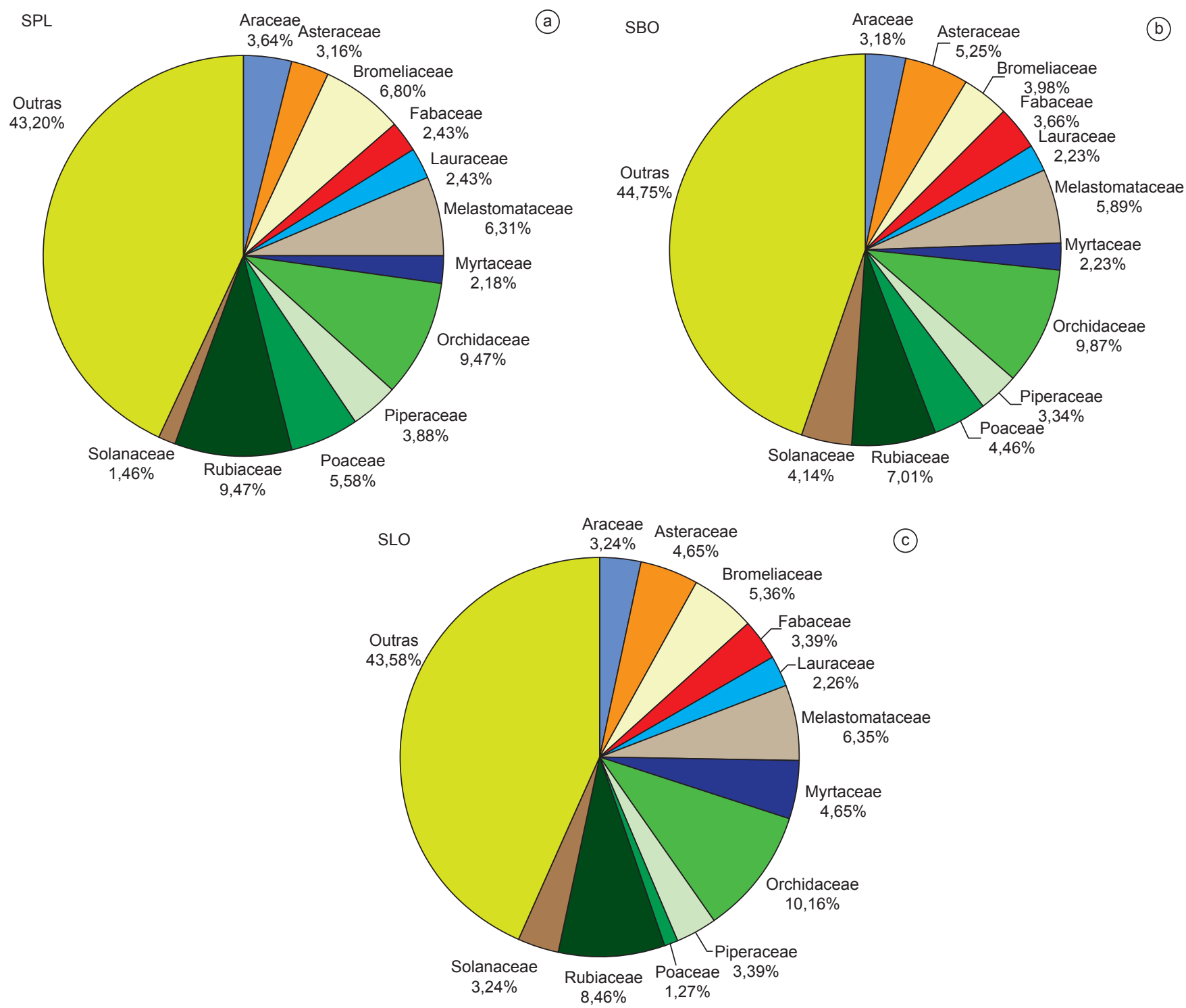

Figura 3. Famílias de angiospermas com o maior número de espécies nas três áreas de floresta montana inventariadas no sul da Bahia, Brasil. a) Serra das Lontras (SLO). b) Serra Bonita (SBO). c) Serra da Pedra Lascada (SPL). Nota-se que apenas 12 famílias contribuem com mais de 55\% do total de espécies de angiospermas nas três áreas.

Figure 3. The most species-rich angiosperm families found in the three areas of montane forest studied in southern Bahia, Brazil. a) Serra das Lontras (SLO). b) Serra Bonita (SBO). c) Serra da Pedra Lascada (SPL). Note that only 12 families contribute more than 55\% of total of angiosperm species registered in these areas.

(Myristicaceae), Myrsine hermogenesii (Myrsinaceae), Sauvagesia vellozii (Ochnaceae), Fuchsia regia (Onagraceae), Brachionidium restrepioides, Eltroplectris janeirensis e Phymatidium falcifolium (Orchidaceae), Meliosma sellowii (Sabiaceae), Schlegelia parviflora (Schlegeliaceae), Solanum hoehnei (Solanaceae) e Valeriana scandens (Valerianaceae). O presente estudo também apresentou a ocorrência no sul da Bahia de Begonia digitata (Begoniaceae), Neoregelia pauciflora (Bromeliaceae), Beilschmiedia linharensis (Lauraceae), Calathea crocata (Marantaceae), Schwartzia jucuensis (Marcgraviaceae) e Bertolonia wurdackiana (Melastomataceae), cujos registros anteriores estavam restritos às florestas e afloramentos rochosos do Espírito Santo.

Áreas florestais localizadas em altitudes elevadas da região Neotropical apresentam gêneros em comum, alguns dos quais foram encontrados nas florestas montanas do sul da Bahia, por exemplo, Achyrocline, Clethra, Clusia, Drimys, Hedyosmum, Ilex, Laplacea, Meliosma, Meriania, Miconia, Myrceugenia, Myrsine, Notopleura, Prunus, Roupala e Weinmannia (Webster 1995, Oliveira-Filho \& Fontes 2000, Taylor 2001, Pereira et al. 2006, Safford 2007). Embora não tenha sido indicada em trabalhos anteriores, a ocorrência de Macrocarpaea (Gentianaceae), Napeanthus (Gesneriaceae), Fuchsia (Onagraceae) e Chusquea (Poaceae) também exemplificam o efeito da altitude na distribuição de táxons em florestas neotropicais, visto que estes são tipicamente encontrados em florestas ombrófilas da Região Sudeste, onde a Mata Atlântica ocupa áreas cujas altitudes são mais elevadas (Lima \& Guedes-Bruni 1997). Vale ressaltar que dos gêneros mencionados acima como típicos de altitudes elevadas, apenas quatro foram encontrados na RPPN Serra do Teimoso (Miconia, Myrsine, 

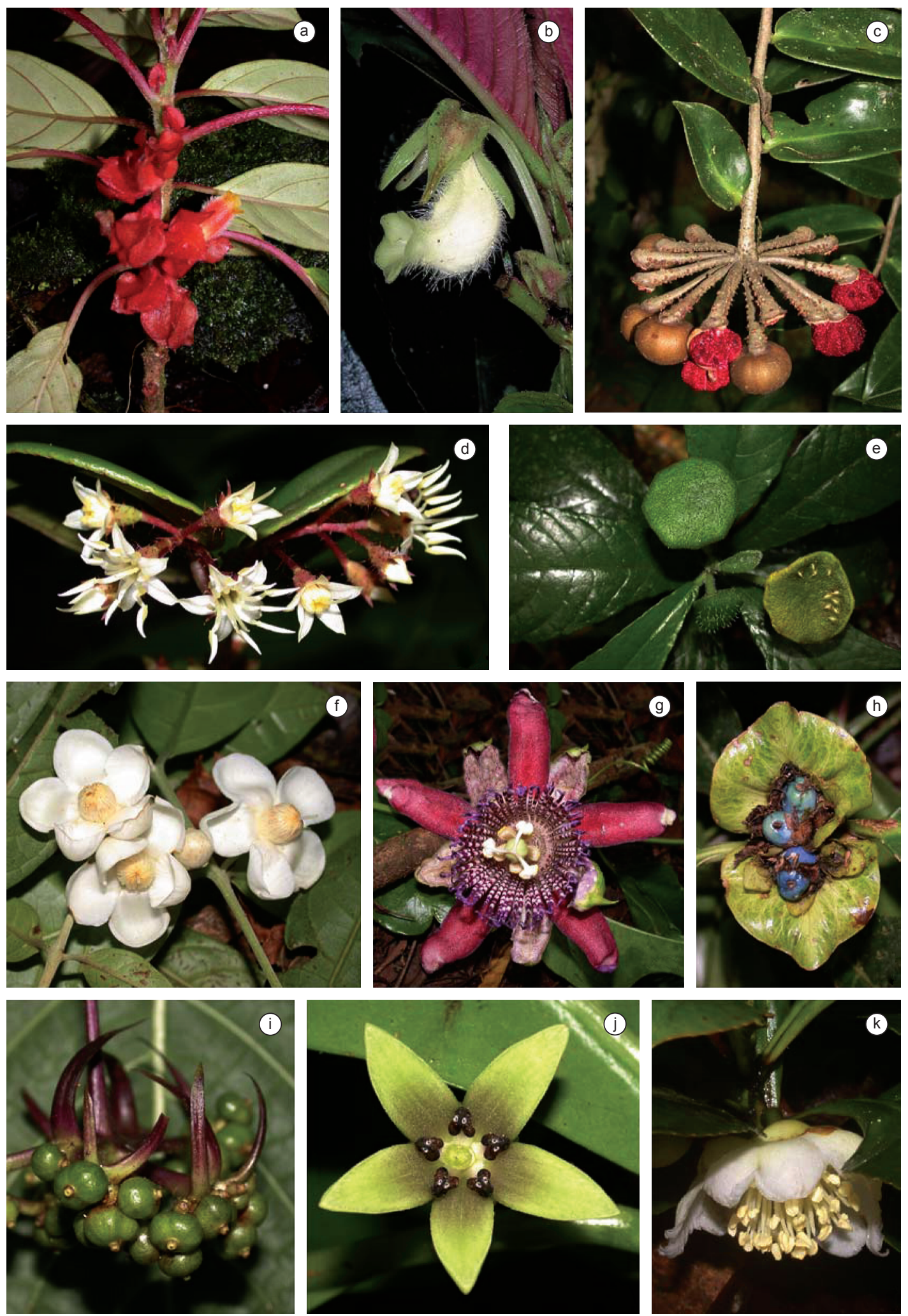

Figura 4. Algumas espécies documentadas nas três áreas de floresta montana inventariadas no sul da Bahia. a) Nematanthus lanceolatus (Gesneriaceae). b) Sinningia barbata (Gesneriaceae). c) Marcgravia coriacea (Marcgraviaceae). d) Pleiochiton sp.1 (Melastomataceae). e) Dorstenia hirta (Moraceae). f) Campomanesia laurifolia (Myrtaceae). g) Passiflora alata (Passifloraceae). h) Psychotria colorata (Rubiaceae). i) Psychotria sp.3 (Rubiaceae). j) Solanum caavurana (Solanaceae). K. Gordonia fruticosa (Theaceae). Fotos: a,c-k) A.Amorim; b) W.Thomas.

Figure 4. Some of the species found in the three areas of montane forest studied in southern Bahia. a) Nematanthus lanceolatus (Gesneriaceae). b) Sinningia barbata (Gesneriaceae). c) Marcgravia coriacea (Marcgraviaceae). d) Pleiochiton sp. 1 (Melastomataceae). e) Dorstenia hirta (Moraceae). f) Campomanesia laurifolia (Myrtaceae). g) Passiflora alata (Passifloraceae). h) Psychotria colorata (Rubiaceae). i) Psychotria sp. 3 (Rubiaceae). j) Solanum caavurana (Solanaceae). k) Gordonia fruticosa (Theaceae). Photos: a,c-k) A.Amorim; b) W.Thomas. 
Prunus e Roupala - Amorim et al. 2005) e na REBIO Una (Clusia, Ilex, Miconia e Roupala - Amorim et al. 2008).

Dentre as 64 espécies arbóreas indicadas por Oliveira-Filho \& Fontes (2000) como características de florestas ombrófilas e semideciduais montanas, 14 (ca. 22\%) foram aqui registradas: Casearia obliqua, Cecropia glaziovii, Clethra scabra, Drimys brasiliensis, Laplacea fruticosa, Hedyosmum brasiliense, Heisteria silvianii, Meliosma selowii, Miconia chartacea, Picramnia glazioviana, Psychotria suterella, Salacia elliptica, Schefflera angustissima e Weinmannia pauliniifolia.

Levantamentos florísticos em florestas de terras baixas do sul da Bahia têm revelado uma composição bastante distinta daquela verificada em áreas do Sudeste do Brasil (Oliveira-Filho \& Fontes 2000). Contribui para isso o fato das florestas sul-baianas estarem situadas em áreas cujo clima é mais quente e úmido e o relevo menos acidentado, com planícies costeiras bem desenvolvidas na desembocadura dos grandes rios da região (Villwock et al. 2005) e montanhas intensamente erodidas que raramente atingem $1.000 \mathrm{~m}$ de altitude. Prováveis conexões florísticas entre o sul da Bahia e a Floresta Amazônica durante o Quaternário também são relevantes na diferenciação florística entre áreas de Mata Atlântica ao norte e ao sul do Rio Doce (Soderstrom \& Calderón 1974, Prance 1979, Oliveira et al. 1999), já que há vários elementos em terras baixas do Nordeste que são típicos de áreas ao norte deste rio (e.g., Aptandra, Gustavia, Lacmellea, Macrolobium, Naucleopsis, Pagamea, Pariana, Parkia, Pseudolmedia, Roucheria, Trattinickia). Por outro lado, alguns gêneros essencialmente andinos e/ou mesoamericanos (e.g., Beilschmiedia, Fuchsia, Gaultheria, Hedyosmum, Rhamnus, Rustia, Weinmannia) ou subtropicais (e.g., Araucaria, Myrceugenia) são raramente ou nunca encontrados em áreas ao norte do Rio Doce, exceção sendo feita a alguns topos de morros.

Estudos em áreas de terras baixas na Bahia têm apresentado um número expressivo de espécies em comum com a Floresta Amazônica, variando entre 7 e 7,9\% do total de espécies amostradas (Mori et al. 1981, Thomas et al. 1998, Amorim et al. 2008). Nas áreas montanas do sul da Bahia, foi verificada uma menor proporção de espécies tipicamente encontradas em florestas amazônicas (entre 0,8 a $1 \%$ das espécies amostradas). Podemos citar, por exemplo, Tanaecium jaroba (Bignoniaceae), Persea pseudofasciculata (Lauraceae), Roucheria columbiana Hallier f., Conostegia icosandra e Graffenrieda intermedia (Melastomataceae), Anomospermum reticulatum e Orthomene schomburgkii (Menispermaceae), Notopleura tapajozensis e Schradera polycephala (Rubiaceae). A distribuição disjunta entre táxons das florestas Atlântica e Amazônica já havia sido reportada em trabalhos de Andrade-Lima (1953, 1966), Bigarella et al. (1975), Mori et al. (1981), Gentry (1982), Prance (1979, 1982), Rizzini (1997), Martini et al. (2007) e Amorim et al. (2008).

Dentre as formas de vida documentadas nas três áreas, 524 espécies apresentam hábito arbóreo/arbustivo, 220 espécies hábito epifítico/hemi-epifítico, 208 espécies hábito herbáceo e 146 espécies hábito trepador, ou seja, praticamente metade das espécies reportadas apresentou hábito não-arbóreo (Figura 5, Tabela 2). Quando comparados com outros levantamentos florísticos em áreas de Mata Atlântica, os valores obtidos assemelharam-se bastante aos verificados em florestas montanas de Macaé de Cima (Lima \& Guedes-Bruni 1997) e, em menor grau, aos da Serra da Juréia (Mamede et al. 2001), dada a considerável contribuição de espécies com hábito epifítico/ hemi-epifítico. Notou-se também uma clara distinção dessas áreas com as áreas de terras baixas, tanto do Nordeste quanto do Sudeste (Tabela 2). Esses resultados corroboram estudos que têm apontado uma grande riqueza de espécies não-arbóreas de angiospermas em florestas tropicais (Gentry \& Dodson 1987), mais especificamente as localizadas em áreas montanas (Gentry 1988, Webster 1995).

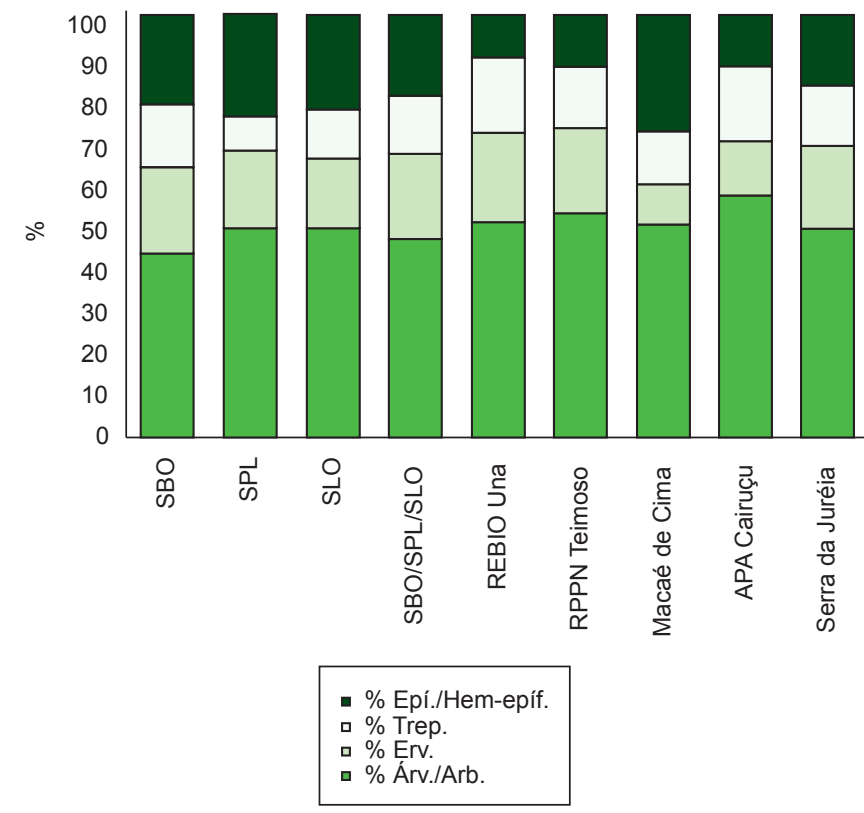

Figura 5. Histograma de formas de vida nas três áreas de floresta montana inventariadas no sul da Bahia (SBO, SPL, SLO) e em outras áreas da Mata Atlântica. $\mathrm{SBO}=$ Serra Bonita, $\mathrm{SPL}=$ Pedra Lascada, $\mathrm{SLO}=$ Serra das Lontras. Epí./Hemi-epíf. = Epífitas e hemiepífitas, Trep. = Trepadeiras, Erv. = Herbáceas, Árv./Arb. = Árvores e arbustos.

Figure 5. Lifeform histogram for the three montane forest areas surveyed in southern Bahia and for other localities in the Atlantic Forest. $\mathrm{SBO}=$ Serra Bonita, SLO $=$ Serra das Lontras, SPL = Pedra Lascada. Epí $/$ Hemi-epíf. = Epiphytes and hemiepiphytes, Trep. = Lianas, Erv. = Herbs, Árv./Arb. = Trees and shrubs.

De forma geral, existe certa homogeneidade entre a proporção das formas de vida reportadas em cada área de floresta montana inventariada no sul da Bahia (Tabela 2), ainda que sutis diferenças sejam evidenciadas, por exemplo, em relação à maior riqueza de epífitas na SPL ou de trepadeiras na SBO. Entretanto, consideramos que a amostragem nas três áreas estudadas é ainda insuficiente, especialmente em relação ao componente arbóreo, uma vez que estudos florísticos em áreas próximas (Amorim et al. 2005, 2008, Martini et al. 2007, Thomas et al. 2008) têm alertado sobre a necessidade e importância de métodos quantitativos na obtenção de dados sobre a riqueza de comunidades arbóreas.

A comparação das floras registradas nas três áreas sugere uma maior semelhança entre a SBO e a SLO, enquanto a SPL apresentase distinta em relação às duas primeiras (Figura 6). A proximidade geográfica que, entre outros fatores, condiciona a presença de características geoclimáticas similares, pode ser apontada como a principal causa deste panorama (Nekola \& White 1999). Além disso, o maior tamanho das áreas florestais amostradas na SBO e na SLO também deve ter influenciado na maior riqueza destas quando comparada à da encontrada na SPL (Whittaker et al. 2001). É evidente a heterogeneidade florística entre as três áreas (Figura 6), o que pode ser inicialmente atribuído a um esforço amostral ainda incompleto, mas também pode indicar uma alta diversidade e especificidade da flora existente em cada área amostrada.

Estudos quantitativos recentes têm chamado a atenção para os efeitos da heterogeneidade de fatores abióticos na composição florística e estrutura de comunidades arbóreas da Mata Atlântica (OliveiraFilho \& Fontes 2000, Pereira et al. 2006, Oliveira-Filho et al. 2006), no entanto ainda há poucos dados disponíveis acerca da composição 


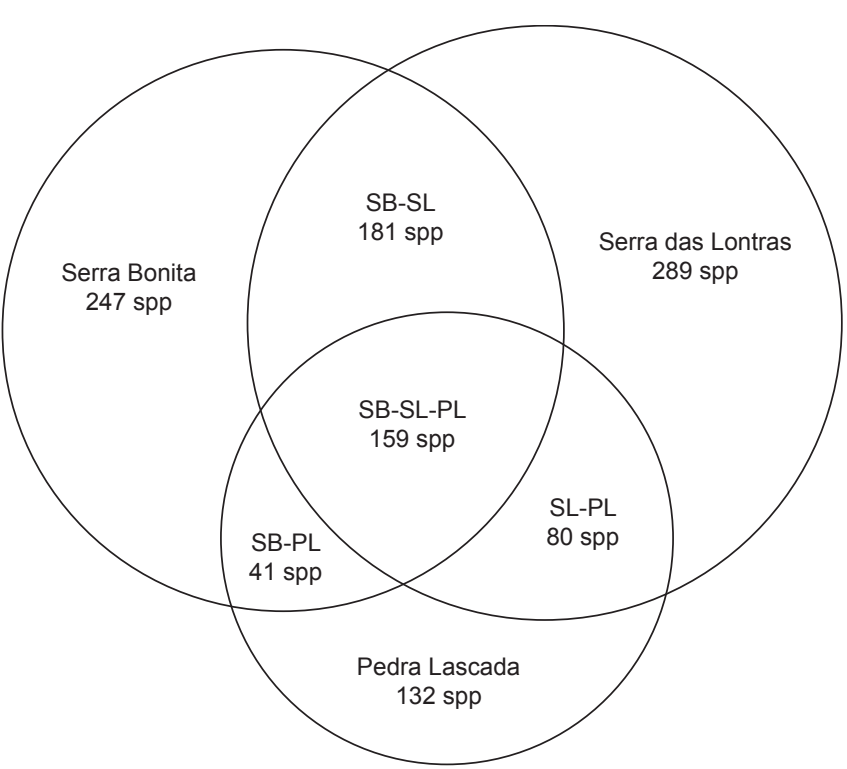

Figura 6. Diagrama de Venn mostrando o número de espécies de angiospermas compartilhado entre as três áreas de floresta montana inventariadas no sul da Bahia. $\mathrm{SBO}=$ Serra Bonita, $\mathrm{SLO}=$ Serra das Lontras, $\mathrm{SPL}=$ Pedra Lascada.

Figure 6. Venn diagram showing proportions of shared species among the three montane forest areas studied. SBO $=$ Serra Bonita, SLO $=$ Serra das Lontras, SPL = Pedra Lascada.

florística de áreas no sul da Bahia. Dentre os inventários floristicos realizados nesta região, apenas Amorim et al. $(2005,2008)$ fornecem dados comparáveis aos aqui apresentados, uma vez que não se restringiram ao componente arbóreo. Quando esses dados são comparados aos levantados em áreas montanas, observa-se que aproximadamente $82 \%$ (723 de 883 spp.) dos táxons aqui identificados até espécie não haviam sido previamente amostrados na RPPN Serra do Teimoso (Amorim et al. 2005) e na REBIO Una (Amorim et al. 2008).

A heterogeneidade florística e a elevada riqueza verificada entre as três áreas estudadas (Figura 6), e destas comparadas com outras áreas da Bahia, evidenciam a enorme importância dos remanescentes florestais em áreas de altitude no sul da Bahia, já que essas áreas compõem apenas $2,62 \%$ da área total do estado. Como exemplo específico, os táxons identificados até espécie de Orchidaceae (78 spp.) perfazem $27 \%$ de todas as espécies da família registradas para a Bahia até o momento. Assim como sugerido por Mori (1989), os resultados apresentados fornecem argumentos adicionais para que esforços conservacionistas na Mata Atlântica levem em consideração que há diferenças floristicas marcantes entre as florestas de terras baixas e as de altitudes elevadas no sul da Bahia.

Duas das áreas estudadas (e.g., Serra das Lontras e Serra Bonita) foram apontadas por Martinelli (2007) como áreas do Brasil ainda desprovidas de inventários, mas extremamente importantes para subsidiar ações em políticas de conservação internacional. Apesar de parte dos remanescentes florestais da SBO e SLO encontraremse parcialmente protegidas sob a forma de Reserva Particular do Patrimônio Natural (RPPN), essas reservas representam menos de $20 \%$ da formação montanhosa onde então inseridas. Já na SPL, até o momento não houve qualquer ação efetiva para o estabelecimento de uma unidade de proteção legal, mesmo com o forte apelo político e geomorfológico da área (i.e., é o remanescente de maior altitude e, por isso, considerado legalmente como Área de Proteção Permanente, e o mais próximo dos municípios de Ilhéus e Itabuna, que são os principais centros urbanos do sul da Bahia).

\section{Agradecimentos}

Ao apoio financeiro concedido pela Beneficia Foundation, National Science Foundation — NSF (Pesquisa 0516233), National Geographic Society — NGS (Pesquisa 7785-05), Conselho Nacional de Pesquisa - CNPq (Edital Universal 474648-4, Bolsa de Doutoramento 200682/2006-7 a P. Fiaschi e Bolsa PIBIC/UESC a R.O. Perdiz), Fundação de Amparo a Pesquisa no Estado da Bahia FAPESB (Bolsa de Inovação Tecnológica 0091/2006 a M.M. Lopes), Coordenação de Aperfeiçoamento a Pesquisa e Ensino Superior CAPES (Bolsa de Doutoramento a J.G. Jardim) e a VCU's Integrative Life Sciences Program (suporte a P. Fiaschi). Também agradecemos a Vitor e Clemira Becker, proprietários da RPPN Serra Bonita, pela hospitalidade e auxílio e ao Instituto de Estudos Sócio Ambientais do Sul da Bahia - IESB pelo apoio logístico na Reserva Serra das Lontras.

Agradecemos a Alexandre B. Rodrigues, André P. Fontana, Fernando B. Matos, José Lima da Paixão, Luís Carlos J. Gomes, Paulo Labiak, Renato Goldenberg, Sérgio C. Sant'Ana, Wallace São-Mateus e Wesley D. Rocha pelo auxílio no trabalho de campo e no herbário. Assumimos a responsabilidade pelos nomes de espécies apresentadas, mas somos gratos aos botânicos que identificaram parte do material: S.R. Profice (Acanthaceae), L. Senna (Amaranthaceae), A.Q. Lobão (Annonaceae), A. Rapini e R.F. Silva (Apocynaceae), M. Groppo (Aquifoliaceae), L. Temponi e M.L. Soares (Araceae), A. Henderson (Arecaceae), H. Robinson (Asteraceae), L. Kollmann (Begoniaceae), M. Stapf (Boraginaceae), T. Fontoura, E. Leme, R.C. Forzza, A. Costa, G.M. Souza, H. Luther e M.G. Wanderley (Bromeliaceae), M.F. Freitas (Cactaceae e Myrsinaceae), G. Prance (Chrysobalanaceae), L. Aona (Commelinaceae), M. Alves (Cyperaceae), I. Cordeiro e R. Riina (Euphorbiaceae e Phyllanthaceae), H.C. Lima, M.P. Morim e L.P. Queiroz (Fabaceae), A. Chautems (Gesneriaceae), L. Assis e P. Moraes (Lauraceae), S. Mori (Lecythidaceae), J. Kuijt (Loranthaceae), M. Duarte (Malvaceae), S. Vieira (Marantaceae), R. Goldenberg (Melastomataceae), J.R. Pirani (Meliaceae e Rutaceae), A.L. Peixoto (Monimiaceae e Siparunaceae), M. Sobral (Myrtaceae), A.P. Fontana, C. Azevedo, C. Van den Berg e C.N. Fraga (Orchidaceae), E.F. Guimarães, R. Callejas e M.A. Jaramillo (Piperaceae), R.P. Oliveira e F. Moreira (Poaceae), D. Zappi (Rubiaceae), A.A. Alves (Sapotaceae), J. Stehman (Solanaceae) e J. Lombardi (Vitaceae).

\section{Referências Bibliográficas}

AMORIM, A.M., FIASCHI, P., JARDIM, J.G., THOMAS, W.W., CLIFTON, B.C. \& CARVALHO, A.M.V. 2005. The vascular plants of a forest fragment in southern Bahia, Brazil. Sida 21(3):1727-1752.

AMORIM, A.M., THOMAS, W.W., CARVALHO, A.M.V. \& JARDIM, J.G. 2008. Floristic of the Una Biological Reserve, Bahia, Brazil. In The Atlantic Coastal Forests of Northeastern Brazil (W.W. Thomas, ed.). Mem. New York Bot. Gard. 100:67-146.

AMORIM, A.M. \& LEME, E. 2009. Two new species of Quesnelia (Bromeliaceae: Bromelioideae) from the Atlantic Rain Forest of Bahia, Brazil. Brittonia 61(1):14-21.

ANDRADE-LIMA, D. 1953. Notas sobre a dispersão de algumas espécies vegetais no Brasil. An. Soc. Biol. Pernambuco 11(1):25-49.

ANDRADE-LIMA, D. 1966. Contribuição ao estudo do paralelismo da flora Amazônico-Nordestina. Inst. Pesq. Agron. Pernambuco 19(1)3-30. (Boletim técnico).

Angiosperm Phylogeny Group - APG. 2003. An update of the Angiosperm Phylogeny Group classification for the orders and families of flowering plants: APG II. Bot. J. Linn. Soc. 141(4):399-436.

ASHTON, P.S. 2003. Floristic zonation of tree communities on wet tropical mountains revisited. Perspect. Plant. Ecol. 6(1-2):87-104. 
BIGARELLA, J.J., ANDRADE-LIMA, D. \& RIEHS, P.J. 1975. Considerações a respeito das mudanças paleoambientais na distribuição de algumas espécies vegetais e animais no Brasil. An. Acad. Bras. Cienc. 47:411-464.

BORGES, R.A.X., FORZZA, R.C. \& FRAGA, C.N. 2009. Taxonomic novelties in Mikania (Asteraceae: Eupatorieae) from Atlantic Forest, Brazil. Blumea (No prelo).

CLARK, L.G. 1995. Diversity and distribution of the Andean woody bamboos (Poaceae: Bambuseae). In Biodiversity and conservation of Neotropical Montane Forests (S.P. Churchill, H. Baslev, E. Forero \& J.L. Luteyn, eds.). New York Botanical Garden, New York, p. 501-512.

FUNK, V.A. 2006. Floras: a model for biodiversity studies or a thing of the past? Taxon 55(3):581-588.

GALINDO-LEAL, C. \& CÂMARA, I.G. 2003. Atlantic Forest hotspot status: an overview. In The Atlantic Forest of South America: biodiversity status, trends, and outlook (C. Galindo-Leal \& I.G. Câmara, eds.). Center for Applied Biodiversity Science and Island Press, Washington, p. 3-11.

GALINDO-LEAL, C., JACOBSEN, T.R., LANGHAMMER, P.F. \& OLIVIERI, S. 2003. State of the hotspots: the dynamics of biodiversity loss. In The Atlantic Forest of South America: biodiversity status, trends, and outlook (C. Galindo-Leal \& I.G. Câmara, eds.). Center for Applied Biodiversity Science and Island Press, Washington, p. 12-23.

GENTRY, A.H. 1982. Neotropical floristic diversity: phytogeographical connections between Central and South America, Pleistocene climatic fluctuations, or an accident of the Andean orogeny? Ann. Mo. Bot. Gard. 69(3):557-593.

GENTRY, A.H. 1988. Changes in plant community diversity and floristic composition on environmental and geographical gradients. Ann. Mo. Bot. Gard. 75(1):1-34.

GENTRY,A.H. 1995. Patterns of diversity and floristic composition in neotropical montane forests. In Biodiversity and conservation of Neotropical Montane Forests (S.P. Churchill, H. Balslev, E. Forero \& J.L. Luteyn, eds.). The New York Botanical Garden, New York, p. 103-126.

GENTRY, A.H. \& DODSON, C.H. 1987. Diversity and biogeography of neotropical vascular epiphytes. Ann. Mo. Bot. Gard. 74(2):205-233.

GRUBB, P.J., PENNINGTON, T.O. \& WHITMORE, T.C. 1963. A comparison of montane and lowland rain forest in Ecuador. I. The forest structure, physiognomy and floristics. J. Eco. 51(3):567-601.

GRUBB, P.J. \& WHITMORE, T.C. 1966. A comparison of montane and lowland rain forests in Ecuador. II. The climate and its effects on the distribution and physiognomy of the forests. J. Eco. 54(2):303-333.

JARDIM, J.G. \& ZAPPI, D.C. 2008. Carapichea lucida (Rubiaceae: Psychotrieae), a new species from Eastern Bahia, Brazil. Kew Bull. 63(4):661-664

KÖPPEN, W. 1936. Das geographische System der Klimate. In Handbuch der Klimatologie (W. Köppen \& W. Geiger, eds.). Tiel C. G. Bornträger, Berlin.

LIMA, H.C. \& GUEDES-BRUNI, R.R. 1997. Diversidade de plantas vasculares na Reserva Ecológica de Macaé de Cima. In Serra de Macaé de Cima: diversidade florística e conservação em Mata Atlântica (H.C. Lima \& R.R. Guedes-Bruni, orgs.). Jardim Botânico do Rio de Janeiro, Rio de Janeiro, 346p.

MAMEDE, M.C.H., CORDEIRO, I. \& ROSSI, L. 2001. Flora vascular da Serra da Juréia, Município de Iguape, São Paulo, Brasil. Bol. Inst. Bot. 15:63-124.

MARQUES, M.C.M. 1997. Mapeamento da cobertura vegetal e listagem das espécies ocorrentes na Área de Proteção Ambiental de Cairuçu, Parati, RJ. Instituto de Pesquisas Jardim Botânico do Rio de Janeiro, Rio de Janeiro. Série Estudos e Contribuições 13, p.1-96.

MARTINELLI, G. 2007. Mountain biodiversity in Brazil. Rev. Bras. Bot. 30(4):587-597.

MARTINI, A.M.Z., FIASCHI, P., AMORIM, A.M. \& PAIXÃO, J.P. 2007. A hot-point within a hot-spot: a high diversity site in Brazil's Atlantic Forest. Biodivers. Conserv. 16(11):3111-3128.
MITTERMEIER, R.A., GIL, P.R., HOFFMANN, M., PILGRIM, J., BROOKS, J., MITTERMEIER, C.G., LAMOURUX, J. \& FONSECA, G.A.B. 2004. Hotspots revisited: earth's biologically richest and most endangered terrestrial ecoregions. Ceme, Washington.

MORI, S.A. 1989. Eastern, extra-Amazonian Brazil. In Floristic inventory of tropical countries: the status of plant systematics, collections, and vegetation, plus recommendations for the future (D.G. Campbell \& H.D. Hammond, eds.). The New York Botanical Garden, Bronx, p. 427-454.

MORI, S.A., BOOM, B.M. \& PRANCE, G.T. 1981. Distribution patterns and conservation of eastern Brazilian coastal forest tree species. Brittonia 33(2):233-245.

MORI, S.A., BOOM, B.M., CARVALHO, A.M.V. \& SANTOS, T.S. 1983. Southern Bahian moist forests. Bot. Rev. 49(2):155-232.

MYERS, N., MITTERMEIER, R.A., MITTERMEIER, C.G., FONSECA, G.A.B. \& KENT, J. 2000. Biodiversity hotspots for conservation priorities. Nature 403:853-858.

NEKOLA, J.C. \& WHITE, P.S. 1999. The distance decay of similarity in biogeography and ecology. J. Biogeogr. 26(4):867-878.

OLIVEIRA, P.E., BARRETO, A.M.F. \& SUGUIO, K. 1999. Late Pleistocene/ Holocene climatic and vegetational history of the Brazilian caatinga: the fossil dunes of the middle São Francisco River. Paleogeogr., Paleoclim., Paleocol. 152(2):319-337

OLIVEIRA-FILHO, A.T. \& FONTES, M.A.L. 2000. Patterns of floristic differentiation among Atlantic Forests in southeastern Brazil and the influence of climate. Biotropica. 32(4b):793-810.

OLIVEIRA-FILHO, A.T., JARENKOW, J.A. \& RODAL, M.J.N. 2006. Floristic relationships of seasonally dry forests of eastern South America based on tree species distribution patterns. In Neotropical savannas and seasonally dry forests: plant diversity, biogeography and conservation (R.T. Pennington, G.P. Lewis \& J.A. Ratter, eds.). CRC Press, Boca Raton, p. 151-184.

PEREIRA, I.M., OLIVEIRA-FILHO, A.T., BOTELHO, S.A., CARVALHO, W.A.C., FONTES, M.A.L., SHIAVINI, I. \& SILVA, A.F. 2006. Composição florística do compartimento arbóreo de cinco remanescentes florestais do Maçico do Itatiaia, Minas Gerais e Rio de Janeiro. Rodriguesia. 57(1):103-126.

PRANCE, G.T. 1979. The taxonomy and phytogeography of the Chrysobalanaceae of the Atlantic coastal forests of Brazil. Rev. Bras. Bot. 2(1):19-39.

PRANCE, G.T. 1982. A review of the phytogeographic evidences for Pleistocene climate changes in the neotropics. Ann. Mo. Bot. Gard. 69(3):594-624.

PRANCE, G.T. 2001. Discovering the plant world. Taxon 50(2):345-359.

PRANCE, G.T., BEENTJE, H., DRANSFIELD, J. \& JOHNS, R. 2000. The tropical flora remains undercollected. Ann. Mo. Bot. Gard. 87(1):67-71.

RAVEN, P.H. 2004. Taxonomy: where are we now? Philos. T. Roy. Soc. B. 359(1444):729-730.

RICHARDS, P.W. 1996. The Tropical Rain Forest: an ecological study. Cambridge University Press, United Kingdom, 575p.

RIZZINI, C.T. 1997. Tratado de Fitogeografia do Brasil. 2 ed. Âmbito Cultural Edições Ltda., Rio de Janeiro, 747p.

ROEDER, M. 1975. Reconhecimento climatológico. In Diagnóstico socioeconômico da região cacaueira (Comissão Executiva do Plano da Lavoura Cacaueira e Instituto Interamericano de Ciências Agricolas OEA, orgs.). Editora CEPLAC, Ilhéus, v.4, p. 1-89.

SAFFORD, H.D. 2007. Brazilian Páramos IV: phytogeography of the campos de altitude. J. Biogeogr. 34(10):1701-1722.

SCARANO, F. 2002. Structure, function and floristic relationships of plant communities in stressful habitats marginal to the Brazilian Atlantic Rainforest. Ann. Bot. 90(4):517-524.

SILVA, J.M.C. \& CASTELETI, C.H.M. 2003. Status of the biodiversity of the Atlantic forest of Brazil. In The Atlantic Forest of South America: biodiversity status, trends, and outlook (C. Galindo-Leal \& I.G. Câmara, 
eds.). Center for Applied Biodiversity Science and Island Press, Washington, p. 43-59.

SODERSTROM, T. \& CALDERÓN, C. 1974. Primitive forest grasses and evolution of the Bambusoideae. Biotropica. 6(3):141-152.

SOUSA, L.O.F. \& WENDT, T. 2008. Taxonomy and conservation of the genus Lymania (Bromeliaceae) in the southern Bahian Atlantic Forest of Brazil. Bot. J. Linn.Soc. 157(1):47-66.

TABARELLI, M., PINTO, L.P., SILVA, J.M.C., HIROTA, M. \& BEDÊ, L. 2005. Challenges and opportunities for biodiversity conservation in the Brazilian Atlantic Forest. Conserv. Biol. 19(3):695-700.

TAYLOR, C. 2001. Overview of the Neotropical genus Notopleura (Rubiaceae: Psychotrieae), with the description of some new species. Ann. Mo. Bot. Gard. 88(3):478-515.

TELES, A.M. \& STEHMANN, J.R. 2008. Plantae, Magnoliophyta, Asterales, Asteraceae, Senecioneae, Pentacalia desiderabilis and Senecio macrotis: distribution extensions and first records for Bahia, Brazil. Check List 4(1):62-64.

THOMAS, W.W. \& BARBOSA, M.R.V. 2008. Natural vegetation types in the Atlantic Coastal Forest of Northeastern Brazil. In The Atlantic Coastal Forests of Northeastern Brazil (W.W. Thomas, ed.). Mem. New York Bot. Gard. 100:6-20.

THOMAS, W.W., CARVALHO, A.M.V., AMORIM, A.M., GARRISON, J. \& ARBELÁEZ, A.L. 1998. Plant endemism in two forests in southern Bahia, Brazil. Biodivers. Conserv. 7(3):311-322.

THOMAS, W.W., JARDIM, J.G., FIASCHI, P. \& AMORIM, A.M. 2003. Lista preliminar das angiospermas localmente endêmicas do Sul da Bahia e Norte do Espírito Santo, Brasil. In Corredor de Biodiversidade da Mata Atlântica do sul da Bahia (P.I. Prado, E.C. Landau, R.T. Moura,
L.P.S. Pinto, G.A.B. Fonseca \& K. Alger, eds.). IESB/CI/CABS/UFMG/ UNICAMP, Ilhéus. (CD-ROM.)

THOMAS, W.W., CARVALHO, A.M.V., AMORIM, A.M., GARRISON, J. \& SANTOS, T.S. 2008. Diversity of woody plants in the Atlantic coastal forest of southern Bahia, Brazil. In The Atlantic Coastal Forests of Northeastern Brazil (W.W. Thomas, ed.). Mem. New York Bot. Gard. 100:21-66.

VELOSO, H.P. 1992. Sistema fitogeográfico. In Manual técnico da vegetação brasileira. Fundação Instituto Brasileiro de Geografia e Estatística, Rio de Janeiro, p. 9-38.

VILLWOCK, J.A., LESSA, G.C., SUGUIO, K., ANGULO, R.J. \& DILLENBURG, S.R. 2005. Geologia e geomorfologia de regiões costeiras. In Quaternário do Brasil (C.R.G. Souza, K. Suguio, A.M.S.P. Oliveira \& P.E. Oliveira, eds.). Holos Editora, Ribeirão Preto, p. 52-74.

WEBSTER, G.L. 1995. The panorama of neotropical cloud forests. In Biodiversity and conservation of Neotropical Montane Forests (S.P. Churchill, H. Balslev, E. Forero \& J.L. Luteyn, eds). The New York Botanical Garden, New York, p. 53-77.

WHITTAKER, R.J., WILLIS, K.J. \& FIELD, R. 2001. Scale and species richness: towards a general, hierarchical theory of species diversity. J. Biogeogr. 28(4):453-470.

Recebido em 11/11/08 Versão reformulada recebida em 10/08/09 Publicado em 25/08/09 